\title{
SYNTHESIS OF DIMETHYL ETHER AND ALTERNATIVE FUELS IN THE LIQUID PHASE FROM COAL-DERIVED SYNTHESIS GAS
}

\author{
Final Technical Report
}

\author{
Contractor
}

AIR PRODUCTS AND CHEMICALS, INC.

Allentown, PA 18195-1501

February 1993

Prepared for the United States Department of Energy

Under Contract No. DE-AC22-90PC89865

Contract Period December 1989-February 1993 


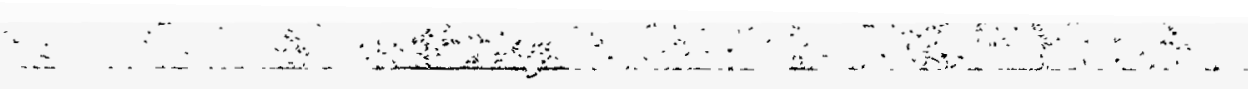




\section{DISCLAIMER}

This report was prepared as an account of work sponsored by an agency of the United States Government. Neither the United States Government nor any agency thereof, nor any of their employees, make any warranty, express or implied, or assumes any legal liability or responsibility for the accuracy, completeness, or usefulness of any information, apparatus, product, or process disclosed, or represents that its use would not infringe privately owned rights. Reference herein to any specific commercial product, process, or service by trade name, trademark, manufacturer, or otherwise does not necessarily constitute or imply its endorsement, recommendation, or favoring by the United States Government or any agency thereof. The views and opinions of authors expressed herein do not necessarily state or reflect those of the United States Government or any agency thereof. 


\section{DISCLAIMER}

\section{Portions of this document may be illegible in electronic image products. Images are produced from the best available original document.}




\section{Contents}

INTRODUCTION

TASK 2 SYNTHESIS GAS CONVERSION TO DME AND METHANOL FOR DIRECT USE 3

Subtask 2.1 Process Evaluation Performance Target .......................................................... 3

Subtask 2.2 Definition of Preferred Catalyst System ......................................................... 3

Subtask 2.3 Process Variable Scans on the Preferred Catalyst System .............................. 3

Subtask 2.4 Life-Test on the Preferred Catalyst System ....................................................... 4

Subtask 2.5 Detailed Process and Economic Evaluations ..................................................... 4

Subtask 2.6 Plan for Demonstrating LPDME in the LaPorte AFDU ................................ 4

\section{TASK 3 ONE-STEP LIQUID PHASE SYNTHESIS OF ALTERNATTVE}

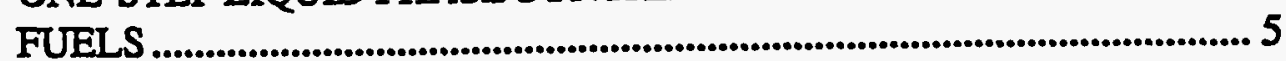

Subtask 3.2 Screen Novel Catalyst System ........................................................................... 6

Subtask 3.3 Evaluation of Preferred Catalyst System ........................................................... 6

Subtask 3.4 Update Process and Economic Evaluations........................................................ 7 


\section{INTRODUCTION}

From September 1981 to October 1991, Air Products and Chemicals, Inc., with the support of the U.S. Department of Energy (DOE), Chem Systems Inc., and the Electric Power Research Institute (EPRI), developed the liquid phase methanol (LPMEOH) process. The process, which uses slurry reactor technology, has the potential to be a more cost-effective route to produce methanol from coal than conventional gas phase processes. Primarily because of the presence of the well-mixed liquid phase in the reactor, the process is particularly suited to coal-derived synthesis gas, normally rich in carbon monoxide.

Extensive testing of the technology started in laboratory reactors and was extended to a DOEowned, nominal 10 ton-per-day (TPD) Process Development Unit.(PDU) located at LaPorte, Texas. In 1990 DOE renamed the PDU the Altemative Fuels Development Unit (AFDU) to emphasize DOE's interest in extending slurry phase processing to the development of a range of altemative fuels. In addition to different simulated coal derived feedstocks, process variables such as temperature, pressure, and flow rate were investigated thoroughly in both the laboratory and AFDU. A 120-day catalyst activity maintenance test in 1989 confirmed superior methanol catalyst stability in the liquid phase reactor compared to conventional packed-bed reactors. An on-stream factor at pilot level of greater than $98 \%$ was achieved. Furthermore, significant effort was utilized to maximize reactor productivity. Very high catalyst slurry concentrations (up to $50 \mathrm{wt} \%$ ) and high gas linear velocity (up to $.72 \mathrm{ft} / \mathrm{sec}$ ) were successfully demonstrated in the slurry bubble column reactor at LaPorte.

After these process and engineering development efforts, the LPMEOH process was deemed ready for the next scale of demonstration towards commercialization. Currently, a plan is in place to build a 200-500 TPD LPMEOH unit under DOE's Clean Coal III Program.

Through the mid-1980s, Air Products has brought the liquid phase approach to a number of other synthesis gas reactions where effective heat management is a key issue. In 1989, in response to DOE's PRDA No. DE-RA22-88PC88805, Air Products proposed a research and development program entitled "Synthesis of Dimethyl Ether and Alternative Fuels in the Liquid Phase from Coal Derived Syngas". The proposal aimed at extending the LPMEOH experience to convert coalderived synthesis gas to other useful fuels and chemicals.

The work proposed included development of a novel one-step synthesis of dimethyl ether (DME) from syngas, and exploration of other liquid phase syntheses of alternative fuels directly from syngas. The one-step DME process, conceived in 1986 at Air Products as a means of increasing syngas conversion to liquid products, envisioned the concept of converting product methanol in siru to DME in a single reactor. The slurry reactor based liquid phase technology is ideally suited for such an application, since the second reaction (methanol to DME) can be accomplished by adding a second catalyst with dehydration activity to the methanol producing reactor. An area of exploration for other alternative fueis directly from syngas was single-step slurry phase synthesis of hydrocarbons via methanol and DME as intermediates. Other possibilities included the direct synthesis of mixed alcohols and mixed ethers in a siurry reactor. 
Based on this proposal, DOE Contract No. DE-AC22-90PC89865 was awarded to Air Products on 21 December 1989. The primary objectives of this contract were to:

- Develop the technology for the single-step, slurry phase synthesis of DME.

- Investigate other potential slurry phase syntheses of alternative fuels.

For DME development, a further objective was to develop the process sufficiently for demonstration in the AFDU at LaPorte. The objective for other alternative fuels was to screen several novel catalyst systems and recommend preferred routes for further investigation.

The scope of work to be performed by Air Products was divided into three tasks as shown in Table 1. A detailed discussion of each task/subtask was presented in the Management Plan dated 21 February 1990.

\title{
TABLE 1 WORK BREAKDOWN STRUCTURE
}

\section{Task 1. Project Management}

\section{Task 2. Synthesis Gas Conversion to DME/Methanol for Direct Use}

\author{
Subtask 2.1 - Process Evaluation Performance Targets \\ Subtask 2.2 - Definition of Preferred Catalyst System \\ Subtask 2.3 - Process Variable Scans on the Preferred Catalyst System \\ Subtask 2.4 - Life-Test on the Preferred Catalyst System \\ Subtask 2.5 - Detailed Process and Economic Evaluations \\ Subtask 2.6 - Plan for Demonstration LPDME in the LaPorte AFDU
}

\section{Task 3. One-Step Liquid Phase Synthesis of Alternative Fuels}

Subtask 3.1 - Product/Process Definition

Subtask 3.2 - Screen Novel Catalyst Systems

Subtask 3.3 - Evaluation of the Preferred Catalyst System

Subtask 3.4 - Update Process and Economic Evaluations

The two topical reports shown below were issued separately to document experimental details from the laboratories.

1. Task 2.2 "Definition of Preferred Catalyst System", Task 2.3 "Process Variable Scans on the Preferred Catalyst.System", Task 2.4 "Life-Test on the Preferred Catalyst System".

2. Task 3.2 "Screen Novel Catalyst Systems", Task 3.3 "Evaluation of the Preferred Catalyst System".

It is not intended to reproduce the content of each Topical Report in this Final Report. A brief summary of all subtasks is included. More detail can be found in the above mentioned Topical Reports. 


\section{TASK 2 SYNTHESIS GAS CONVERSION TO DME AND METHANOL FOR DIRECT USE}

\section{Subtask 2.1 Process Evaluation Performance Target}

The objective of this subtask was to develop a process economic model of the one-step liquid phase DME (LPDME) process that can be used to set performance targets for catalysts and reactor systems. Under this subtask, a kinetic model was developed to describe the three reaction steps in the LPDME process,

$$
\begin{array}{lll}
\mathrm{CO}+2 \mathrm{H}_{2} & \leftrightarrow \mathrm{CH}_{3} \mathrm{OH} & : \text { Methanol Synthesis } \\
2 \mathrm{CH}_{3} \mathrm{OH} & \leftrightarrow \mathrm{CH}_{3} \mathrm{OCH}_{3}+2 \mathrm{H}_{2} \mathrm{O} & : \text { Methanol Dehydration } \\
\mathrm{CO}+\mathrm{H}_{2} \mathrm{O} & \leftrightarrow \mathrm{CO}_{2}+\mathrm{H}_{2} & : \text { Water Gas Shift }
\end{array}
$$

Attachment A, a memo entitled "Kinetics of Methanol/DME Synthesis" provides details of the kinetic modeling.

Process flow diagrams for various LPDME applications are presented in Attachment B, "Economics of DME/Methanol Coproduction". Cost estimates were developed for three promising configurations.

\section{Subtask 2.2 Definition of Preferred Catalyst System}

Under this subtask, three methanol catalysts, five alumina-based dehydration catalysts, and one water-gas shift catalyst (all commercially available) were tested. A gas simulating the product from a Texaco coal gasifier, with a nominal composition of $51 \% \mathrm{CO}, 35 \% \mathrm{H}_{2}, 13 \% \mathrm{CO}_{2}$, and $1 \% \mathrm{~N}_{2}$, was used as the feed for catalyst screening. Based on activity and slurry properties, BASF S3-86 and Catapal $\gamma$-alumina were selected as the preferred catalysts for the LPDME process. Depending on the application, these two catalysts can be physically mixed in different proportions, to yield essentially any desirable combination of DME and methanol in the product stream.

\section{Subtask 2.3 Process Variable Scans on the Preferred Catalyst System}

The effects of pressure, temperature, gas-hourly-space-velocity (GHSV) and feed composition were studied. The catalyst system chosen for the process variable scans consisted of $81.25 \mathrm{wt} \%$ BASF S3-86 and 18.75 wr\% Catapal $\gamma$-alumina. This proportion of catalysts was determined based on the maximum methanol equivalent productivity (MEP), which was defined as,

$$
\text { MEP }=\text { methanol productivity }+2 \times \text { DME productivity }
$$

MEP measures not only syngas conversion to the methyl group but also relates directly to the heating value of the desirable product, since each molecule of DME contains almost twice the heating value of a molecule of methanol. 


\section{Subtask 2.4 Life-Test on the Preferred Catalyst System}

Two catalyst activity-maintenance experiments were performed. One 620-hour experiment used the simulated Texaco gas as the feed. A subsequent 500 -hour experiment utilized a simulated Shell gas as the feed. Both experiments employed a catalyst mixture of BASF S3-86 and Catapal $\gamma$-alumina in the optimized 81.25 to $18.75 \%$ weight proportion.

In both runs, the catalyst system experienced relatively fast deactivation compared to LPMEOH Post mortem catalyst analyses by XRD and Raman Spectroscopy indicated copper crystallite growth on the catalyst but no graphitic carbon deposit.

Further studies on the catalyst deactivation phenomenon are strongly recommended.

\section{Subtask 2.5 Detailed Process and Economic Evaluations}

Process and economic evaluations for the LPDME process were conducted for three possible scenarios: Key conclusions from the study are:

- LPDME can produce DME more economically than in the conventional two-step process (methanol formation followed by dehydration), and the product holds promise as a feedstock for downstream chemical processes.

- DME and methanol mixtures as peak shaving fuels may be produced at a slightly lower cost than methanol alone. This cost difference is probably not sufficient to warrant the additional complexity associated with collecting and storing this fuel.

- Methanol with a small quantity of DME can be produced at essentially the same cost as methanol alone. The presence of DME may enhance the cold weather startbility of methanol used as a fuel.

A detailed report is included as Attachment B.

\section{Subtask 2.6 Plan for Demonstrating LPDME in the LaPorte AFDU}

A plan for the demonstration of the LPDME process in the LaPorte AFDU was completed in conjunction with the follow-on Alternative Fuels DOE Contract No. DE-AC22-91PC90018. Since the latter contract included performance of the demonstration run, it makes more sense to report the plan in that contract, thus it is not included herein. 


\section{TASK 3 ONE-STEP LIQUID PHASE SYNTHESIS OF ALTERNATIVE FUELS}

\section{Subtask 3.1 Product/Process Definition}

This task turned out to be very exploratory. The emphasis of Subtask 3.1 became product definition rather than process definition. Process definition was premature and inappropriate at this time.

Through a literature search, three syntheses showed potential for liquid phase application because of high acceptance probability of the product in the market place. These syntheses are:

1. Syngas conversion to hydrocarbons.

2. Syngas conversion to mixed alcohols.

3. Syngas conversion to mixed ethers.

Syngas conversion to hydrocarbons takes a similar approach to Mobil's MTG process. However, unlike the Mobil's multi-step process,

syngas $\rightarrow$ methanol $\rightarrow$ DME $\rightarrow$ hydrocarbons

the current method employs only a single-step synthesis,

syngas $\rightarrow$ hydrocarbons.

Conceptually, this single-step synthesis could be accomplished in a liquid phase reactor using a dual catalyst system consisting of a methanol catalyst and a zeolite catalyst (e.g. ZSM-5). The liquid phase would provide excellent temperature control for this highly exothermic reaction.

"Mixed alcohols" product has the potential to be an effective gasoline additive. All alcohols with a carbon number of less than 5 have relatively high octane numbers and provide oxygen for clean burning. Methanol alone as a fuel additive has poor water tolerance causing phase separation in wet gasoline. In addition, methanol has a very high blending Reid Vapor Pressure (RVP) which worsens the evaporative emissions. Commercially, Lurgi offers the Octamix process to produce mixed alcohols. The product from an Octamix unit is claimed to have a $\mathrm{C}_{2}+$ alcohol to methanol ratio of 30 to 70 by weight. The presence of higher alcohols reduces the shortcomings of methanol as a gasoline additive. This $30 \mathrm{wt} \%$ higher alcohol content became the target of this subtask.

Many ethers are known in the industry as excellent gasoline blending agents. Methyl tert-butyl ether (MTBE), ethyl tert-butyl ether (ETBE), and tert-amyl methyl ether (TAME) are all well accepted in the market place. Below are the rationales for developing a single-step mixed ethers process.

- Ethers can easily be made from dehydration of aicohols.

- With the development of a mixed alcohols process, a mixed ethers process is established by adding a dehydration catalyst to the mixed alcohol reactor.

- A liquid phase reactor can accommodate the addition of a second catalyst easily, as demonstrated in the LPDME process. 


\section{Subtask 3.2 Screen Novel Catalyst System}

Catalyst systems for the syntheses discussed above were evaluated.

For the one-step synthesis of hydrocarbons, a mixture of a methanol catalyst and ZSM-5 was used as the catalyst system. The stability of the slurrying liquid became a key issue. The liquids acceptable in the LPMEOH process cracked in the presence of ZSM-5 and hydrogen. Many attempts to mitigate the problem were tried with only limited success, including passivating the external acid site of the ZSM-5 catalyst and choosing different liquids. Although hydrocarbon products were observed, liquid stability remained an issue. The process is not considered viable without further work to identify a suitable liquid medium.

Two commercially available mixed alcohols catalysts and one laboratory prepared catalyst were tested for mixed alcohols synthesis. One of the commercial catalysts was the copper-based Octamix catalyst, and the other was a cobalt-based catalyst obtained through a cooperative secrecy agreement. The laboratory preparation was an alkali promoted BASF S3-86 catalyst. In addition, dual catalyst systems involving mixtures of a copper-based methanol catalyst and a higher alcohol forming co-catalyst were also evaluated. Among all the catalyst systems evaluated, the laboratory prepared alkali-promoted catalyst showed the highest activity for mixed alcohols.

Mixed ether synthesis was accomplished by adding a $\gamma$-alumina catalyst to the alkali-promoted BASF S3-86 catalyst. Various ethers were produced. The majority of the ingredients in the ether product were the statistical expectations from the mixed alcohols intermediate product. For example, DME, methyl iso-butyl ether, methyl ethyl ether, and methyl n-propyl ether were predominant ether products. Evaluation of these ethers as gasoline additives was conducted as part of the Alternative Fuels follow-on contract.

The screening of all these catalyst systems suggested the alkali-promoted BASF S3-86 for mixed alcohols synthesis showed the most promise for further investigation. In fact, preliminary tests showed that once-through conversions achieved the target of $30 \mathrm{wt} \%$ higher alcohol in the product.

\section{Subtask 3.3 Evaluation of Preferred Catalyst System}

The synthesis of mixed alcohols was chosen for further evaluation. Alkali-promoted S3-86 catalyst was studied for process variable effects. Temperature, GHSV, and gas composition were varied to observe the impact on catalyst productivity and selectivity. In addition, co-feeding methanol and ethanol with syngas was studied to simulate the recycle of light alcohols to increase the yield of higher alcohols.

Lurgi's Octamix catalyst was investigated in some detail because it is a "state-of-the-art" commercial catalyst for mixed alcohols synthesis. The effects of temperature, pressure, and gas composition were studied. The results obtained on the Lurgi catalyst provided a basis for performance comparison. 
Subtask 3.4 Update Process and Economic Evaluations

As for Subtask 3.1, this subtask is premature at this time because the reaction system is still embryonic. Air Products has identified that one-step synthesis of mixed alcohols using an alkalipromoted catalyst deserves more detailed study. The optimization of the catalyst system requires more time and effort to finalize. The economics for mixed alcohols synthesis should be similar to that of methanol synthesis and should be done when the process becomes better defined. 
ATTACHMENT A

\section{Kinetics of MeOH/DME Synthesis}



To:
B. Bhatt
'Dept./oc.:
PSG R\&D
From:
D. M. Herron
Dept/Ext::
PSG Process Engineering / 4765
Date: $\quad 7$ May 1993
Subject: Kinetics of MeOH/DME Synthesis - REVISION OF 15 MARCH 1990 DOCUMENT

cc: D. M. Brown

T. H. Hsiung

D. W. Studer / Alt Fuels Modelling File (w/source code)

R. P. Underwood

R. F. Weimer

\subsection{Summany-}

I have completed calculations of the predicted product distribution from a CSTR for the reactions: syngas to methanol, methanol to dimethyl ether, and water-gas shift (all occuring simultaneously).

Based on the results of a single autoclave run (at one wt\% $\mathrm{MeOH}$ catalyst), it is possible to estimate rate constants for each of these three reactions, then proceeded to predict the productivity and selectivity over the entire range of co-catalyst proportions.

The results of my calculations indicate the following:

- The maximum productivity (defined on an equivalent-methanol basis) will occur in the range of 70 wt\% to $90 \mathrm{wt} \% \mathrm{MeOH}$ catalyst. The MeOH rate constant can be determined accurately over the entire range of co-catalyst proportions.

- The DME selectivity (defined as the moles of DME divided by the moles of DME+MeOH) is fairty constant (around 0.8) in the range of 30 wt\% to 70 wt\% MeOH catalyst. Within this range it is difficult to accurately determine the DME reaction order and rate constant. Therefore, it will be best to screen DME catalysts at low proportions in the co-catalyst mix.

- The kinetics of the shitt reaction will be difficult to determine with any accuracy (without the aid of water analysis in the reactor effluent). However, the most sensitive region is below 20 wt\% MeOH catalyst.

I have examined runs 10454-74a, 74c, and 74e, and estimated rate constants. Based on this work, I offer the following comments:

- The activity of the MeOH catalyst (for the MeOH reaction) declined from $83 \%$ of expected (run $74 a$ ) to $50 \%$ of expected (run 74c) and finally to $40 \%$ of expected (run 740 ).

- The activity of the DME catalyst and the MeOH catalyst (towards the shift reaction) both seemed to decline with time-on-stream. However, the rate constants are very sensitive to the measured composition of the reactor effluent - these observations need further experimental verification. 


\subsection{Model Development -}

The reactions under consideration are:

$$
\begin{aligned}
& \mathrm{CO}+2 \mathrm{H}_{2}=\mathrm{MeOH} \\
& 2 \mathrm{MeOH}=\mathrm{DME}+\mathrm{H}_{2} \mathrm{O} \\
& \mathrm{CO}+\mathrm{H}_{2} \mathrm{O}=\mathrm{CO}_{2}+\mathrm{H}_{2}
\end{aligned}
$$

\subsection{Component Balances -}

\begin{tabular}{|c|c|c|c|c|}
\hline $\mathrm{H}_{2}$ & $=$ & $-2 E_{1}$ & & $+E_{3}$ \\
\hline CO & $=$ & $-E_{1}$ & & - $E_{3}$ \\
\hline $\mathrm{N}_{2}$ & $=$ & & & \\
\hline $\mathrm{CO}_{2}$ & $=$ & & & $+E_{3}$ \\
\hline $\mathrm{MeOH}$ & $=$ & $+E_{1}$ & $-2 E_{2}$ & \\
\hline DME & $=$ & & $+E_{2}$ & \\
\hline $\mathrm{H}_{2} \mathrm{O}$ & $=$ & & $+E_{2}$ & $-E_{3}$ \\
\hline TOTAL & $=$ & $-2 E_{1}$ & & \\
\hline
\end{tabular}

The component molar balances are:

FLOW RATE OUT - FLOW RATE IN
(gmole/hr-kg total catalyst)
RATE OF PRODUCTION (gmole/hr-kg total catalyst)

where $E_{1}, E_{2}$, and $E_{3}$ are the extents of reaction for $x_{n} 1,2$, and 3 respectively.

The extent of reaction is defined by:

$$
E_{j}=R \mid X_{j}
$$

where $R \mid$ is the rate of reaction (gmole/hr-kg catalyst $l$ ) and $X \mid$ is the weight fraction of catalyst I (kg catalyst $/ \mathrm{kg}$ total catalyst).

\subsection{Reaction Rates -}

The rates of reaction were assumed to be of the following (simplified) forms:

$$
\begin{aligned}
& R_{1}=k_{1}(f C O)^{1 / 3}(f H 2)^{2 / 3}\left(1-1 / K E Q 1 \frac{f M O O H}{f C O(f H 2)^{2}}\right) \\
& R_{2}=k 2(f M E O H)^{N}\left(1-1 / K E C 2 \frac{f D M E f H 2 O}{f M O O H^{2}}\right) \\
& R_{3}=k 3(f C O)(f H 2 O)\left(1-1 / K E Q 3 \frac{f C O 2 f H 2}{f C O ~ f H 2 O}\right)
\end{aligned}
$$




\subsection{Solution Scheme -}

For a CSTR, the rates of reaction are computed from the outlet compoent fugacities and the solution to this problem becomes straightforward:

- $\quad$ The inlet flow and composition, catalyst weights, reactor temperature and pressure, rate/equilibrium constants, and outlet fugacity coefficients are specified.

- The outlet flow and composition (the remaining unknowns) are computed by plugging the rate expressions into the component balances and solving the system of equations simultaneously (ie iteratively).

The solution scheme which $\mathrm{l}$ use is such that different forms of rate expressions may be used.

\subsection{Equilibrium Constants -}

The following expressions were used to describe the equilibrium constants:

$$
\begin{aligned}
& \text { In KEQ1 }=28.18+16251.2 T_{R} \cdot 7.97 \ln \left(T_{R}\right)+0.0032 T_{R}-2.1 \times 10^{-7} T_{R 2} \\
& \text { In } K_{E Q 2}=-13.36+2835.2 T_{K}+1.68 \ln \left(T_{K}\right)-2.4 \times 10^{-4} T_{K} \cdot 2.1 \times 10^{-7} T_{K} 2 \\
& \text { In } K_{E Q 3}=-4.33+8240 / T_{R}
\end{aligned}
$$

where $T R$ and $T K$ are temperature in ${ }^{\circ} R$ and ${ }^{\circ} K$, respectively. The functional forms for the equilibrium constants of $\operatorname{rxn} 1$ and 3 were taken from reference 1; reference 2 was used as the source the equilibrium constant of rxn 2.

\subsection{Rate Censtants -}

The rate constants $\mathrm{k}_{1}, \mathrm{k} 2$, and $\mathrm{k}_{3}$ were estimated from selected autoclave data (Runs 10454-74A, 74C and 74E). Note that the order of the DME reaction, $N$, was assumed to be either 1 or 2 . The results are summarized in the Tables 1, 2, and 3 .

Also note that the experimental effluent composition was corrected for the presence of water (which was not measured in the lab). The water quantity in the effluent was estimated in such a way as to give the best overall agreement between the measured composition and that which would result from the indicated stoichiometry.

In general, the rate constants are shown to decrease with time-on-stream. In particular, the activity of the MeOH catalyst is decreasing șubstantially.

Once the rate constants have been obtained, it is possible to calculate productivity (in MeOH equivalent terms) and selectivity (towards DME) over a range of co-catalyst proportions. This exercise has been done - the results are plotted in Figure 1 (run 74A), Figure 2 (run 74C), and Figure 3 (run 74E). These results demonstrate that productivity and selectivity are greatest at the higher concentrations of $\mathrm{MeOH}$ catalyst.

\subsection{Model Predictions / Sensitivity Studies -}

Inspection of Figures 1 through 3 leads one to believe that the optimal MeOH catalyst concentration is between $70 \mathrm{wt} \%$ and $90 \mathrm{wt} \%$. To challenge this conclusion, I have looked at the sensitivity of the trends to uncertainty in the various rate constants. 
For this exercise, I have used the run $74 a$ composition (CO-rich, $\mathrm{CO} 2$ lean) as a basis.

\subsection{Variation in MęOH Rate Constant -}

I considered three levels of MeOH catalyst activity: $65 \%, 83 \%$ and $100 \%$ of expected. The "expected" rate constant is that which prevails under Liquid-Phase Methanol synthesis conditions (pre-exponential factor, $\mathrm{Ko}=2.91 \times 10^{6} \mathrm{gmole} / \mathrm{hr} / \mathrm{kg}$-catalyst/atm). The results of my calculations are summarized in Figure 4 (Figure $4 \mathrm{~A}$ for DME rxn order of 1, Figure 4B for DME rxn order of 2). These plots indicate:

- As MeOH catalyst activity increases the maximum productivity shifts to lower concentrations of $\mathrm{MeOH}$ catalyst.

- DME selectivity is unaffected by MeOH catalyst activity.

\subsection{Variation in DME Rate Constant -}

I considered three levels of DME catalyst activity. The results of my calculations are summarized in Figure 5 (Figure 5A for DME rxn order of 1, Figure 5B for DME rxn order of 2). These plots indicate:

- As DME catalyst activity increases the maximum productivity shifts to higher concentrations of $\mathrm{MeOH}$ catalyst.

- DME selectivity falls with decreasing DME catalyst activity.

\subsection{Variation in Shift Bate Constant -}

I considered three levels of Shift activity. The results of my calculations are summarized in Figure 6 (Figure $6 \mathrm{~A}$ for DME IXn order of 1, Figure 6B for DME xn order of 2). These plots indicate that shift reaction kinetics only impact selectivity and productivity modestly.

\subsection{Variation in Space Velocity -}

I considered three different space velocities. The results of my calculations are summarized in Figure 7 (Figure 7A for DME Ixn order of 1, Figure 7B for DME $x \times n$ order of 2). These plots indicate:

- Productivity increases with increasing space velocity but the point of maximum productivity is largely unaffected by space velocity,

- DME selectivity falls with increasing space velocity. For greater selectivity, one is driven to lower concentrations of MeOH catalyst.

\subsection{Conclusion -}

These sensitivity studies strongly suggest that the commercial DME/MeOH synthesis should be carried out at 70 to $90 \mathrm{wt} \% \mathrm{MeOH}$ catalyst. 
A key piece of information which is missing is the kinetic expression of the DME reaction (reaction order in particular). As illustrated clearly in Figure 7, variation in DME selectivity is much stronger for first order kinetics.

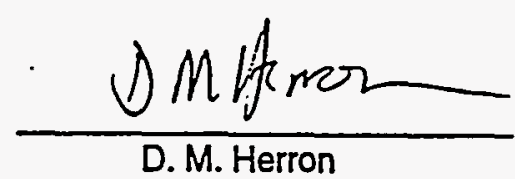

\subsection{References -}

1. J. A. Ager, "LPMEOH Modeling", APCl memo to Distribution, 8 June 1989.

2. B. T. Diep and M. S. Wainwright, "Thermodynamic Equilibrium Constants for the MethanolDimethyl Ether-Water System", J. Chem. Eng. Data, 32, 330-333, 1987. 
TABLE I

Run 74A - 250 C, $52 \mathrm{~atm}, 2250 \mathrm{sL} / \mathrm{kg}-\mathrm{hr}$ (total catalyst) - 50\% MeOH Cat

Measured

IN OUT

Composition (mole $\%$ )

$\begin{array}{lrr}\mathrm{H}_{2} & 39.8 & 22.2 \\ \mathrm{CO} & 56.5 & 50.2 \\ \mathrm{~N}_{2} & 1.2 & 1.8 \\ \mathrm{CO} & 3.4 & 14.2 \\ \mathrm{MeOH} & & 1.8 \\ \mathrm{OME} & & 10.7 \\ \mathrm{H} 2 \mathrm{O} & & ?\end{array}$

Flow (sL/hr)

$67.6 \quad 48.0$

$$
\begin{aligned}
& \text { Corrected } \\
& \text { IN OUT } \\
& \text { Modelled } \\
& \mathrm{N}=1 \quad \mathrm{~N}=2
\end{aligned}
$$

$39.6 \quad 21.8$

$56.0 \quad 49.3$

$1.2 \quad 1.8$

$3.4 \quad 13.9$

1.8

10.5

1.0 .

21.4

49.5

1.8

14.1

1.8

10.4

1.1

46.6

21.3

49.4

1.7

14.1

1.8

10.4

1.1

46.5

\section{Calculated Coefficients}

$\begin{array}{llcc}\text { MeOH } & \begin{array}{l}k_{1} \text { (gmole/hr-kg cat-atm) } \\ \text { Percent of typical }\end{array} & \begin{array}{c}2.36 \\ (82.5)\end{array} & \begin{array}{c}2.36 \\ (82.5)\end{array} \\ \begin{array}{lll}\text { DME 1st order } \\ \text { 2nd order }\end{array} & \begin{array}{l}k_{2} \text { (gmole/hr-kg cat-atm) } \\ k_{2} \text { (gmole/hr-kg cat-atm²) }\end{array} & 28 & 35 \\ \text { Shift } & k_{3} \text { (gmole/hr-kg cat-atm2) } & 0.95 & 0.95\end{array}$


TABLE 2

Run $74 \mathrm{C}-250 \mathrm{C}, 52 \mathrm{~atm}, 1500 \mathrm{sL} / \mathrm{kg}-\mathrm{hr}$ (total catalyst) - 50\% MeOH Cat

Measured

IN OUT
Corrected

IN OUT
Modelied

$\mathrm{N}=1 \quad \mathrm{~N}=2$

Composition (mole $\%$ )

$\begin{array}{lrrrrrr}\mathrm{H}_{2} & 38.7 & 22.1 & 38.2 & 22.2 & 22.3 & 22.4 \\ \mathrm{CO} & 47.7 & 39.4 & 47.1 & 39.6 & 39.5 & 39.6 \\ \mathrm{~N}_{2} & 1.1 & 1.4 & 1.1 & 1.4 & 1.5 & 1.5 \\ \mathrm{CO} & 13.8 & 25.1 & 13.6 & 25.2 & 25.0 & 25.0 \\ \mathrm{MeOH} & & 1.6 & & 1.6 & 1.6 & 1.6 \\ \mathrm{DME} & & 8.2 & & 8.2 & 8.2 & 8.2 \\ \mathrm{H} 2 \mathrm{O} & & ? & & 1.8 & 1.8 & 1.7 \\ & & & & & 33.1 & 33.2\end{array}$

\section{Calculated Coefficients}

$\begin{array}{ll}\text { MeOH } & \begin{array}{l}k_{1} \text { (gmole/hr-kg cat-atm) } \\ \text { Percent of typical }\end{array} \\ \text { OME 1st order } & \begin{array}{l}k_{2} \text { (gmole/hr-kg cat-atm) } \\ \text { 2nd order }\end{array} \\ k_{2} \text { (gmole/hr-kg cat-atm²) } \\ \text { Shift } & k_{3} \text { (gmole/hr-kg cat-atm²) }\end{array}$

$\begin{array}{cc}1.40 & 1.40 \\ (49.0) & (49.0) \\ 27 & 32 \\ & 0.40\end{array}$


TABLE 3

Run $74 E-250 \mathrm{C}, 52 \mathrm{~atm}, 1500 \mathrm{sL} / \mathrm{kg}-\mathrm{hr}$ (total catalyst) - 50\% MeOH Cat

\begin{tabular}{lll} 
Measured & Corrected & \multicolumn{2}{c}{ Modelled } \\
IN OUT & IN
\end{tabular}

Composition (mole $\psi$ )

\begin{tabular}{|c|c|c|c|c|c|c|}
\hline $\begin{array}{l}\mathrm{H}_{2} \\
\mathrm{CO} \\
\mathrm{H}_{2} \\
\mathrm{CO}_{2} \\
\mathrm{HeOH} \\
\mathrm{DME} \\
\mathrm{H}_{2} \mathrm{O}\end{array}$ & $\begin{array}{r}36.5 \\
46.1 \\
1.0 \\
15.3\end{array}$ & $\begin{array}{r}23.2 \\
39.2 \\
1.3 \\
24.6 \\
1.5 \\
6.5 \\
?\end{array}$ & $\begin{array}{r}36.9 \\
46.6 \\
1.0 \\
15.5\end{array}$ & $\begin{array}{r}23.7 \\
40.1 \\
1.3 \\
25.2 \\
1.5 \\
6.6 \\
1.5\end{array}$ & $\begin{array}{r}23.7 \\
40.2 \\
1.3 \\
25.4 \\
1.5 \\
6.6 \\
1.3\end{array}$ & $\begin{array}{r}23.7 \\
40.3 \\
1.3 \\
25.4 \\
1.5 \\
6.6 \\
1.3\end{array}$ \\
\hline (hr) & 45.1 & 345 & & & 34.8 & 34.8 \\
\hline
\end{tabular}

Flow (sL/hr) $\quad 45.1 \quad 34.5$

Calculated Coefficlents

$\begin{array}{llcc}\text { MeOH } & \begin{array}{l}k_{1} \text { (gmole/hr-kg cat-atm) } \\ \text { Percent of typical }\end{array} & \begin{array}{c}1.12 \\ (39.0)\end{array} & \begin{array}{c}1.12 \\ (39.0)\end{array} \\ \begin{aligned} \text { DME 1st order } \\ \text { 2nd order }\end{aligned} & \begin{array}{l}k_{2} \text { (gmole/hr-kg cat-atm) } \\ k_{2} \text { (gmole/hr-kg cat-atm) }\end{array} & 18 & 25 \\ \text { Shift } & k_{3} \text { (gmole/hr-kg cat-atm²) } & 0.50 & 0.50\end{array}$




\section{FIGURE 1}

DME $/ \mathrm{MeOH}$ Catalyst Performance - $250 \mathrm{C}, 52.0 \mathrm{~atm}$ (Based on run $74 a-40 \% \mathrm{H} 2,56 \% \mathrm{CO}, 3 \% \mathrm{CO} 2-\mathrm{SV}=2250$ )

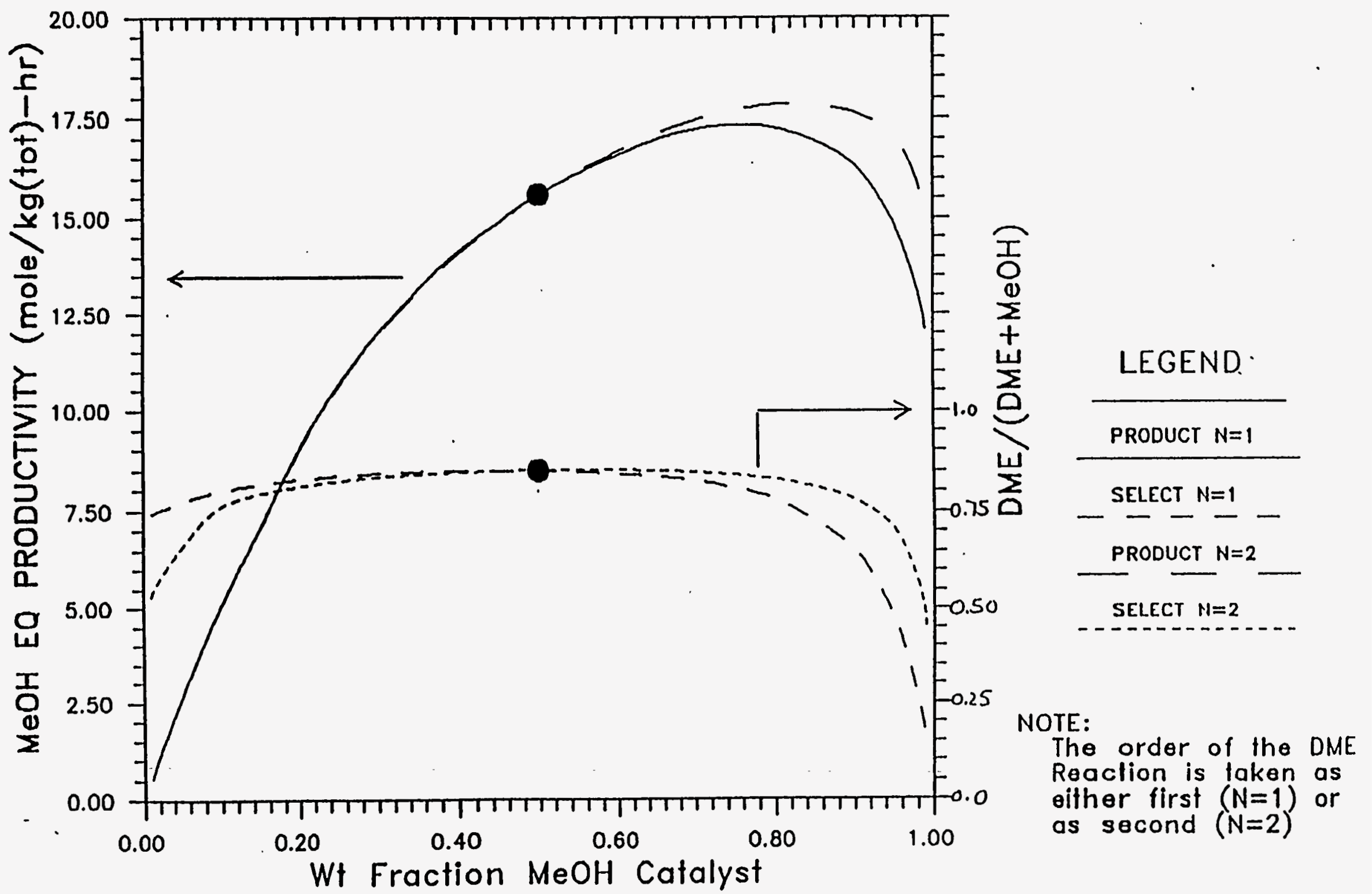


FIGURE 2

DME/MeOH Catalyst Performance - $250 \cdot \mathrm{C}, 52.0 \mathrm{~atm}$

(Based on run 74c - 38\% H2, 47\% $\mathrm{CO}, 14 \% \mathrm{CO} 2-\mathrm{SV}=1500$ )

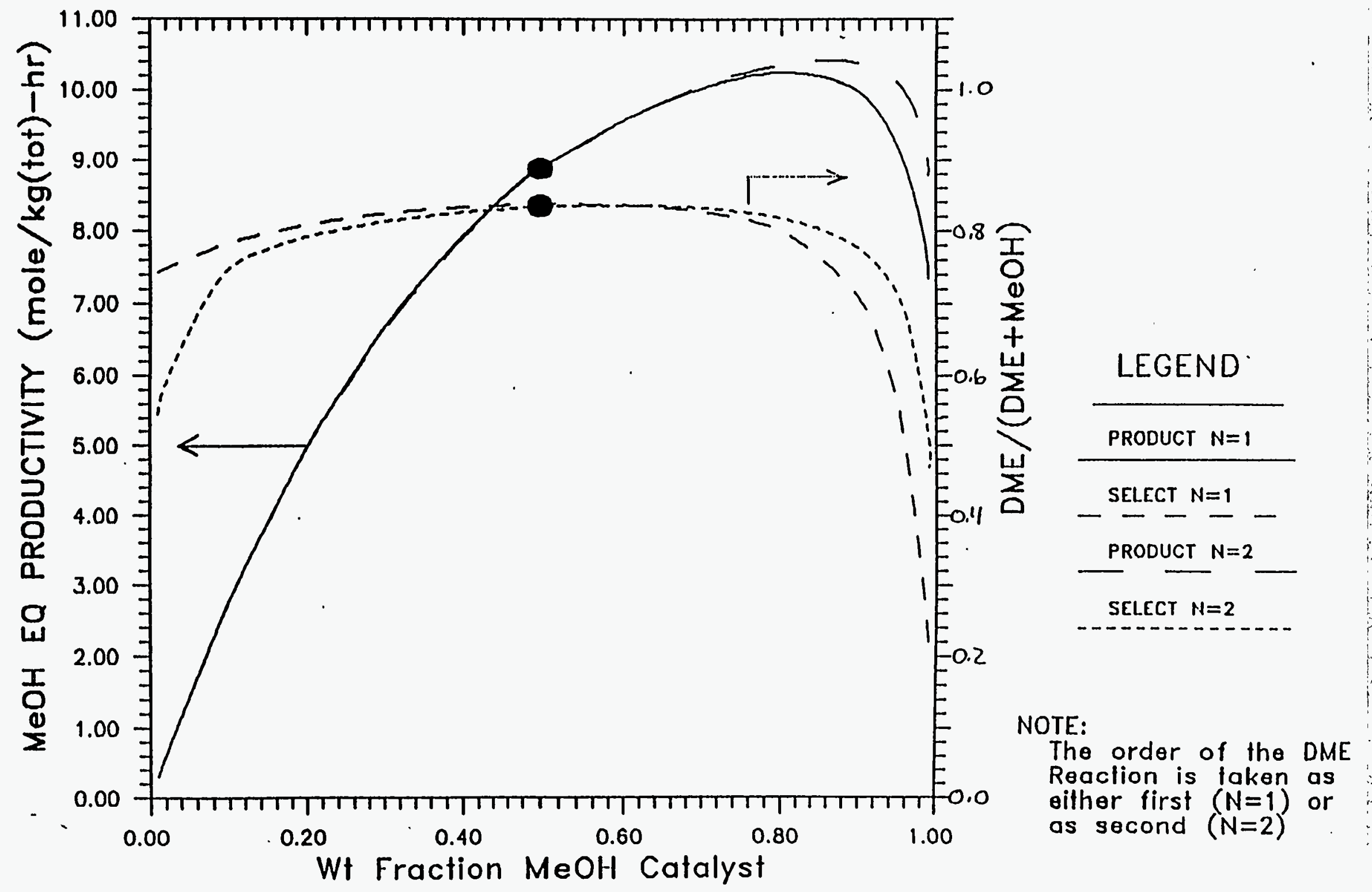



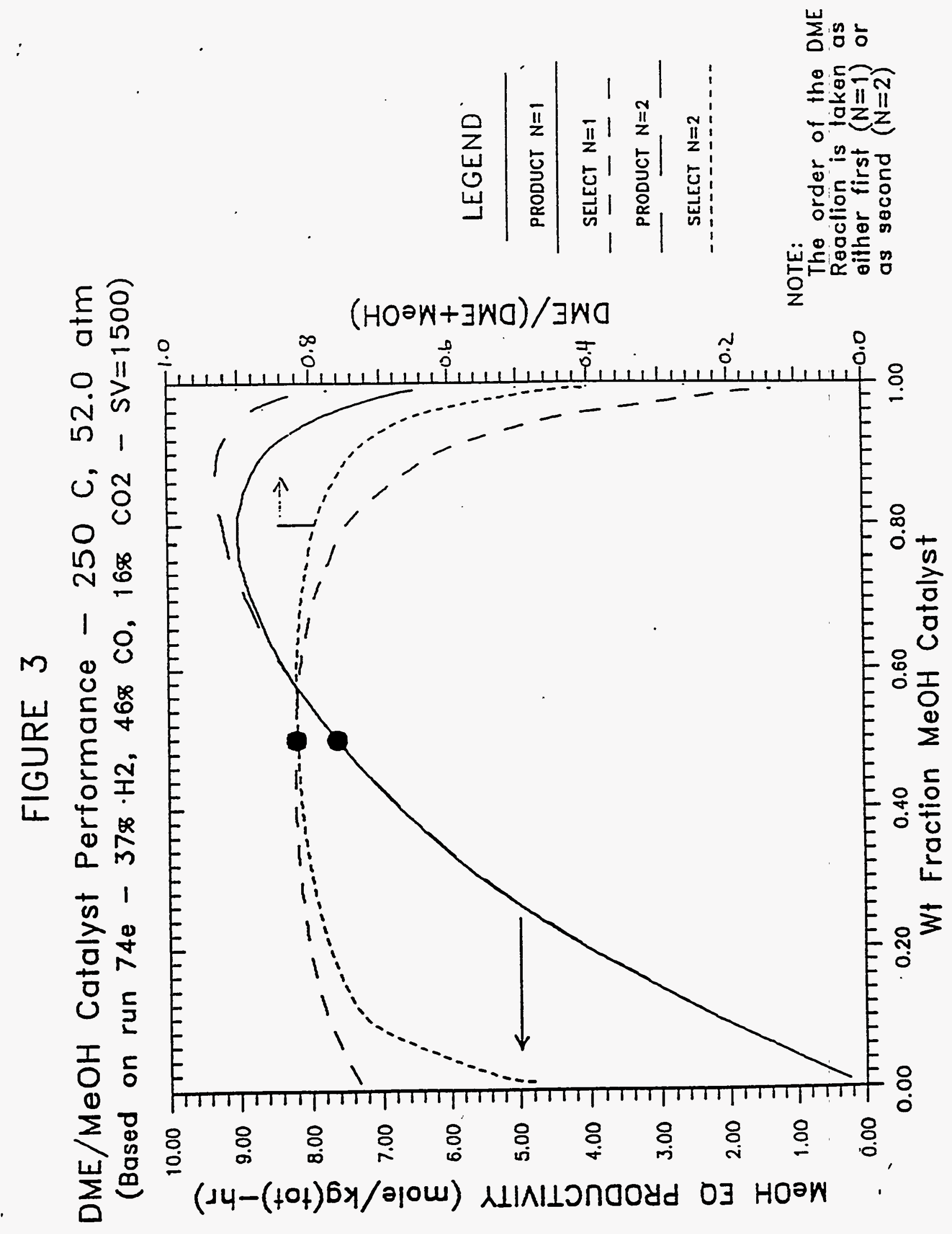


\section{FIGURE $4 \mathrm{~A}$}

DME/MeOH Catalyst Performance - $250 \mathrm{C}, 52.0 \mathrm{~atm}$

(Varition with $\mathrm{MeOH}$ Cotalyst Rate Constont)

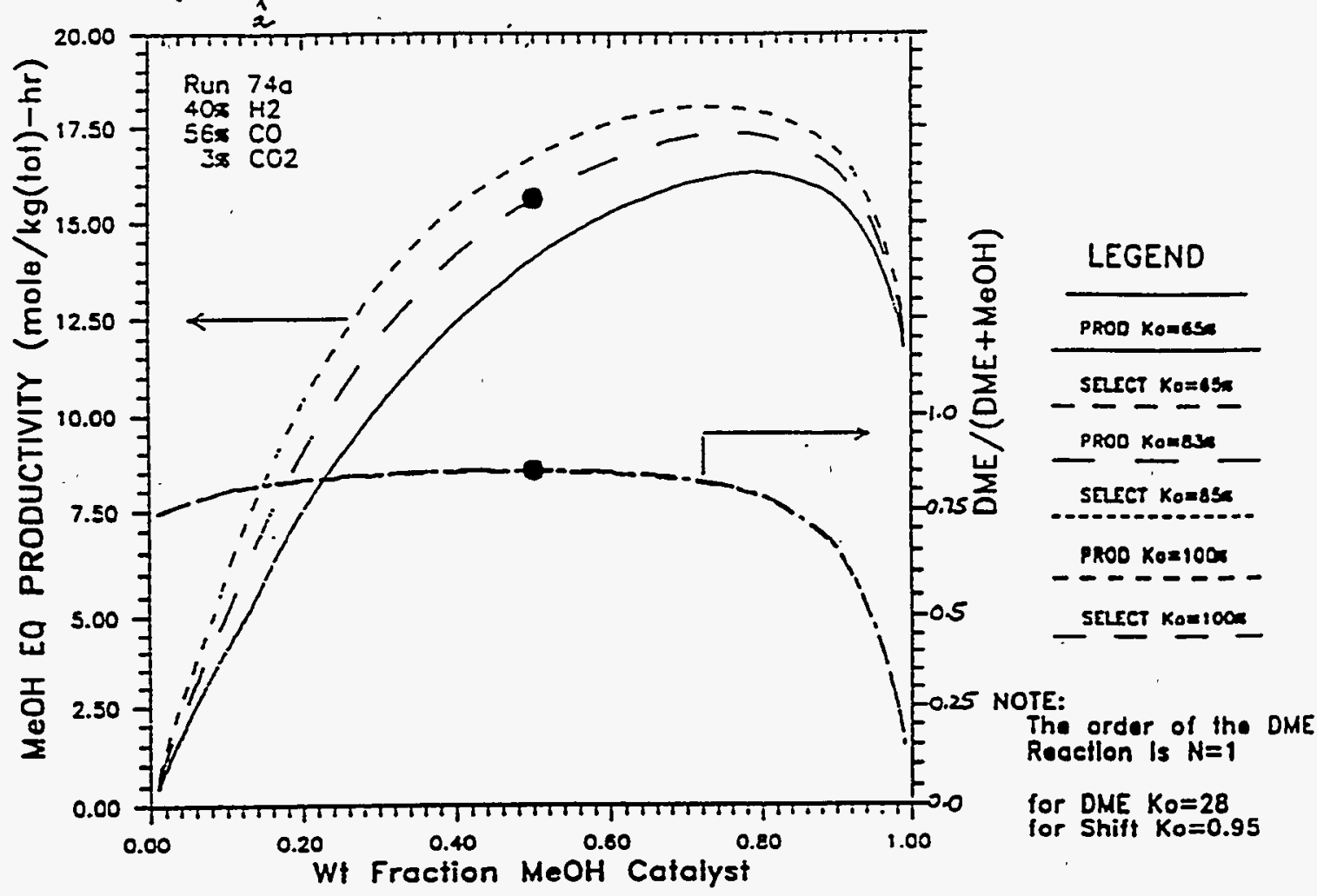

FIGURE 4B

DME/MeOH Catalyst Performance - $250 \mathrm{C}, 52.0 \mathrm{~atm}$

(Vorition with $\mathrm{MeOH}$ Catalyst Rate Constant)

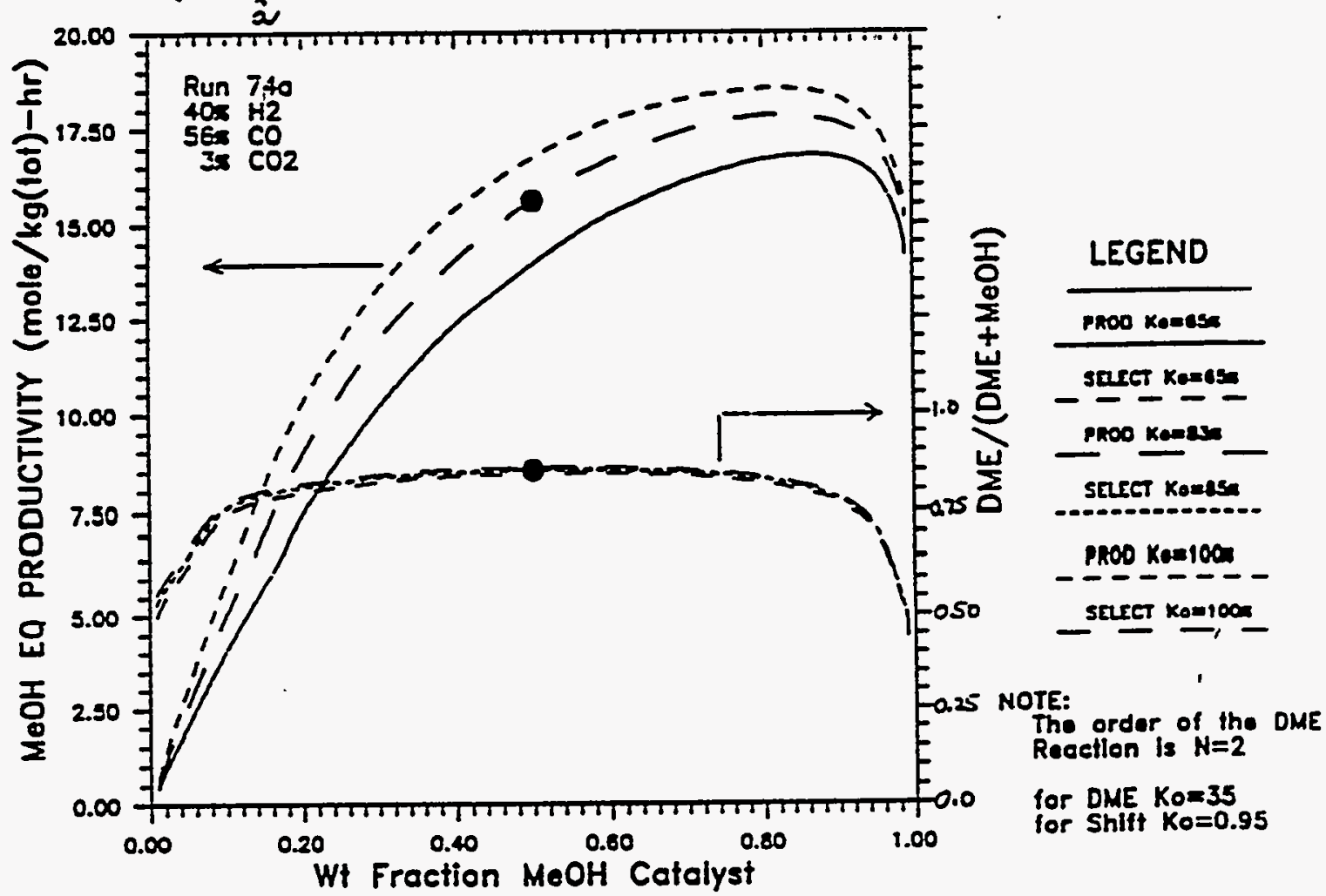


FIGURE 5A

$\mathrm{DME} / \mathrm{MeOH}$ Catalyst Performance - $250 \mathrm{C}, 52.0 \mathrm{otm}$

(Voriation with DME Catalyst Rate Constont)

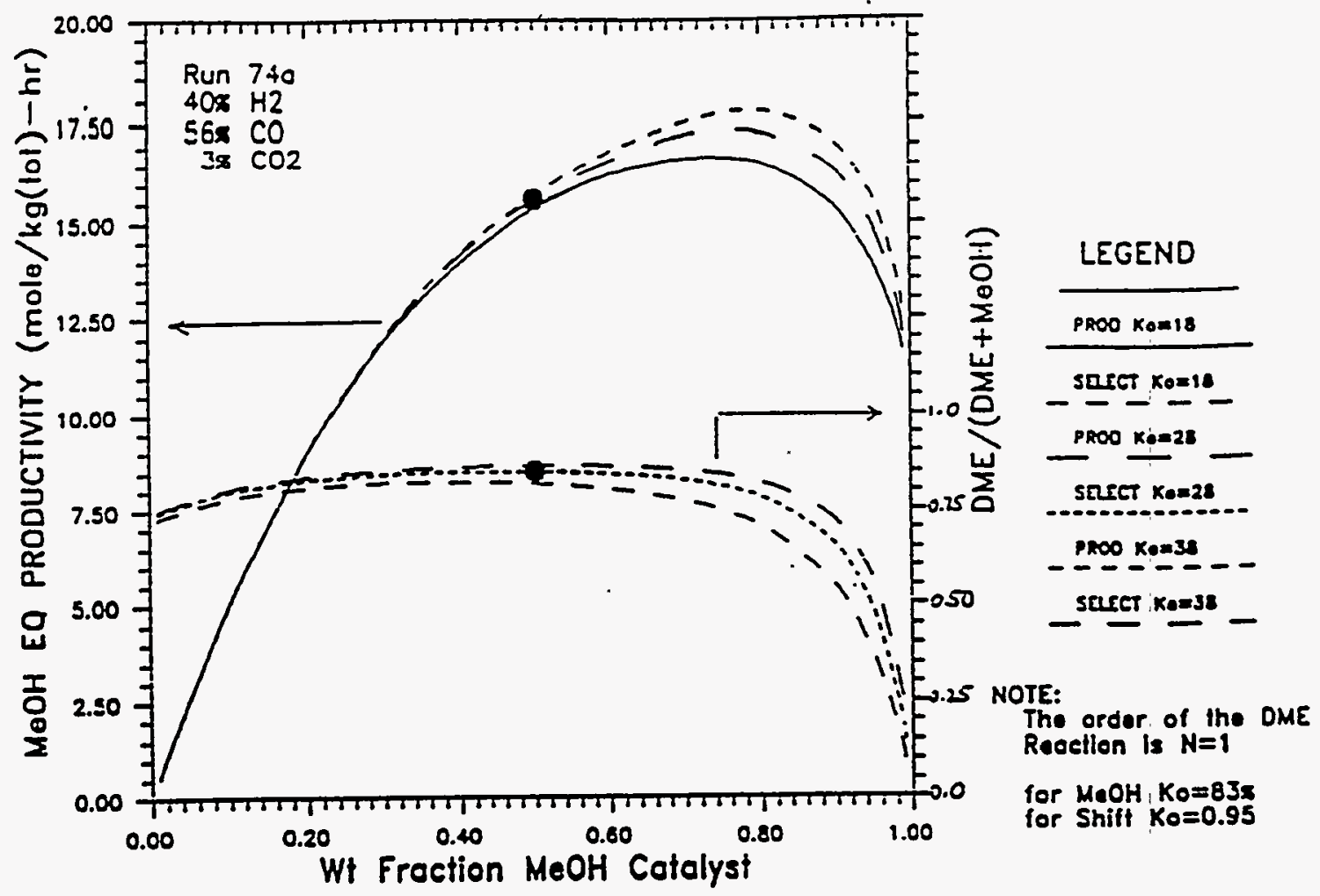

FIGURE 5B

DME/MeOH Catalyst Performance - $250 \mathrm{C}, 52.0 \mathrm{~atm}$

(Voriation with DME Cotalyst Rate Constant)

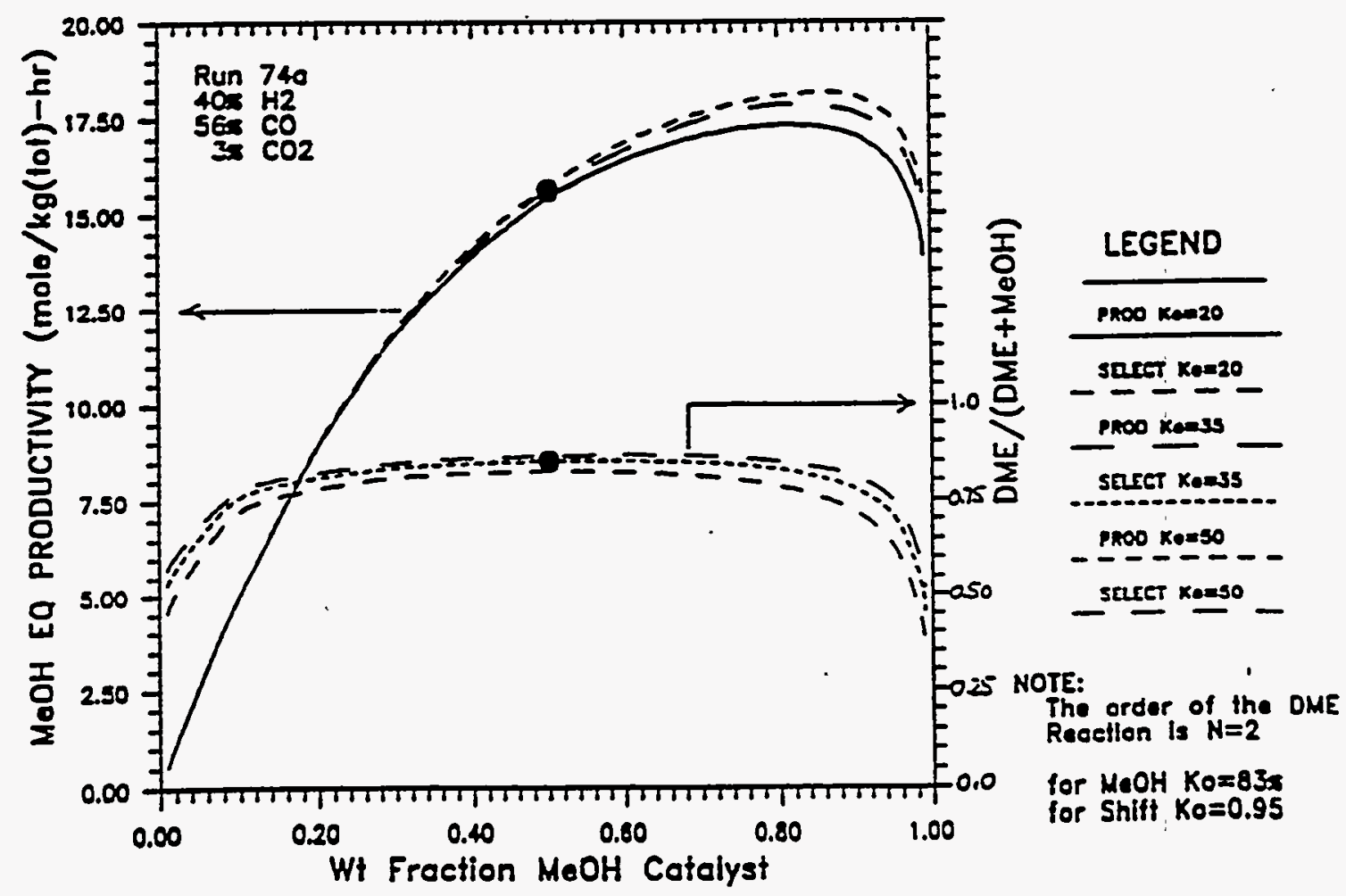


FIGURE 6A

DME/MeOH Catalyst Performance - $250 \mathrm{C}, 52.0 \mathrm{~atm}$

(Voriation with Shift Rate Constont)

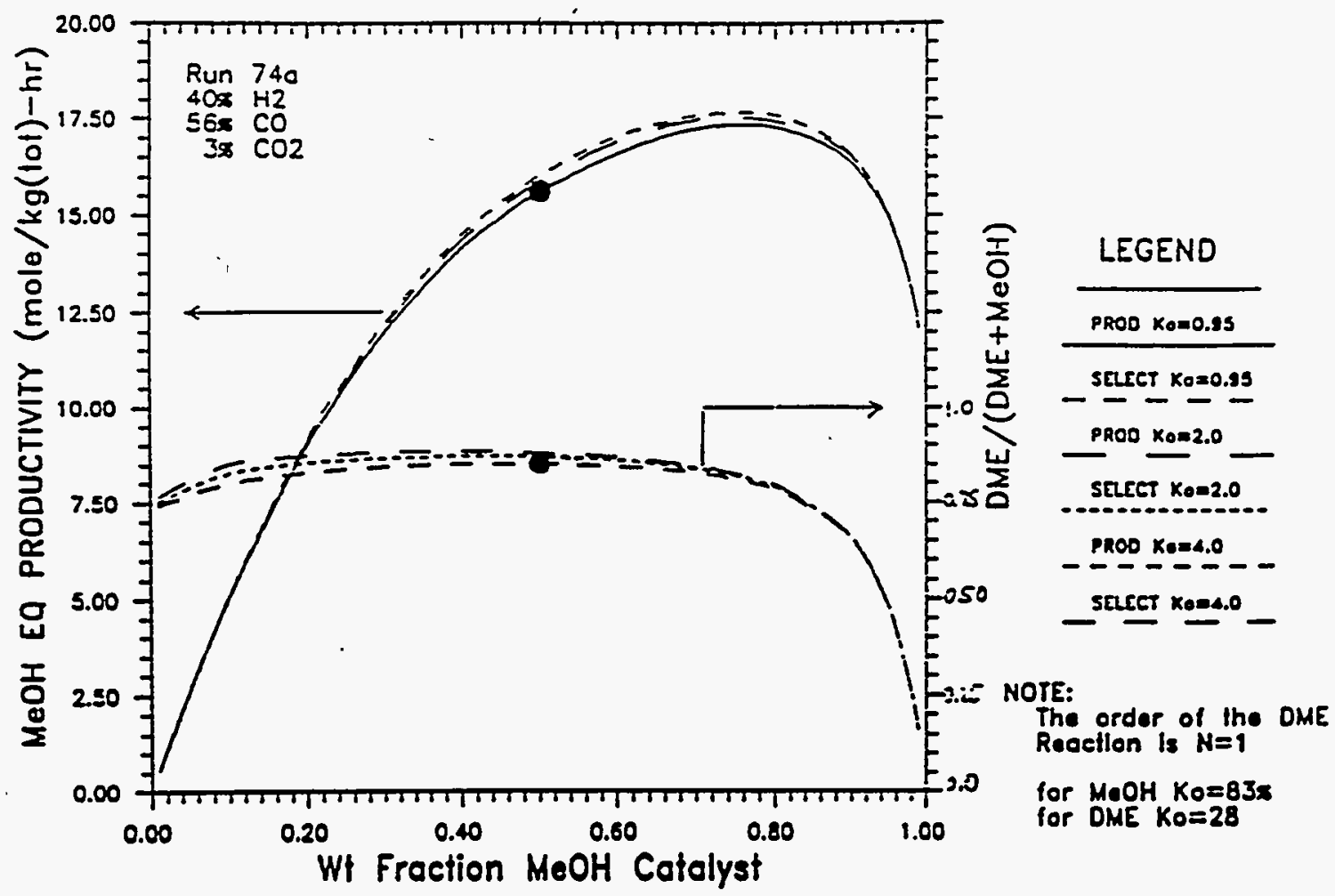

FIGURE 6B

DME/MeOH Catalyst Performance - $250 \mathrm{C}, 52.0 \mathrm{~atm}$ (Voriation with Shift Rate Constont)

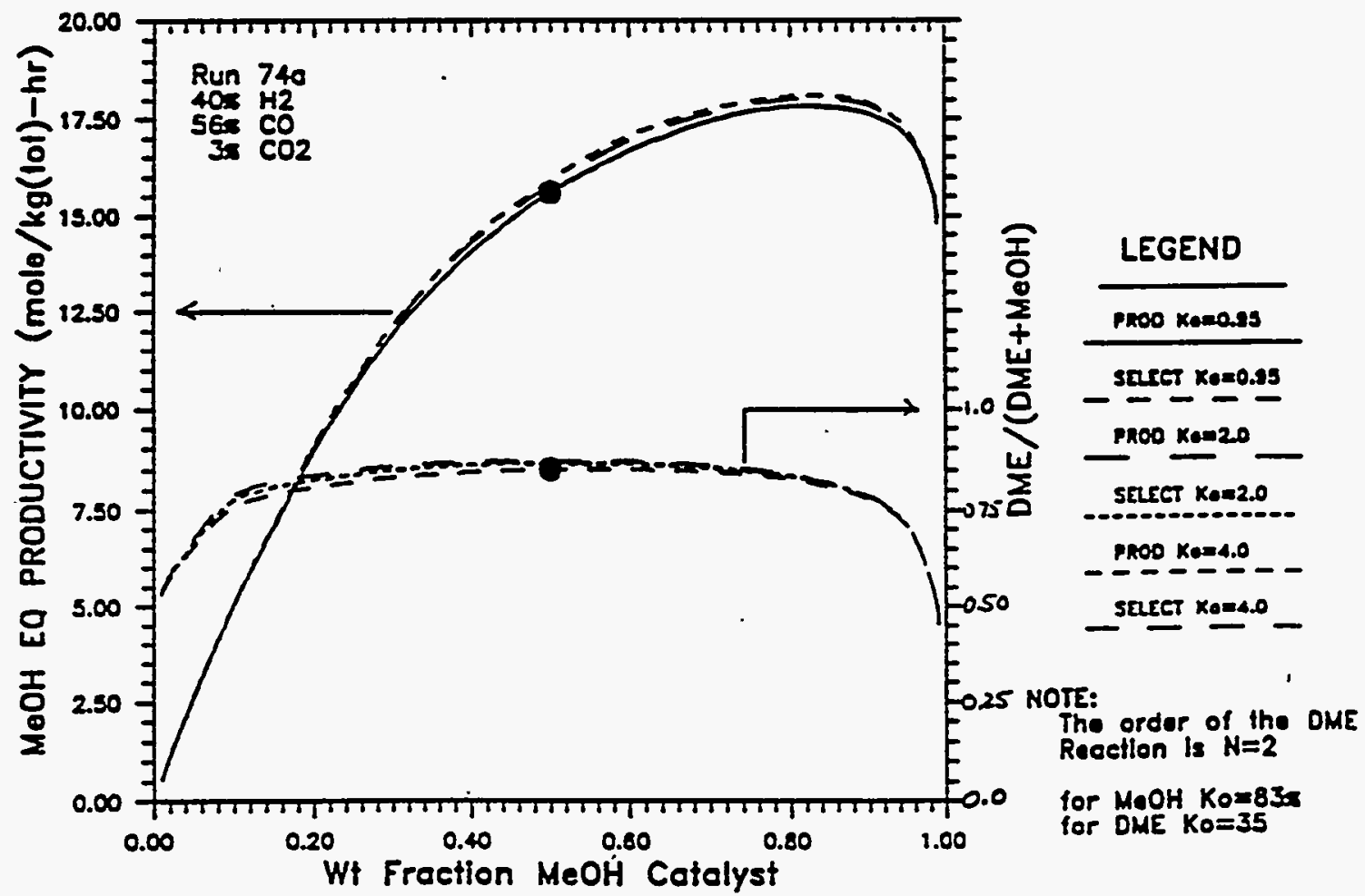


DME $/ \mathrm{MeOH}$ Catalyst Performance - $250 \mathrm{C}, 52.0 \mathrm{~atm}$

(Voriation with Spoce Velocity)

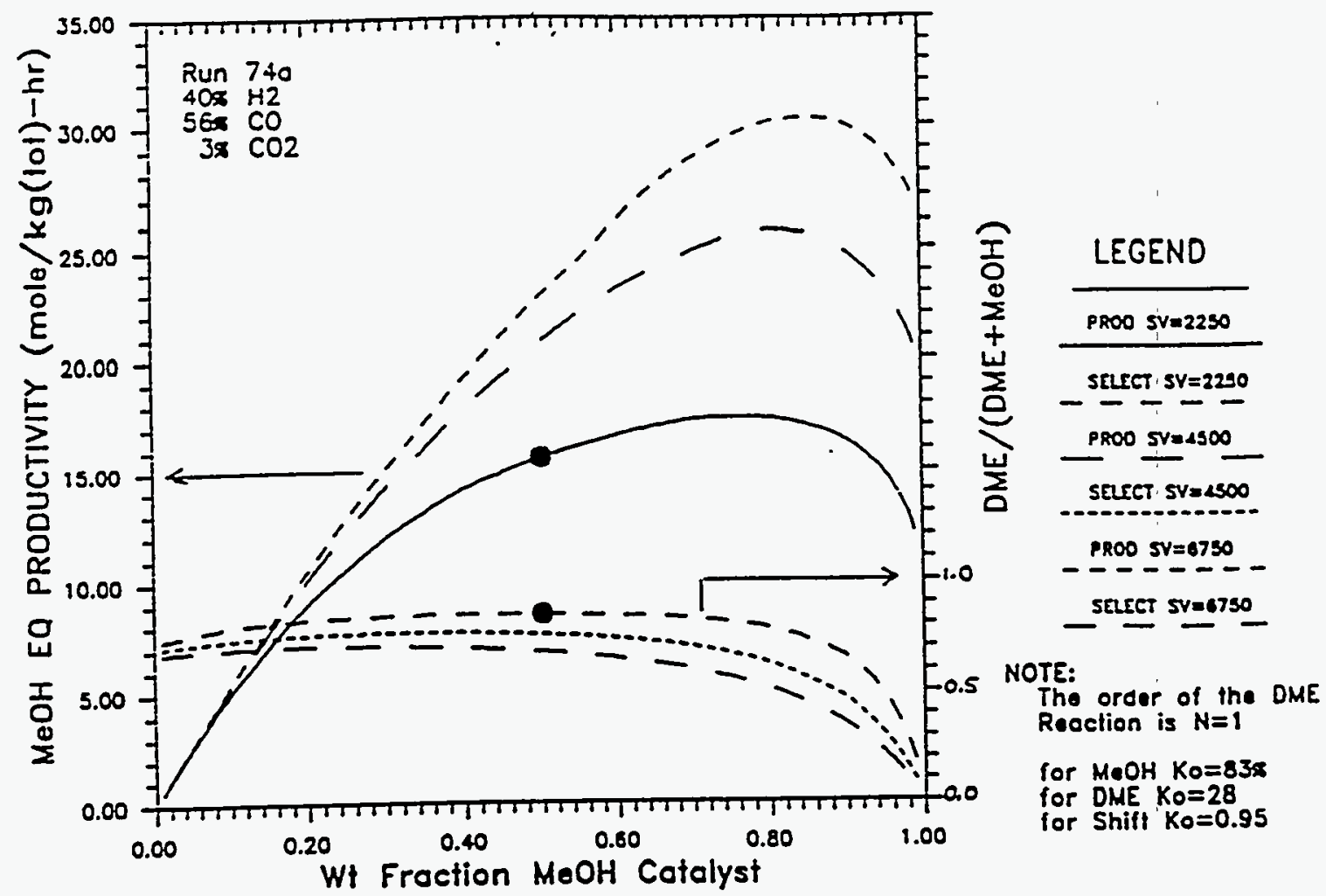

FIGURE 7B

DME/MeOH Catalyst Performance - $250 \mathrm{C}, 52.0$ atm

(Voriation with Space Velocity)

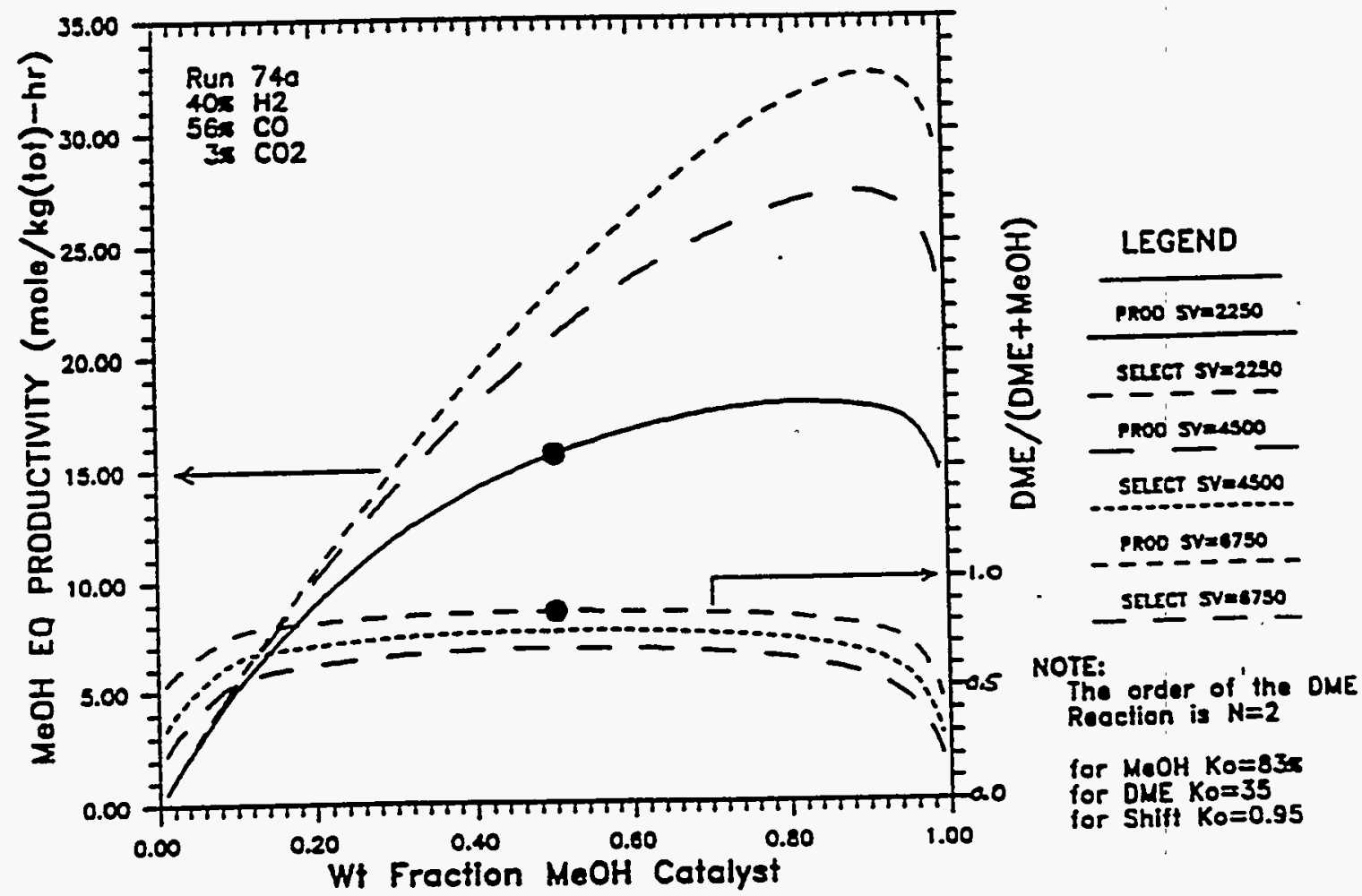


ATTACHMENT B

Economics of DME/MeOH Coproduction 


\section{ECONOMICS OF DME/MEOH COPRODUCTION}

\section{INTRODUCTION}

The results of economic evaluations into the synthesis of DME and DME/MeOH mixtures from coal-derived syngas are presented. Several production scenarios were considered. These options were selected to investigate the merit of the three major reasons for producing DME:

- DME can be produced in small quantities with MeOH to increase the vapor pressure of the mixed fuel. This application is appropriate for improving the cold-start limitations sometimes associated with neat methanol as a motor fuel.

- DME/MeOH mixtures can be synthesized together to minimize the cost of producing a peak-shaving fuel in CGCC applications. The coproduction of the mixture can be accomplished with greater reactor productivity (expressed as BTU of fuel per unit of reactor volume) than $\mathrm{MeOH}$ alone. As a result, the plant size may be reduced for the same quantity of fuel produced.

- DME may be produced for use as a chemical feedstock in a single step. The current, two-step approach is to produce (or purchase) $\mathrm{MeOH}$, then dehydrate it to form DME. By utilizing the single-step syngas-to-DME process, feedstock cost may be minimized.

To summarize the results:

- "Cold-start" methanol may be produced at essentially the same cost ás methanol alone.

- DME/MeOH peak-shaving fuels may be produced at a slightly lower cost than methanol alone. This cost differential is probably not sufficient to warrant the additional processing complexity associated with collecting and storing this mixed fuel.

- DME can be produced in a single step more cheaply than in the two-step process.

\section{BASIS OF STUDY}

The basis for this evaluation is that the $\mathrm{MeOH}$ or DME/MeOH plant would be added on to a CGCC facility. A nominal 600 MW CGCC facility using Shell Gasifiers and producing a total flow of approximately 328 MMSCFD of synthesis gas was selected. Up to $50 \%$ of this gas could be processed in the syngas-to-fuel plant. The unconverted syngas would be recombined with the unprocessed gas and directed to a turbine for power production. 
The syngas to the fuels plant was assumed to be available at $260 \mathrm{psig}$ and have a composition of: $30 \% \mathrm{H}_{2}, 61 \% \mathrm{CO}, 2 \% \mathrm{CO}_{2}, 6.8 \% \mathrm{~N}_{2}$, the remainder $\mathrm{H}_{2} \mathrm{O}$ and sulfur impurities. The syngas heating value was 272 BTU/SCF (LHV). Unconverted syngas was to be retumed at 260 psig.

The syngas-to-plant was compressed to 1200 psig, treated to remove sulfur, passed to a liquid-phase slurry reactor, and further processed to recover the fuel products. The unconverted syngas was subsequently expanded to $260 \mathrm{psig}$ to recover power then sent to the main power turbine.

Steam was produced in the slurry reactor at 230 psig. A portion of this steam was utilized for product recovery and fuel vaporization while the bulk was exported to the CGCC for credit. Cooling water was available at $80^{\circ} \mathrm{F}$ and returned at $100^{\circ} \mathrm{F}$.

\section{CASE STUDIES}

The results from seven case studies are presented in this report. The important features are summarized below and in Tables $1 \mathrm{~A}$ and $1 \mathrm{~B}$.

\section{Methanol Only:}

Case 1 - This is the base case; the product is methanol which is suitable as either a motor fuel or a turbine fuel. The economic desirability of the other cases are to be measured against this case. The flowsheet for this case is a typical LPMEOH scheme with 1:1 recycle of unconverted syngas. The methanol product is stabilized to remove some $\mathrm{CO}_{2}$ from the $\mathrm{MeOH}$ to maintain a vapor pressure of 7.2 psia at $100^{\circ} \mathrm{F}$.

\section{Methanol with DME for "Cold-Start":}

Case 2 - A small amount of alumina is added to the reactor slumy resulting in the production of some DME. The recycle ratio is 1:1 as in Case 1. Additional processing steps are added to recover DME and a distillation column is required to reject $\mathrm{CO}_{2}$ and keep the DME in the MeOH product. The resulting product contains 1.8 wt\% DME and has a vapor pressure of 9 psia at $100^{\circ} \mathrm{F}$. The vapor pressure of the product can be easily adjusted by making slightty more or less DME.

\section{DMEMeOH Mixtures for Peak-Shaving Fuel:}

Case 3 - This case is aimed at coproducing a larger quantity of DME. To take advantage of the inherently higher reactor productivity, no recycle is used. This has the effect of reducing the size of the process equipment associated with the reactor train as well as eliminating the recycle compressor. The equipment used to recover DME is not significantly more complex than that used in Case 2. The 
resulting product contains $61 \mathrm{wt} \%$ DME and has a vapor pressure of 109 psia at $100^{\circ} \mathrm{F}$.

Case 4 - This case is also aimed at coproducing a larger quantity of DME. In contrast with Case 3 , unconverted syngas is recycled at a rate of $1: 1$. The use of recycle plus the higher reactor productivity allows the syngas feed flow to be significantly reduced relative to Case 1 . This has the effect of reducing the size of the frontend compression and sulfur cleanup. However, the equipment used to recover DME is fairly complex relative to Case 3 . The resulting product contains $58 \mathrm{wt} \%$ DME and has a vapor pressure of 112 psia at $100^{\circ} \mathrm{F}$. (The increase in vapor pressure relative to case 3 is due to the higher $\mathrm{CO}_{2}$ content.)

\section{DME for Chemical Feedstock:}

Case 5 - This case is developed to examine the production of DME-only in the simplest and most cost effective manner. The mode of operation is once-through (no syngas recycle) and the coproduced $\mathrm{MeOH}$ is recovered and recycled to the slumy reactor. There is no attempt to recover DME from the syngas; rather the DME produced exits the plant as a vapor together with the unconverted $\mathrm{H}_{2}$ and $\mathrm{CO}$. This mode of operation has applicability when the downstream process uses both $\mathrm{CO}$ and DME as chemical feedstock and can tolerate $\mathrm{CO}_{2}$.

Case 6 - In this case, DME is separated from the unconverted syngas and is recovered as a vapor along with $\mathrm{CO}_{2}$. As in Case 5 , the mode of operation is once-through and the coproduced MeOH is recovered and recycled to the slurry reactor. The DME recovery scheme is fairly simple, along the lines of Case 3. This mode of operation has applicability when the downstream process requires DME as chemical feedstock and can tolerate $\mathrm{CO}_{2}$.

Case 7 - The final case collects DME as a concentrated liquid (98 wt\%). As in Case 5, the mode of operation is once-through and the coproduced $\mathrm{MeOH}$ is recovered and recycled to the slumy reactor. The DME recovery scheme is more complex than that used in Case 6. This mode of operation has applicability when the downstream process requires only DME and/or DME must be temporarily stored (product vapor pressure is 133 psia at $100^{\circ} \mathrm{F}$ ).

Table 1A highlights the various options and ranks them according to relative capital cost and relative product cost. Note that all the comparisons are "relative to case 1 . Table 1B presents pertinent plant and performance data in more detail.

\section{PROCESS DESCRIPTIONS}

The process descriptions for each of the cases share many similarities. A detailed description will be presented for Case 1 (MeOH only); differences from Case 1 will be highlighted for the other cases. 


\subsection{Case 1:}

Figure 1.1 depicts an overall block diagram for the Fuels Plant. A portion of syngas from the gasifier is diverted from the saturator/superieater and directed to feed compression and sulfur removal. Power is consumed in this unit operation to drive the feed compressor and operate the closed loop propane refrigeration unit (refrigeration is used to aid sulfur removal). The cleaned syngas is combined with recycle gas and passed into the Liquid-Phase Synthesis unit operation. Steam is generated from this operation as the reaction is exothermic. Most of the steam is exported to the CGCC plant while a portion is used to operate the distillation column in the Product Recovery unit operation. Within the Product Recovery unit the methanol product is separated from the unreacted syngas; the methanol is subsequently stabilized in a fractionator to remove $\mathrm{CO}_{2}$. The stabilized methanol is then directed to storage. The syngas from Product Recovery unit is split into two streams; one is recycled to the front end, the remainder is expanded (to recover power) and combined with the syngas from the saturator. Since this plant is producing peak-shaving fuel, the liquid product is periodically pumped, vaporized with steam, and combined with the main gas flow to the turbine.

Figure 2 illustrates the feed/recycle compression and storage/vaporization area in greater detail. Syngas-to-plant is compressed in two stages from 260 psig to 1200 psig (in the 01.10A\&B). The compressor discharge is subsequently cleaned in the Sulfur/Carbonyl Removal unit operation. The Sulfur Removal unit is shown here as a black box. This unit is fundamentally an absorber/stripper arrangement which uses methanol as the absorbent and propane refrigeration to assist in providing condenser duties. Carbonyl removal is accomplished with packed beds. Recycle syngas from downstream processing is compressed in the 01.20 compressor and combined with the cleaned feed and directed to the Synthesis Section (Figure 3).

Figure 3 shows the Synthesis Section. The cleaned and compressed syngas is preheated in the 21.11 exchanger. Water is pumped to pressure in the 10.64 pump then combined with the hot feed. The mixed stream passes through the 02.20 Sulfur Guard Bed and on to the 27.10 Slurry Reactor. Within the reactor, the syngas is partially converted to methanol; the heat of reaction is used to generated 230 psig steam. Catalyst is continually added and removed during operation to maintain a steady rate of production. The reactor effluent enters the 21.11 exchanger and is cooled to approximately $230^{\circ} \mathrm{F}$. Slurry oil is condensed in the 21.11 and retumed to the reaction via the 10.50 pump. The net reactor effluent exits the 21.11 exchanger and flows to the Liquids Recovery section (Figure 4.1).

Figure 4.1 represent the Liquids Recovery section. The methanol bearing reactor effluent is cooled, fist in the 21.33 Economizer then in the 21.31 Methanol Condenser, and passed into the 22.10 HP Methanol Separator. From the 22.10, methanol is removed as a liquid and unconverted syngas as a vapor. A portion of this vapor is returned to the recycle compressor (Figure 2); the remainder is heated in the 21.33 exchanger then expanded to 260 psig in the 10.10 Purge Gas Expander. The liquid from the 22.10 separator is let-down to 260 psig to degas dissolved vapors (in the 22.12 separator). The degassed vapors are combined with the 10.10 expander discharge and sent to the CGCC turbine header. The liquid from the 22.12 separator is directed to the stabilization section. Within the stabilizer methanol is boiled in the 07.73 (using steam) and refluxed (in the 07.72) to remove the remnants of dissolved $\mathrm{CO}_{2}$ (which is sent to the incinerator, Figure 7). The stabilized methanol is then pumped and delivered to Storage (Figure 2). Returning to Figure 2, methanol from storage $(28.40$ ) is 
periodically removed and pumped to 260 psig in the 10.40 pump. The liquid is subsequently vaporized in the 21.80 vaporizer and transferred to the turbine header to be used as peak shaving fuel. Altematively, the methanol may be withdrawn from storage and sold as motor fuel.

Figures 5, 6, and 7 illustrate the associated unit operations. Figure 5 is a schematic of the Catalyst Preparation and Slurry Reduction sections. This section is used to activate the catalyst with dilute syngas (nitrogen diluent). Reactor temperature is controlled with circulating utility oil. The reduction off-gas is sent to the incinerator (Figure 7). This unit operates continuously to facilitate the on-line catalyst addition/withdrawal. Figure 6 shows the Catalyst/Oil Separation section. This operation uses a centrifuge to produce a spent catalyst cake; the recovered oil is retumed to the reactor. Figure 7 illustrates the General Utilities section. The equipment associated with propane refrigeration, gas incineration, and the steam system are shown.

Figures 2, 3, 5, 6, and 7 are common to all the Cases considered in this study. Only the Overall Block Diagram (Figures 1.x) and Product Recovery sections (Figures 4.x) differ.' The Overall Block Diagrams are self-evident; the subsequent discussions will focus on product recovery.

\subsection{Case 2:}

This mode of operation is very similar to Case 1 in that plant flows and recycle rate are similar. A small fraction of alumina catalyst $(0.3 \mathrm{wt} \%)$ has been added to synthesize a small fraction of DME.

Figure 4.2 represents the Liquids Recovery section for Case 2. The MeOH/DME bearing reactor effluent is chilled in the 21.31 Methanol Condenser and passed into the $22.10 \mathrm{HP}$ Methanol Separator. From the 22.10, methanol is removed as a liquid and unconverted syngas (plus DME) removed as a vapor. A portion of this vapor is returned to the recycle compressor (Figure 2); the remainder is split and cooled to $-65^{\circ} \mathrm{F}$, in the 21.32 Cross Exchanger and 21.33 Economizer, then recombined and passed into the 22.11 HP Liquids Separator. From the 22.11, additional methanol and much of the DME is recovered as a liquid; the light syngas is rejected as vapor. This vapor is then warmed in the 21.32 exchanger, expanded to 270 psig in the 10.10 Purge Gas Expander, then rewarmed in the 21.33 exchanger. The liquid from the 22.11 separator is let-down to $270 \mathrm{psig}$ and warmed in the 07.72 exchanger then combined with the liquid from the 22.10 separator and introduced to the 22.12 MP separator to degas dissolved vapors. The liquid from the 22.12 is fractionated at 260 psig to remove dissolved $\mathrm{CO}_{2}$. The 07.72 Condenser duty is supplied by vaporizing column feed liquid; reboil is provided with steam. The liquid bottoms product is chilled in the 21.71 Product Cooler then sent to Storage (Figure 2). The vapor overheads are combined with the degassed vapors from the 22.12 separator and with the 10.10 expander discharge and sent to the CGCC turbine header.

As in Case 1, the liquid may be subsequently vaporized in the 21.80 vaporizer (Figure 2) and transferred to the turbine header to be used as peak shaving fuel. Alternatively, this DMEcontaining methanol may be withdrawn from storage and sold as motor fuel. 


\subsection{Case 3:}

The mode of operation is dissimilar to Case 2 in several ways. First, the reactor now contains $7.4 \mathrm{wt} \%$ alumina and consequently produces a significant amount of DME in addition to $\mathrm{MeOH}$. Second, no syngas recycle is utilized. Finally, the Liquid Recovery section is more complex and the product liquid is stored at elevated pressure.

Figure 4.3 represents the Liquids Recovery section for Case 3. The MeOH/DME bearing reactor effluent is chilled in the 21.31 Methanol Condenser and passed into the $22.10 \mathrm{HP}$ Methanol Separator. From the 22.10, MeOH and DME are recovered as liquid and unconverted syngas (plus DME) removed as vapor. This vapor is split and cooled, in the 21.32 Cross Exchanger and 21.33 Economizer, then recombined and passed into the 22.11 HP Liquids Separator. From the 22.11, additional MeOH and DME are recovered as a liquid and light syngas (plus DME) is rejected as vapor. The vapor is then expanded to 270 psig in the 10.10 Gas Expander, then introduced to the bottom of the 07.65 Absorber Column. The 07.65 column is refluxed with methanol. This allows the DME (and some $\mathrm{CO}_{2}$ ) to be absorbed and recovered as bottoms. The vapor overhead from the 07.65 is warmed in the 21.32 exchanger. The liquid from the 07.65 is warmed in the 21.33 and 21.73 exchangers then combined with the liquids from the 22.10 and 22.11 separators to form the feed to the 07.71 Fractionation Column. Within the 07.71 column, $\mathrm{CO}_{2}$ is rejected as vapor, the mixed $\mathrm{DME} / \mathrm{MeOH}$ product is withdrawn as a side-stream, and purified methanol is withdrawn as bottoms. The condenser duty is provided in the 07.72 exchanger by vaporizing propane; the reboiler duty is provided in the 07.73 exchanger with steam. The vapor overhead is combined with the main gas flow from the 21.32 and sent to the CGCC turbine header. The liquid side draw is chilled in the 21.71 Product Cooler then sent to Storage (Figure 2). The liquid bottoms stream is cooled in the 21.72 Recycle Chiller, pumped in the 10.62, further cooled in the 21.73 exchanger, then retumed to the 07.65 column as reflux.

As in Case 1, the liquid may be subsequently vaporized in the 21.80 vaporizer (Figure 2) and transferred to the turbine header to be used as peak shaving fuel. Alternatively, this liquid (containing 62 wt\% DME) may be withdrawn from storage and sold as a crude product.

\subsection{Case 4:}

The mode of operation is similar to Case 3 in that a significant amount of DME is produced in addition to $\mathrm{MeOH}$. However, Case 4 is based on 1:1 recycle and, as a consequence, requires a more complex Liquid Recovery section. Because reactor recycle is used, the DME content in the syngas-exit-reactor is lower in case 4 than in case 3. As a result, the recovery of DME is more difficult and greater levels of methanol-absorbent circulation (and refrigeration) is required. The number of unit operations is also greater as discussed below.

Figure 4.4 depicts the Liquids Recovery section for Case 4. The MeOH/DME bearing reactor effluent is chilled in the 21.31 Methanol Condenser and passed into the 22.10 HP Methanol Separator. From the 22.10, MeOH and DME are recovered as liquid and unconverted syngas (plus DME) removed as vapor. This vapor is split and cooled, in the 21.32 Cross Exchanger and 21.33 Economizer, then recombined and passed into the bottom of the 07.65 Absorber Column. The 07.65 column is refluxed with methanol (additional reflux is provided in the 07.66 
condenser by vaporizing propane). This allows the DME (and some $\mathrm{CO}_{2}$ ) to be absorbed and recovered as bottoms. The vapor overhead from the 07.65 is warmed in the 21.32 exchanger. A portion of the vapor flow is returned to the recycle compressor (Figure 2); the remainder is expanded to 270 psig in the 10.10 Purge Gas Expander.

The liquid from the 07.65 is warmed in the 07.74 and 21.73 exchangers then combined and sent to the 21.12 separator where dissolved, light components are degassed. The liquid from the 22.12 is further warmed in the 21.72 exchanger then directed to the 07.71 Fractionation Column. Within the 07.71 column, $\mathrm{CO}_{2}$, DME, and some $\mathrm{MeOH}$ are rejected as a mixed vapor/liquid overhead product and purified methanol is withdrawn as bottoms. The condenser duty is provided in the 07.72 exchanger with cooling water, the reboiler duty is provided in the 07.73 exchanger with steam. The liquid from the bottom of the 07.71 is cooled in the 07.77 Reboiler and 21.72 Recycle Chiller, pumped in the 10.62, further cooled in the 21.73 exchanger, then retumed to the 07.65 column as reflux.

The vapor overhead product from the 07.71 is chilled in the 07.74 exchanger and fed to a third column, the 07.75. The liquid overhead product from the 07.71 is combined with other liquid streams and fed to the 07.75 as well. Within the 07.75 Fractionator, $\mathrm{CO}_{2}$ is rejected as vapor and the mixed DME/MeOH product is withdrawn as bottoms liquid. The condenser duty is provided in the 07.78 exchanger with vaporizing propane; the reboiler duty is provided in the 07.72 exchanger via cross exchange with the circulating methanol stream.

The vapor overhead product from the 07.74 is combined with the main gas flow from the 10.10 expander, then warmed in the 21.33 exchanger and finally sent to the CGCC turbine header. The liquid product is chilled in the 21.71 Product Cooler then sent to Storage (Figure 2).

As in Case 1, the liquid may be subsequently vaporized in the 21.80 vaporizer (Figure 2) and transferred to the turbine header to be used as peak shaving fuel. Alternatively, this liquid (containing 58 wt\% DME) may be withdrawn from storage and sold as a crude product.

Relative to case 3 , the case 4 recovery section is indeed more complex. Recall that case 3 utilizes a modest degree of methanol absorbent circulation to aid in DME recovery. In contrast, the absorbent circulation rate in case 4 is fairty high. As a result, it is no longer practical (economical) to strip the DME and $\mathrm{CO}_{2}$ from the methanol in a column with a refrigerated condenser (as is used in case 3). Therefore, an additional distillation column has been added: the main column, 07.71, separates the DME and $\mathrm{CO}_{2}$ from the circulating methanol (using cooling water for the condenser); the second column, 07.75 , rejects $\mathrm{CO}_{2}$ (using propane refrigeration to provide the condenser duty). Another important difference between case 3 and case 4 is that case 4 requires a propane refrigeration-supplied condenser on the 07.65 absorber column (this refrigeration is needed to chill the overhead). Clearly, case 4 utilizes refrigeration to a much more significant degree than case 3 and hence is both more complex and more costly. The benefit of case 4 over case 3 is that the reactor productivity is higher and therefore the flow through the front-end compression and pretreatment is reduced to $2 / 3$ of case 3.

\subsection{Case 5:}

This mode of operation is the simplest of the All-DME plant schemes. No syngas recycle is utilized and the DME product is withdrawn as a vapor along with the unreacted syngas. All 
that needs to be accomplished with the Liquids Recovery section is to recover MeOH so that it may be recycle to the reactor.

Figure 4.5 represents the Liquids Recovery section for Case 5. The MeOH/DME bearing reactor effluent is chilled in the 21.31 Methanol Condenser and 21.33 exchanger then passed into the 22.10 HP Methanol Separator. From the 22.10, methanol is removed as a liquid and unconverted syngas (plus DME) removed as a vapor. This vapor is expanded to 270 psig in the 10.10 Purge Gas Expander, then introduced to the 22.12 separator where the last remnants of methanol drop-out as liquid. The vapor off the 22.12 is rewarmed in the 21.33 exchanger. The liquid from the 22.12 separator is let-down to $270 \mathrm{psig}$, combined with the liquid from the 22.10 separator, then warmed in the 07.72 exchanger before being introduced to the 07.71 column. Within the 07.71 column, $\mathrm{CO}_{2}$ and DME are rejected as a vapor overhead product and purified methanol is withdrawn as bottoms. The condenser duty is provided in the 07.72 exchanger via cross exchange; the reboiler duty is provided in the 07.73 exchanger with steam. The liquid bottoms product is pumped to pressure in the 10.62 then recycled to the reactor as supplemental feed (Figure 3 ). The vapor overheads are combined with the main syngas flow from the 21.33 and exit the plant for further processing.

\subsection{Case 6:}

This mode of operation is similar to Case 5 except the DME product is withdrawn as a vapor along with $\mathrm{CO}_{2}$ (separated from the syngas stream).

Figure 4.6 represents the Liquids Recovery section for Case 6. Note that it is very similar to the flowsheet for Case 3. The major exception being that intemal circulation of methanol is not utilized - thereby simplifying the design (and operation). Also note that the vapor overhead from the 07.71 constitutes the mixed $\mathrm{DME} / \mathrm{CO}_{2}$ product. The 07.71 bottoms are returned to the reactor as in Case 5.

\subsection{Case 7:}

This mode of operation is similar to Case 6 except the DME product is withdrawn as a liquid, purified product from a second column.

Figure 4.7 represents the Liquids Recovery section for Case 7. Note the similarity to the flowsheet for Case 6. However, note that the vapor overhead from the 07.71 constitutes a $\mathrm{CO}_{2}$ purge to the gas turbine: the 07.71 bottoms contain MeOH and DME. This bottoms stream is passed to the 07.75 column to affect a DME-MeOH separation. The DME is withdrawn from the top of the 07.75 column, condensed in the 07.74 exchanger and sent to storage. The 07.75 bottoms contain the $\mathrm{MeOH}$ and as such are retumed to the reactor as in Case 6.

\section{PROCESS SPECIFICATIONS}

The process data required to carry-out the economic evaluation were developed and are , attached: 
- Overall material balances are included in Table 2.

- An equipment list is attached as Table 3.

- Budgetary-quality equipment specifications are contained in Table 4.

- The utility summary is presented in Table 5.

The information contained in the above tables were utilized to estimate the cost of producing fuels from each of the seven operating options. The methodology used and estimation of cost is presented next.

\section{COST ESTIMATES}

\subsection{Production Cost Estimate Basis}

The capital costs are based on instantaneous 1992 Construction at a Gulf Coast location. These costs represent a battery limits erected facility added on to a large CGCC power plant.

The direct capital costs were broken-down by unit as follows:

- Feed Compression and Gas Pretreatment

Feed Compressor including Driver and Coolers

Bulk Acid Gas Removal, Absorber, Stripper, Pumps, Heat Exchangers Refrigeration Unit

- Basic Synthesis Section

Recycle Compressor

Purge Gas Expander

Carbonyl and Sulfur Guard Beds

Reactor

Product Condenser and HP Separator

Stabilizer

Process Pumps

- Extra Synthesis Equipment

Equipment added to recover/separate DME

- Slurry Reduction

Heated Reduction Vessel

Catalyst Feed Equipment

- Spent Catalyst Recovery

Slurry Centrifuge

Oil Storage

- Storage Loading and Vaporization 
- General Utilities

Steam Drum

Slurry Tank

Flare Knockout Drum

The production costs were computed using the following factors:

Syngas
Steam Credit
Electric Power
Cooling Water
Make-up Oil
Catalyst
Catalyst/Oil Disposal
Adsorbents
Adsorbent Disposal
Operating Labor
Plant Overhead
Maintenance
Taxes and Insurance

$\$ 4.00$ per MM BTU, HHV

$\$ 3.15$ per $\mathrm{M}$ lb

$\$ 0.05$ per $\mathrm{kW}$-hr

$\$ 0.10$ per $M$ gal

$\$ 2.87$ per gal

$\$ 10.09$ per lb

$\$ 1.00$ per lb

$\$ 0.98$ per lb carbon, \$2.56 per lb ZnO

$\$ 1.00$ per lb

10 persons \$ \$50,000/yr

2 times Operating Labor

$2 \%$ of Capital Investment

$2 \%$ of Capital Investment

A Capital Charge Rate of $14 \%$ of investment was used which includes a ROI as well as depreciation and interest charges. This is typical for 'Utility Economics'.

\subsection{Production Cost Comparison}

Table 6 summarizes the unit cost of production for Cases 1-7. The Capital Cost break-down by section is contained in the upper portion of Table 6; the Unit Costs are presented in the lower portion. Conclusions drawn from these results are discussed below:

- DME Coproduction for Use as a Turbine Fuel for Power Plant Peaking:

The relevant options to consider for peak shaving are Cases 1-4. For these cases the Capital investment lies between $\$ 63.7 \mathrm{MM}$ (Case 3) and \$70.8 MM (Case 4). The appropriate unit costs range from \$8.76/MM BTU, LHV (Case 3) to \$9.10/MM BTU, LHV (Case 4).

The superiority of Case 3 (DME, no syngas recycle) over Case 4 (DME, 1:1 syngas recycle) demonstrates that the preferred method of coproducing DME is without the use of recycle. This can be explained as being a consequence of the relative difficulty in condensing the volatile DME from the syngas vapor.

Nevertheless, DME coproduction can reduce product cost as demonstrated by the favorable economics of Case 3 over either Case 1 or 2 . Specifically, the conclusion is that one could produce and store a high pressure DME (61 wt\%)/MeOH mixture at 25\%/MM BTU cheaper than it would be to store neat methanol. This represents a 2.8\% 
reduction in fuel cost. It could also be represented as an increase in gross ROl from $14 \%$ to $16.4 \%$.

As it tumed out, coproduction of DME carries only a very slight savings in capital, the major savings comes from lower utility requirements. Since the Case 3 scheme is more complex than the LPMEOH case, and since it introduced a 100 psi liquid storage requirement, it may be difficult to justify further development of $\mathrm{DME} / \mathrm{MeOH}$ mixtures as a turbine fuel; however, the results do show that the mix can be made at a lower cost than methanol alone. Therefore in cases where mixtures of $\mathrm{DME} / \mathrm{MeOH}$ would have been derived from a separate dehydration of methanol step (e.g. the MTG process), this process should be economically attractive. Furthermore, DME coproduction plants can operate with lower syngas throughputs than LPMEOH plants (for equivalent production). In applications where the desired production rates would force an LPMEOH plant into parallel pretreatment units, DME coproduction plants would clearly be favored.

- DME as a Cold Start Additive to Methanol:

Cases 1 and 2 can be modified slightly to produce the new cases $1 \mathrm{~A}$ and $2 \mathrm{~A}$ for the transportation fuel application. To accomplish this, the storage pump and vaporizer are removed and the utilities adjusted to eliminate the steam required to vaporize the product. This reduces the cost of each case by about 28 cents/MM BTU, LHV.

A comparison of Case $2 \mathrm{~A}$ and Case $1 \mathrm{~A}$ indicates that at a $14 \% \mathrm{RO}$, the DME mix yields a lower required selling price (\$8.65/MM BTU) than that of the neat methanol value of (\$8.73/ MM BTU). In addition the DME will have a value as an additive. One might use MTBE as a guide to determine an additive value.

If MTBE sells at $1.00 \$ / g a l$ when unleaded gasoline sells for $0.62 \$ / g a l$, this would represent a premium of about $90 \%$ over it's fuel value ( ie.MTBE's value as an additive is approximately 1.9 times its value as a fuel.).

If the DME in the product were valued at 1.9 times fuel value, the mix would be valued at approximately $1.4 \%$ higher than fuel value. If one uses $\$ 8.73 / \mathrm{MM}$ BTU for the basis, then the mix would have a value of $1.014 \times \$ 8.73 / \mathrm{MM}$ BTU $=\$ 8.85 / \mathrm{MM}$ BTU. The difference between 8.85 and 8.65 represents a 20 $/$ MM BTU advantage for the mix; this would result in an increase in the ROI from $14 \%$ to $15.9 \%$.

The conclusion is that there would be economic incentive to produce such a mixture. Furthermore, there would be little technical risk in such a process.

\section{- DME Production for Chemical Feedstock:}

Depending on the downstream application, it may be desirable to produce DME in any one of the three forms represented by Cases 5-7. The cost differential between Case 5 and Case 6 reflects the cost of separating DME from the unreacted syngas; the differential between Case 6 and Case 7 reflects the cost of recovering DME as a purified liquid. 
It is also interesting to compare the cost differential between Case 1 and Case 7. Both these cases produce relatively pure liquid products (Case $1-\mathrm{MeOH}$, Case 7 - DME). On a weight basis, the cost of methanol from Case 1 is $\$ 0.083 / \mathrm{lb}$. If this methanol could be dehydrated to DME at zero cost, the cost of that DME would be $\$ 0.115 / \mathrm{lb}$ DME.

An estimate of the cost of methanol dehydration is approximately \$0.017/lb DME (1992 basis). This processing cost was estimated from an SRI study of a similar operation (PEP 111) where methanol was dehydrated to produce ethylene. Combining the methanol dydration cost with the Case $1 \mathrm{MeOH}$ production cost yields a DME-frommethanol cost of $0.115+0.017=\$ 0.132 / \mathrm{b}$ DME. Therefore, the estimated cost to produce DME from Case 7 (only $\$ 0.118 / \mathrm{lb}$ ) represents a significant savings. 
FIGURE 1.1: BLOCK DIAGRAM FOR CASE 1

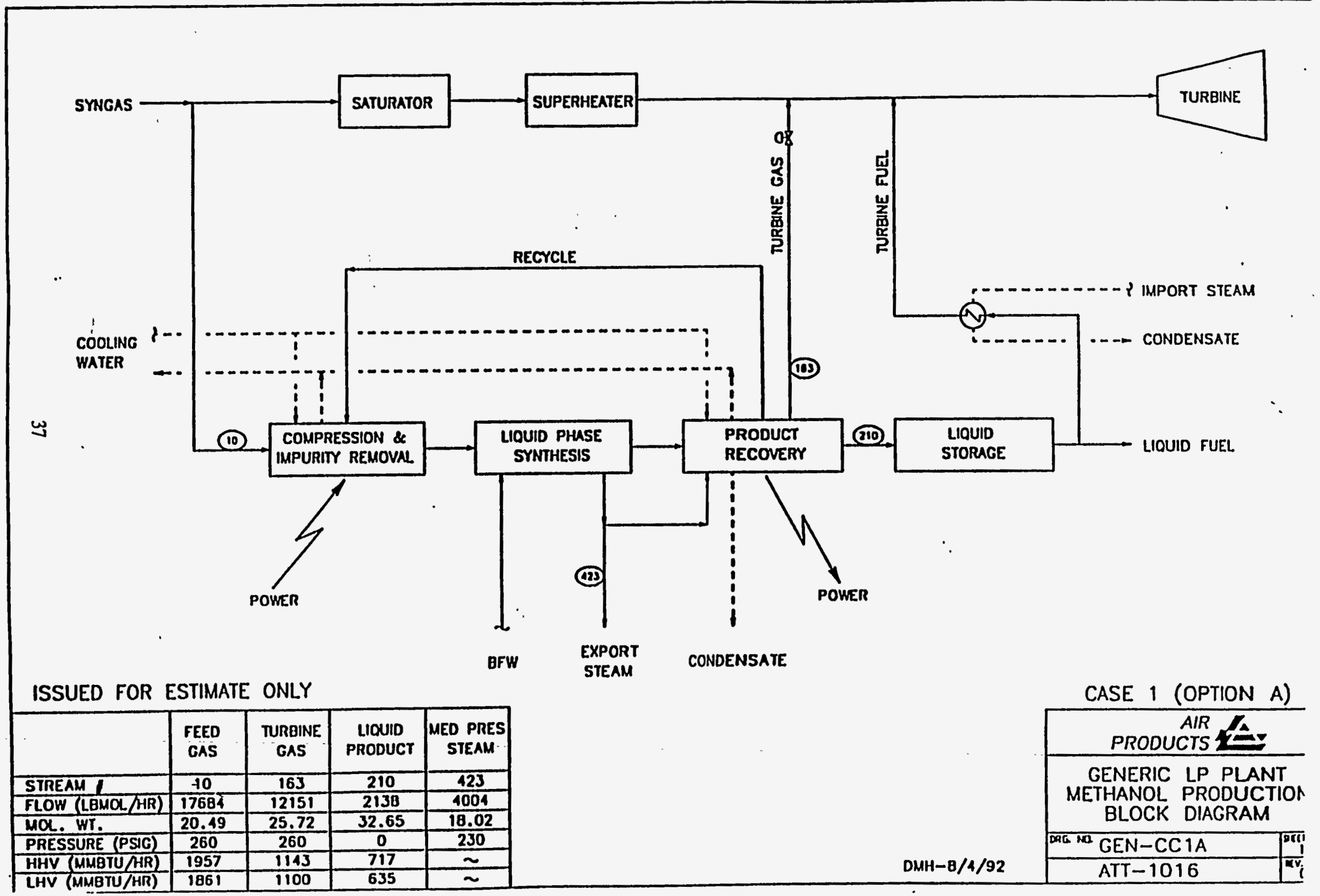




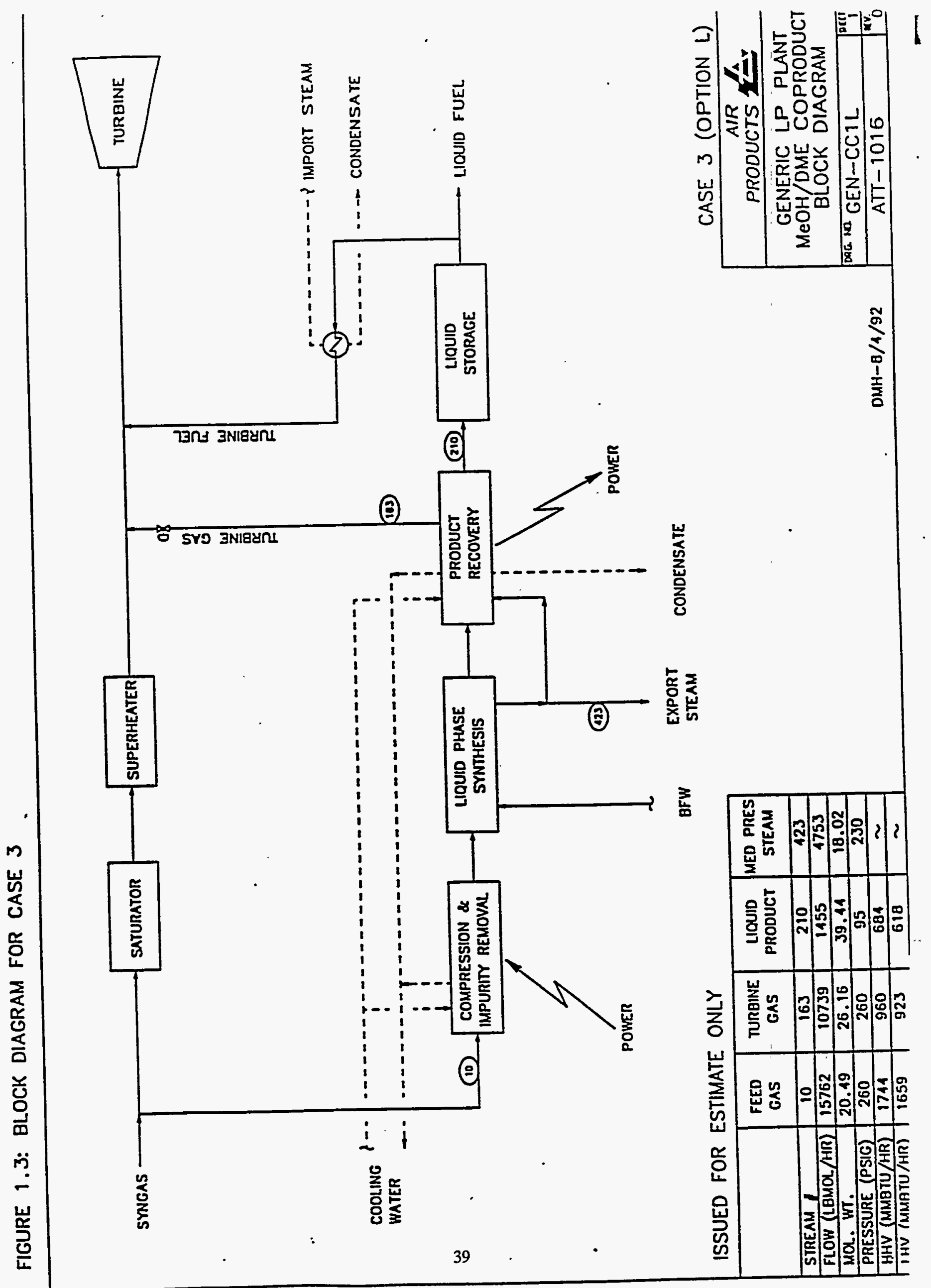




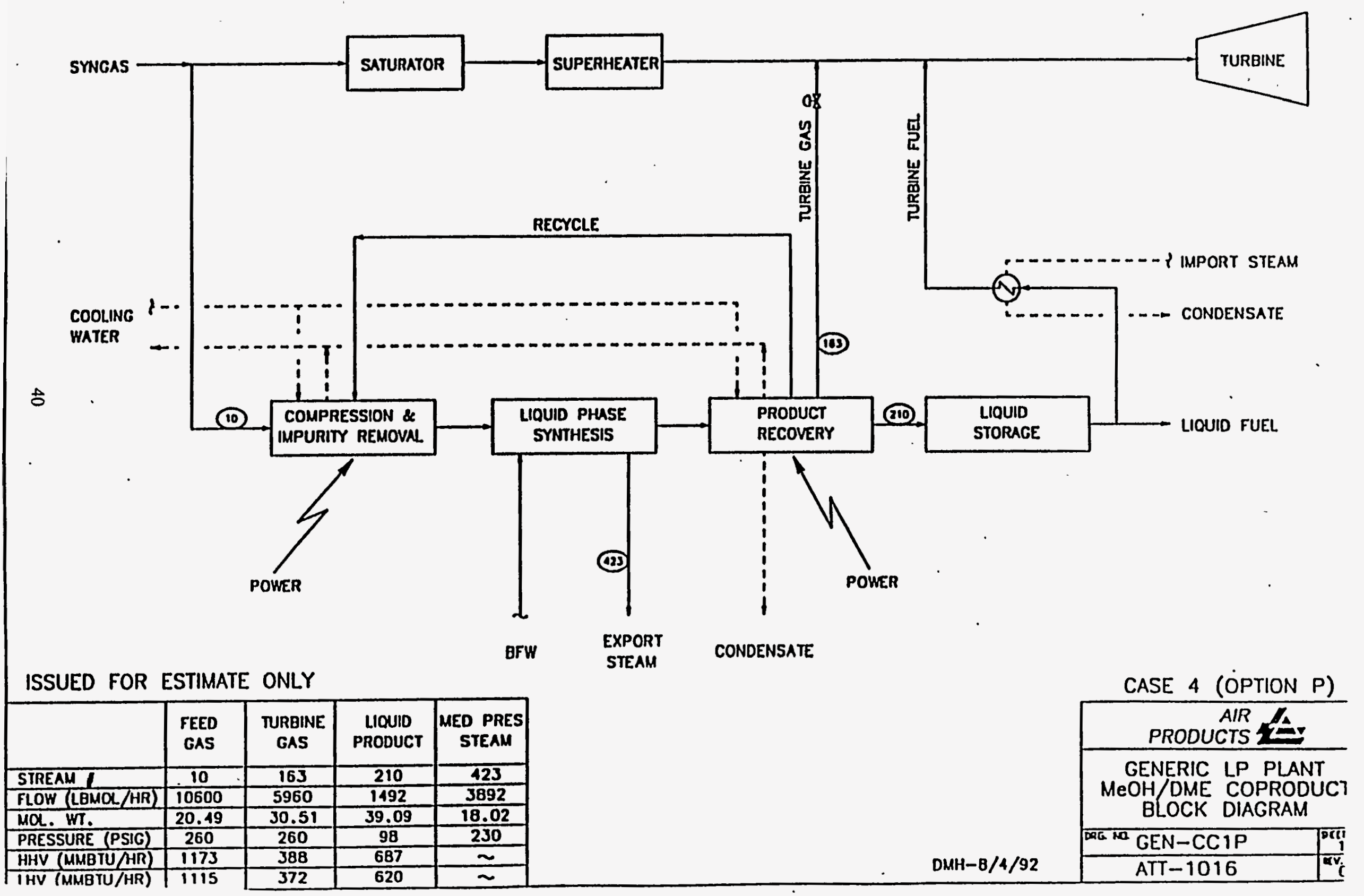


FIGURE 1.5: BLOCK DIAGRAM FOR CASE 5

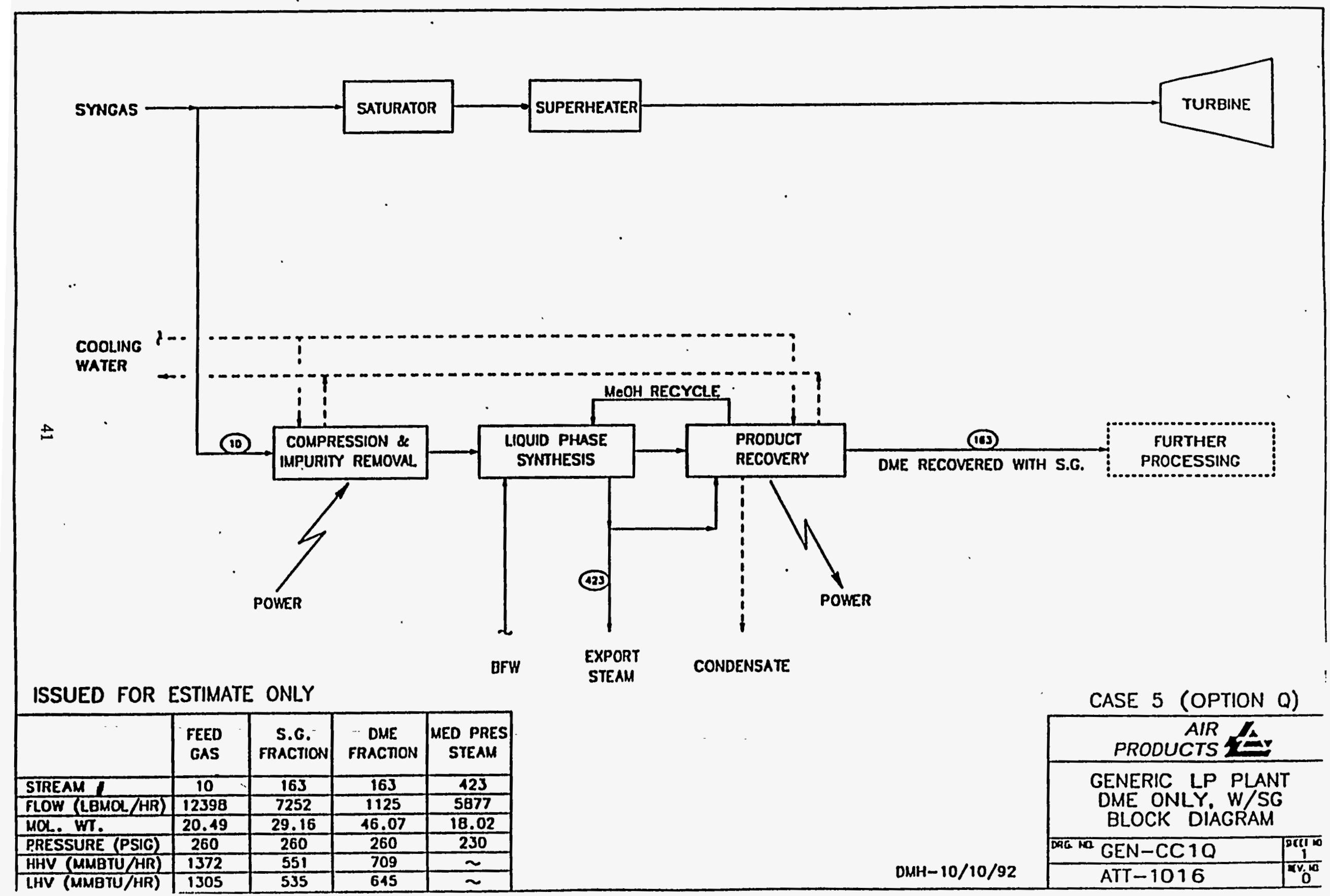


FIGURE 1.7: BLOCK DIAGRAM FOR CASE 7

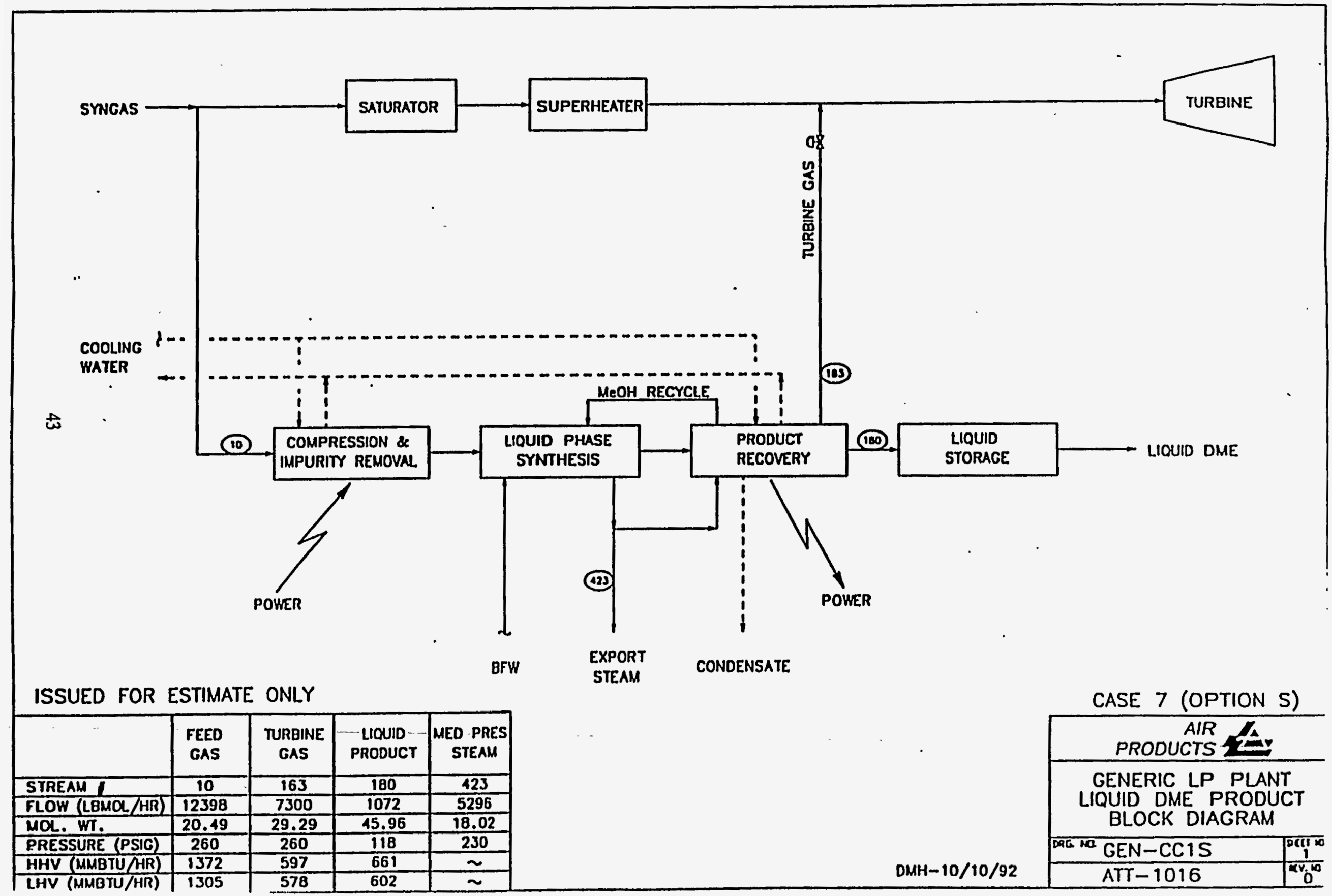




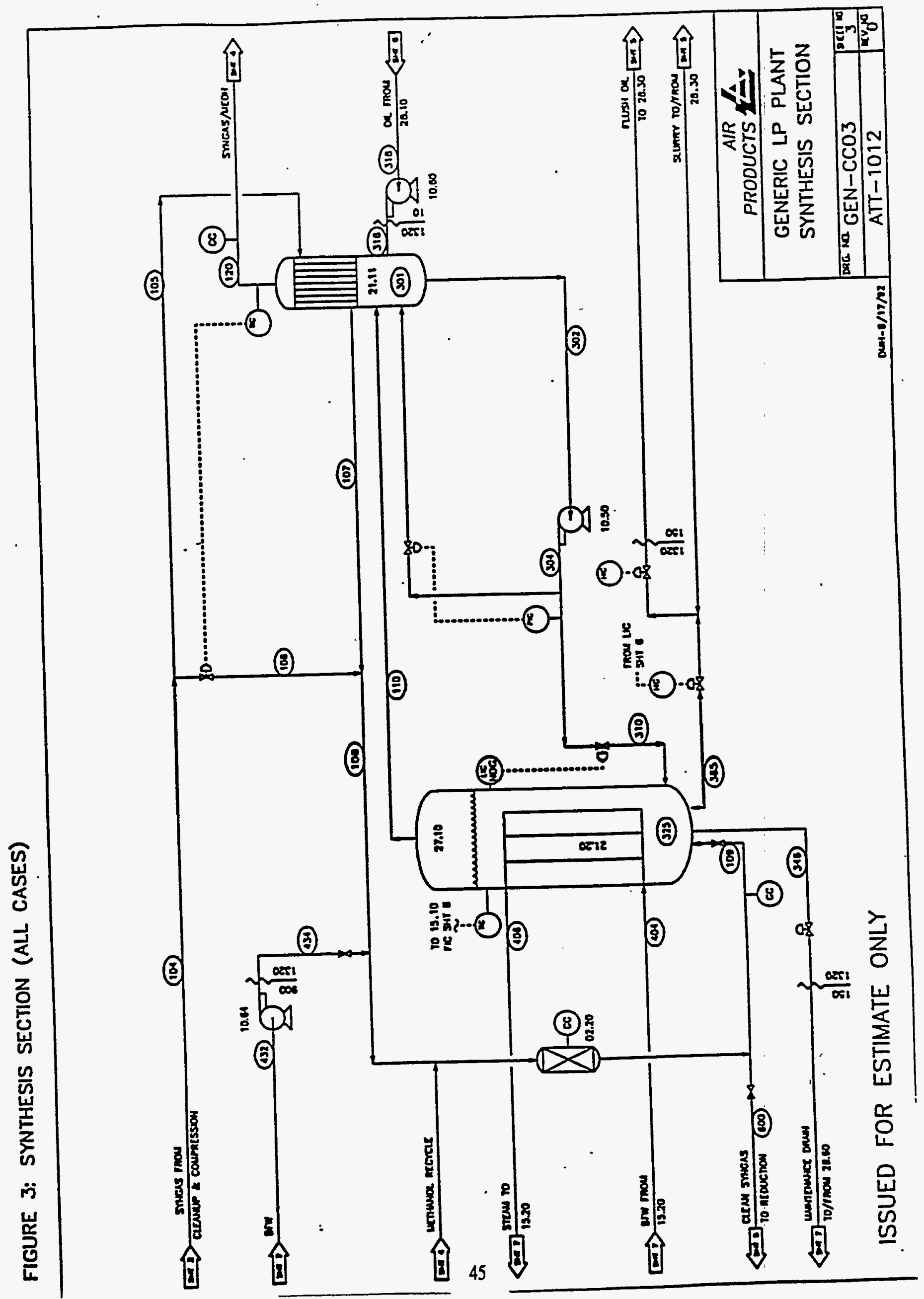




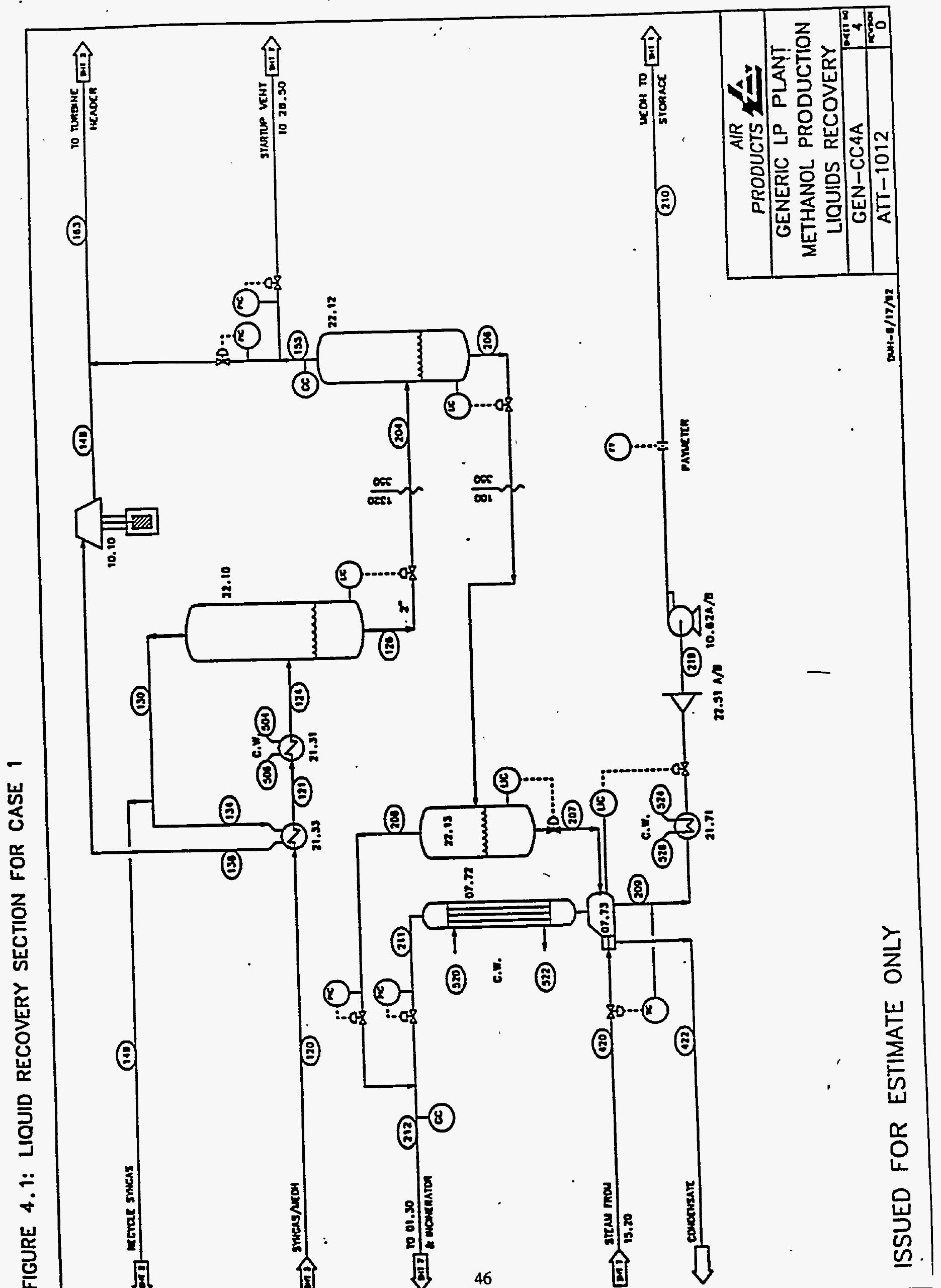




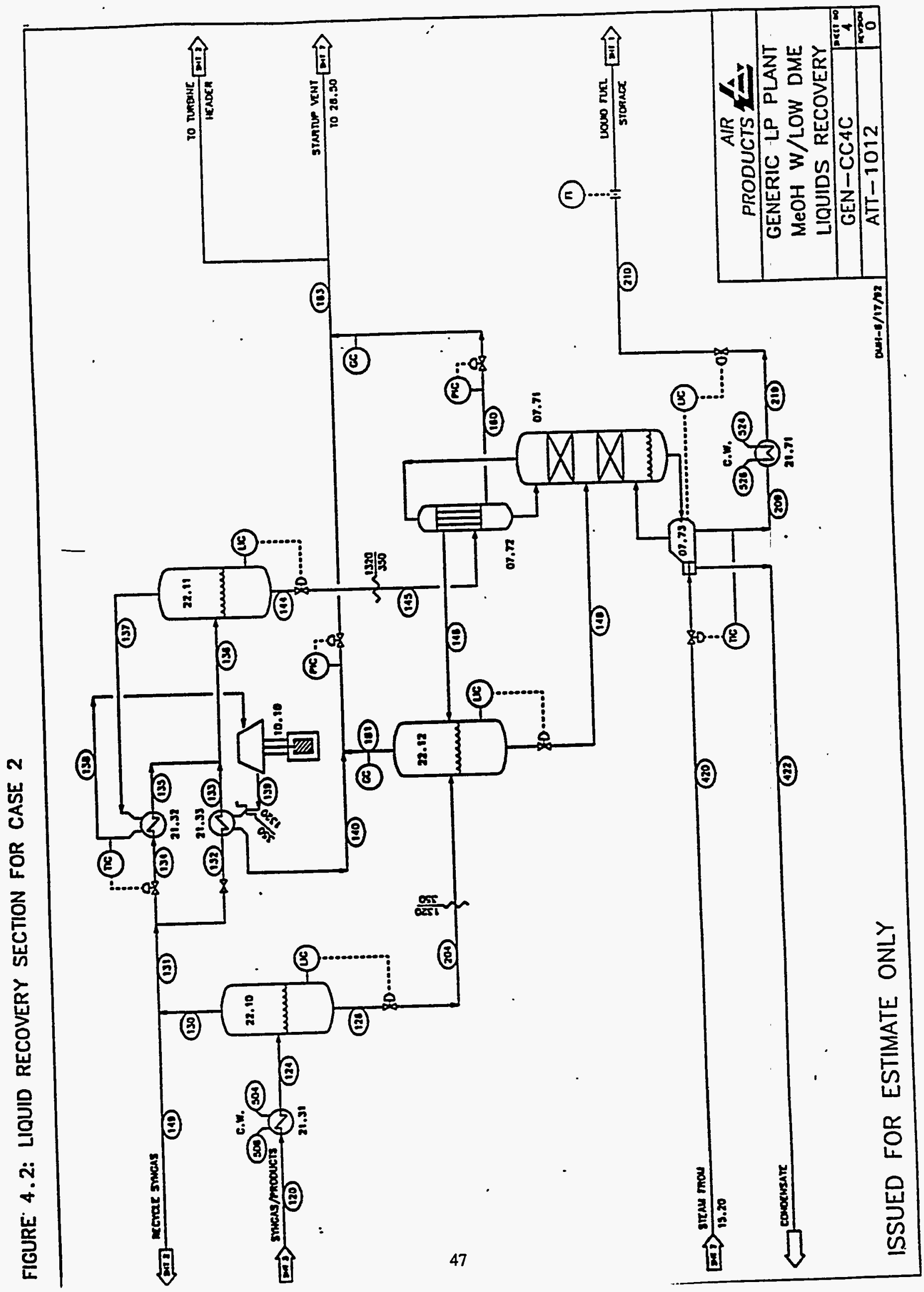




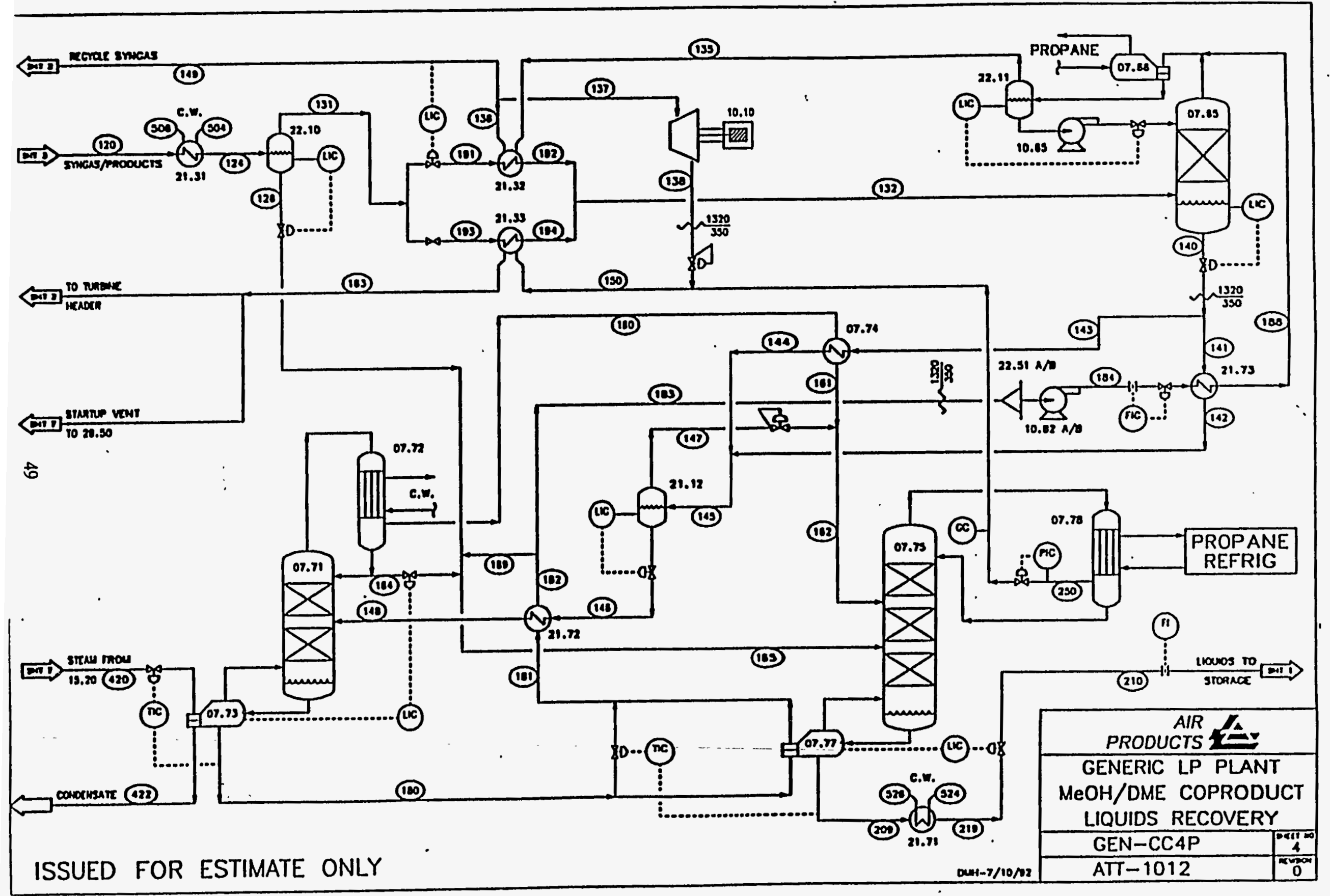




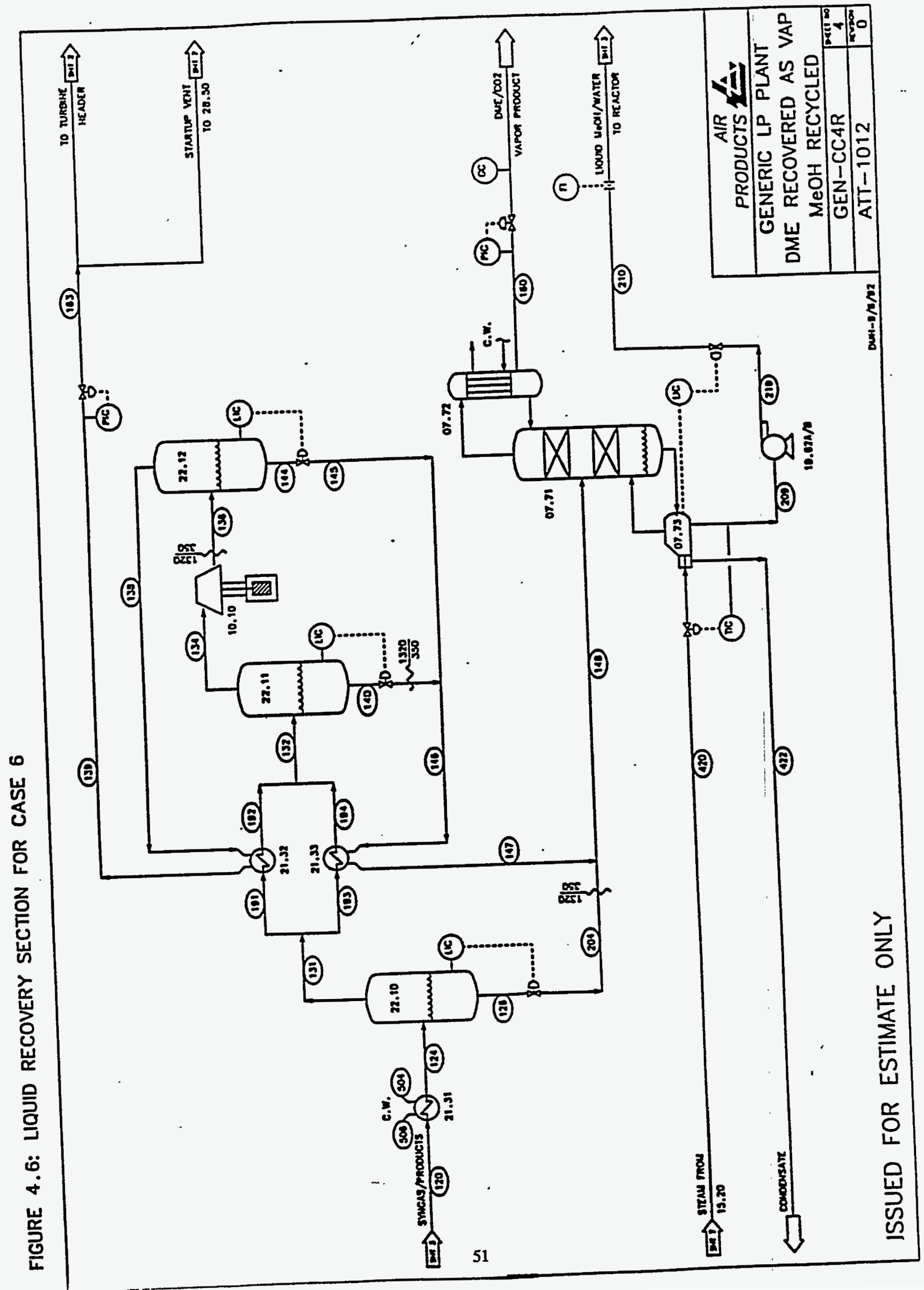









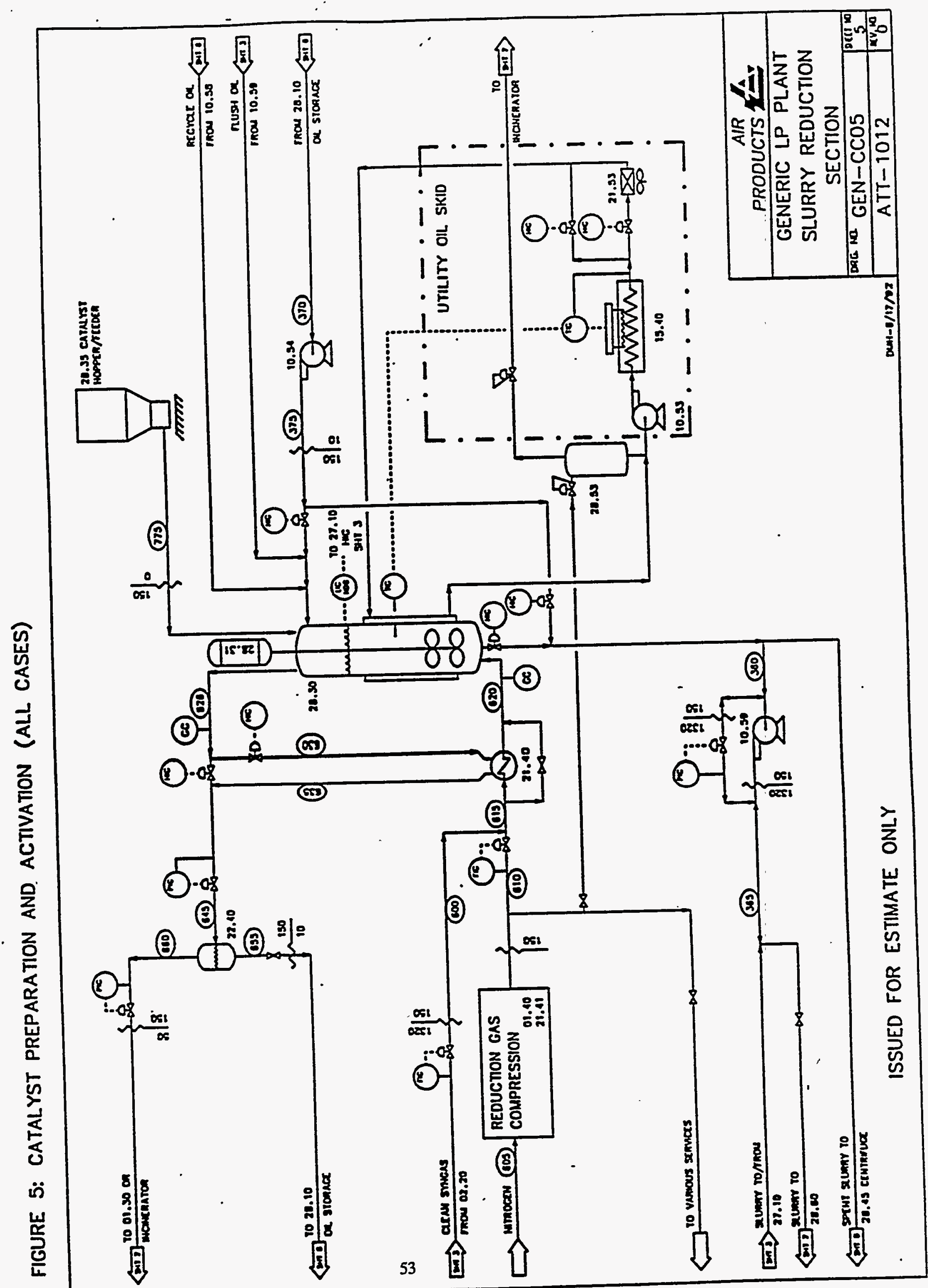




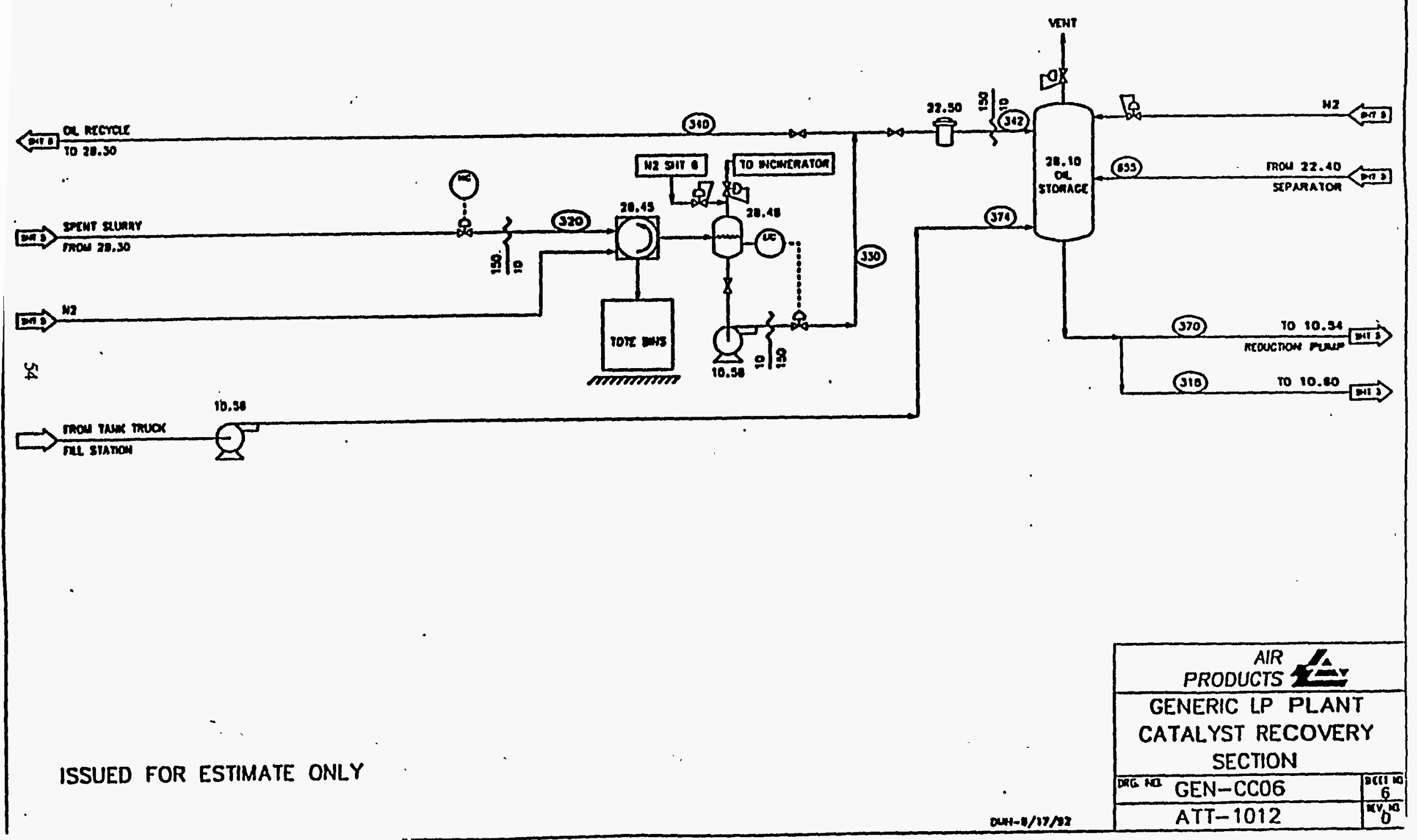




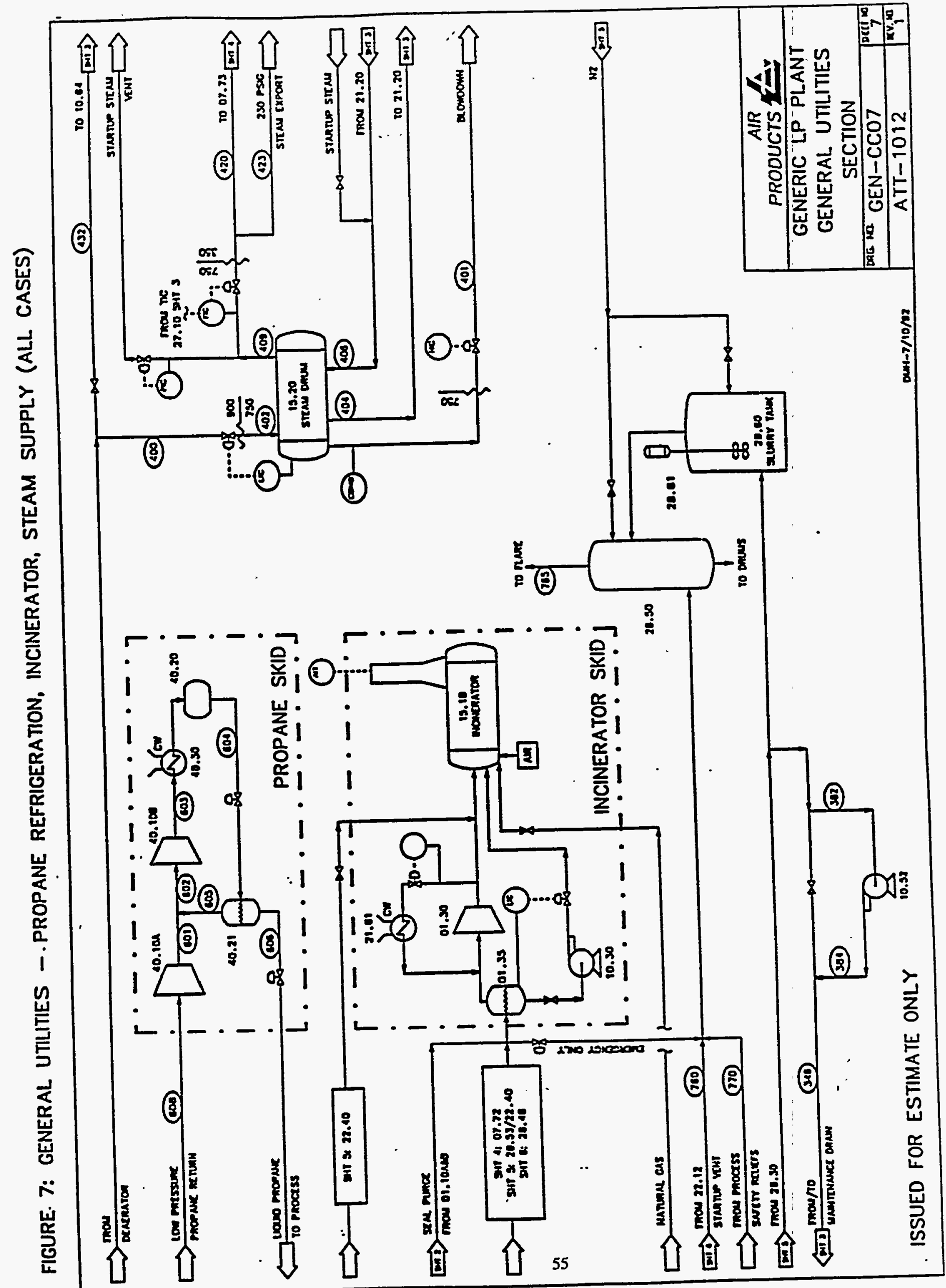


TABLE IA : SUMMARY OF CASE STUDIES

\begin{tabular}{|c|c|c|c|c|c|c|c|c|c|}
\hline Caso & Process Objective & Speclal features & $\begin{array}{l}\text { Reactor } \\
\text { Rocycle } \\
\text { Ratio }\end{array}$ & $\begin{array}{c}\text { Relative } \\
\text { Cleanup \& } \\
\text { Compression } \\
\text { Size }\end{array}$ & $\begin{array}{l}\text { Relative } \\
\text { Reactor } \\
\text { Train Size }\end{array}$ & $\begin{array}{l}\text { Relative } \\
\text { Reactor } \\
\text { Volume }\end{array}$ & $\begin{array}{c}\text { Ranking of } \\
\text { Product } \\
\text { Recovery } \\
\text { Complexity }\end{array}$ & $\begin{array}{l}\text { Relative } \\
\text { Capilal } \\
\text { Cost (\$) }\end{array}$ & $\begin{array}{l}\text { Relative } \\
\text { Unit Cost } \\
\text { (\$/BTU } \\
\text { LHV }\end{array}$ \\
\hline 1 & Produce methanol-only & $\begin{array}{l}\text { Base-case plant with } \\
\text { methanol stabllizer column. }\end{array}$ & $1: 1$ & 1.00 & 1.00 & 1.00 & 1 & 1.00 & 1.00 \\
\hline 2 & $\begin{array}{l}\text { Methanol with a small } \\
\text { amount of DME to } \\
\text { increase vapor } \\
\text { pressure. }\end{array}$ & $\begin{array}{l}\text { Partial condensation process } \\
\text { for DME recovery, CO2 } \\
\text { degasser, gas expander for } \\
\text { refrigeration. }\end{array}$ & $1: 1$ & 1.00 & 1.00 & 1.00 & 4 & 1.04 & 0.99 \\
\hline 3 & $\begin{array}{l}\text { DME \& Methanol } \\
\text { coproduction to } \\
\text { minimize production } \\
\text { cost of turblne fuel }\end{array}$ & $\begin{array}{l}\text { Partlal condensation with } \\
\text { absorber fluid assist (using } \\
\text { methanol). Refrlgeration by } \\
\text { expander with propane }\end{array}$ & 0 & 0.89 & 0.45 & 0.88 & 5 & 0.99 & 0.97 \\
\hline 4 & $\begin{array}{l}\text { DME \& Methanol } \\
\text { coproduction to } \\
\text { minimize production } \\
\text { cost of turblne fuel }\end{array}$ & $\begin{array}{l}\text { Absorber fluld circulation } \\
\text { process. Refrlgeratlon by } \\
\text { expander with propane } \\
\text { assist. }\end{array}$ & $1: 1$ & 0.60 & 0.60 & 1.19 & 7 & 1.10 & 1.01 \\
\hline 5 & $\begin{array}{l}\text { Produce DME-only. } \\
\text { DME product taken as } \\
\text { vapor with unreacted } \\
\text { syngas }\end{array}$ & $\begin{array}{l}\text { Partial condensation for } \\
\text { methanol knock-out. } \\
\text { Methanol recycle to reactor. } \\
\text { Expander refrlgeration. }\end{array}$ & 0 & 0.70 & 0.35 & 1.59 & 2 & 0.83 & 0.93 \\
\hline 6 & $\begin{array}{l}\text { Produce DME-only. } \\
\text { DME product taken as } \\
\text { vapor with CO2 } \\
\text { impurlty. }\end{array}$ & $\begin{array}{l}\text { Partial condensation for DME } \\
\text { recovery. DME/CO2 } \\
\text { recovery column. Expander } \\
\text { refrigeration. Methanol }\end{array}$ & 0 & 0.70 & 0.35 & 1.59 & 3 & 0.87 & 0.99 \\
\hline 7 & $\begin{array}{l}\text { Produce DME-only. } \\
\text { DME product taken as } \\
\text { purifled liquld. }\end{array}$ & $\begin{array}{l}\text { Like case } 6 \text { except staged } \\
\text { distillation columns for DME } \\
\text { recovery and liquefaction. } \\
\text { Methanol recycle to reactor. }\end{array}$ & 0 & 0.70 & 0.35 & 1.59 & 6 & 1.05 & 1.05 \\
\hline
\end{tabular}




\begin{tabular}{|c|c|c|c|c|c|c|c|}
\hline & Case 1 & Case 2 & Case 3 & Case 4 & Case 5 & Case 6 & Cose 7 \\
\hline \multicolumn{8}{|l|}{ Reactor Feed Flows } \\
\hline Plant Feed Flow (SCFD) & 164 & 164 & 146 & 98 & 115 & 115 & 115 \\
\hline Syngas Recycle Rate (SCFD) & 164 & 164 & 0 & 98 & 0 & 0 & 0 \\
\hline Water Injection Rate (gph) & 3.053 & 3.053 & 1,785 & 2,704 & 1.075 & 1,057 & 1.057 \\
\hline MeOH Recycle Rote (gph) & 0 & 0 & 0 & 0 & 564 & 578 & 581 \\
\hline \multicolumn{8}{|l|}{ Reactor } \\
\hline Diameter (tt) & 13.6 & 13.6 & 11.7 & 13.6 & 13.2 & 13.2 & 13.2 \\
\hline Height (ft) & 76.1 & 76.1 & 90.7 & 90.6 & 120.8 & 120.8 & 120.8 \\
\hline Temperouture ( $F$ ) & 482 & 482 & 482 & 482 & 482 & 482 & 482 \\
\hline Pressure (psig) & 1050 & 1060 & 1060 & 1060 & 1060 & 1060 & 1060 \\
\hline Gas Space Velocity (sL/kg-hr) & 6250 & 6250 & 2850 & 2950 & 1320 & 1320 & 1320 \\
\hline Alumina Loading (wi\%) & 0 & 0.3 & 7.4 & 7.4 & 13 & 13 & 13 \\
\hline Catalyst Usage Rate (lb/yr) & 151110 & 151110 & 149533 & 195523 & 383321 & 383321 & 383321 \\
\hline \multicolumn{8}{|l|}{ Performanice } \\
\hline MeOH Production (TPD) & 828 & 861 & 418 & 403 & nil & nil & nil \\
\hline DME Production (TPD) & nil & 16 & 240 & 262 & 622 & 590 & 579 \\
\hline Product LHV (MMBTU/hr) & 635 & 676 & 618 & 620 & 645 & 628 & 602 \\
\hline \multicolumn{8}{|l|}{ Product Composition (mole\%) } \\
\hline Hydrogen & 0.00 & 0.00 & 0.00 & 0.00 & 10.05 & 0.34 & 0.00 \\
\hline Carbon Monoxide & 0.00 & 0.00 & 0.00 & 0.00 & 43.77 & 5.64 & 0.00 \\
\hline Carbon Dioxide & 0.12 & 0.03 & 2.30 & 2.60 & 22.53 & 39.50 & 1.80 \\
\hline Nitrogen & 0.00 & 0.00 & 0.00 & 0.00 & 10.08 & 0.77 & 0.00 \\
\hline Dimethyl Ether & 0.01 & 1.31 & 52.02 & 48.90 & 13.43 & 53.50 & 97.79 \\
\hline Methyl Formate & $1 . \infty$ & 1.34 & 0.53 & 0.55 & 0.01 & 0.01 & 0.02 \\
\hline Woter . & 1.16 & 0.82 & 3.65 & 3.81 & 0.03 & 0.09 & 0.12 \\
\hline Methanol & 95.96 & 94.81 & 40.82 & 43.39 & 0.11 & 0.14 & 0.27 \\
\hline Ethanol & 1.07 & 1.04 & 0.42 & 0.45 & 0.00 & 0.00 & 0.00 \\
\hline Propanol & 0.33 & 0.31 & 0.13 & 0.14 & 0.00 & 0.00 & 0.00 \\
\hline Butanol & 0.33 & 0.31 & 0.13 & 0.14 & 0.00 & 0.00 & 0.00 \\
\hline \multicolumn{8}{|l|}{ Utillities } \\
\hline Steam Production (lb/hr at 230 psig) & 25858 & 14044 & 63247 & 46732 & 105900 & 97586 & 85092 \\
\hline Cooling Woter Flow (gph) & 664500 & 809460 & 472500 & 589560 & 254640 & 326640 & 432060 \\
\hline Electric Power (MW) & 14.60 & 16.16 & 14.23 & 13.21 & 11.77 & 12.54 & 13.53 \\
\hline
\end{tabular}

ISSUED FOE ESTMMATE 
TABLE 2.1: CASE 1

GENERIC LP PLANT - MATERIAL BALANCE LPM - MV FUEL AND PS FUEL

$\begin{array}{lcccccc}\text { Stream } & \text { Gas } & \text { Iniection } & \text { Gas } & \text { Gas } & \text { Product } \\ \text { FiS Number } & 10 & 432 & 163 & 212 & 210 \\ \text { Pressure (psia) } & 275 & 800 & 275 & 15 & 15 \\ \text { Temperature ( } & { }^{\circ} \text { F) } & 110 & 240 & 96 & 100 & 100 \\ \text { Flow (lbmol/hr) } & 17684 & 1415 & 12151 & 151 & 2138 \\ \text { Molecular Weight } & 20.51 & 18.02 & 25.72 & 40.35 & 32.65 \\ \text { Composition (mol\%) } & & & & & \\ \quad \text { Hydrogen } & 30.01 & 0 & 17.77 & 0.38 & 0.000 \\ \text { Carbon Monoxide } & 61.02 & 0 & 57.26 & 5.52 & 0.000 \\ \text { Carbon Dioxide } & 2.00 & 0 & 14.23 & 67.42 & 0.120 \\ \text { Nitrogen } & 6.81 & 0 & 9.90 & 0.83 & 0.000 \\ \text { Dimethyl Ether } & 0 & 0 & 0.020 & 0.390 & 0.009 \\ \text { Methyl Formate } & 0 & 0 & 0.055 & 1.95 & 0.996 \\ \text { Water } & 0.16 & 100 & 0.003 & 0.076 & 1.159 \\ \text { Methanol } & 0 & 0 & 0.760 & 23.30 & 95.96 \\ \text { Ethanol } & 0 & 0 & 0.006 & 0.116 & 1.072 \\ \text { Propanol } & 0 & 0 & 0.001 & 0.011 & 0.329 \\ \text { Butanol } & 0 & 0 & 0.000 & 0.004 & 0.332 \\ \text { COS } & 0.002 & 0 & 0 & 0 & 0 \\ \text { H2S } & 5 E-04 & 0 & 0 & 0 & 0 \\ \text { Mineral Oil } & 0 & 0 & 0 & 0 & 0.03 \\ & & & & & \\ \text { HHV (MMBtu/hr) } & 1,957 & 0 & 1,143 & 14 & 717 \\ \text { LHV (MMBtumr) } & 1,861 & 0 & 1.100 & 13 & 635 \\ & & & & & \end{array}$


TABLE 2.2: CASE 2

\section{GENERIC LP PLANT - MATERIAL BALANCE \\ LPDME - MV FUEL WITH COLD START}

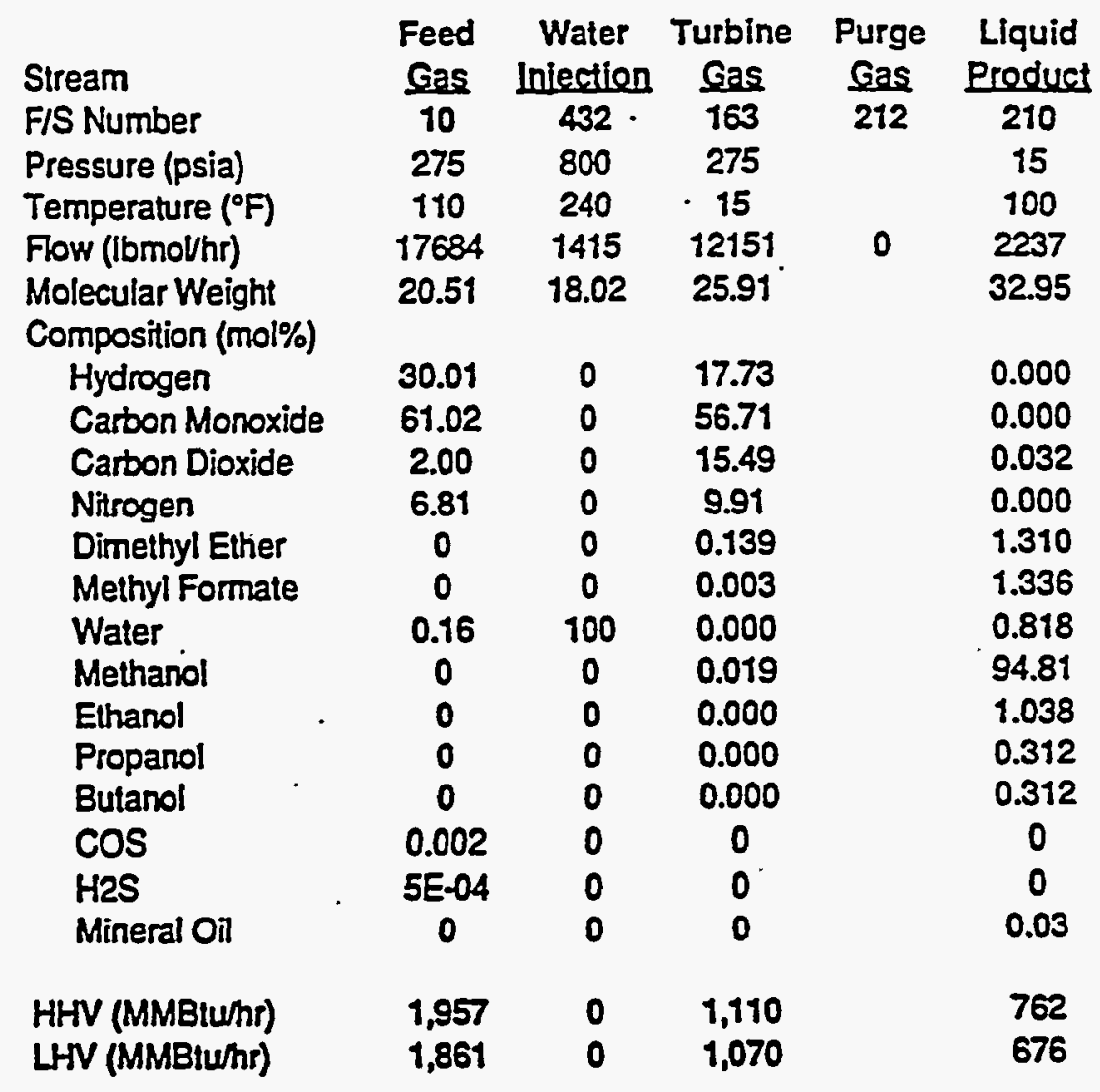


TABLE 2.3: CASE 3

GENERIC LP PLANT - MATERIAL BALANCE LPDME - PS FUEL ONLY - HIGH REC - OPTION 1

\begin{tabular}{|c|c|c|c|c|c|}
\hline $\begin{array}{l}\text { Stream } \\
\text { F/S Number }\end{array}$ & $\frac{\text { Gas }}{10}$ & $\frac{\text { Iniection }}{432}$ & $\frac{\text { Gas }}{163}$ & $\frac{\text { Gas }}{212}$ & $\frac{\text { Preduct }}{210}$ \\
\hline Pressure (psia) & 275 & 800 & 275 & . & 109 \\
\hline Temperature ( ${ }^{\circ} \mathrm{F}$ ) & 110 & 240 & 74 & & 100 \\
\hline Flow (lbmolhr) & 15762 & 827.5 & 10739 & 0 & 1455 \\
\hline Molecular Weight & 20.51 & 18.02 & 26.16 & & 39.44 \\
\hline Composition (mol\%) & & & & & \\
\hline Hydrogen & 30.01 & 0 & 18.07 & & 0.000 \\
\hline Carbon Monoxide & 61.02 & 0 & 54.18 & & 0.000 \\
\hline Carbon Dioxide & 2.00 & 0 & 17.51 & & 2.295 \\
\hline Nitrogen & 6.81 & 0 & 10.00 & & 0.000 \\
\hline Dimethyl Ether & 0 & 0 & 0.244 & & 52.024 \\
\hline Methyl Formate & 0 & 0 & 0.003 & & 0.525 \\
\hline Water & 0.16 & 100 & 0.000 & & 3.651 \\
\hline Methanol & 0 & 0 & 0.008 & & 40.82 \\
\hline Ethanol & 0 & 0 & 0.000 & & 0.421 \\
\hline Propanol & 0 & 0 & 0.000 & & 0.126 \\
\hline Butanol & 0 & 0 & 0.000 & & 0.126 \\
\hline $\cos$ & 0.002 & 0 & 0 & & 0 \\
\hline H2S & 5E-04 & 0 & 0 & & 0 \\
\hline Mineral Oil & 0 & 0 & 0 & & 0.02 \\
\hline HHV (M & 1,74 & 0 & 960 & & 684 \\
\hline LHV (MMBtu/hr) & 1,659 & 0 & 923 & & 618 \\
\hline
\end{tabular}


TABLE 2.4: CASE 4

GENERIC LP PLANT - MATERIAL BALANCE LPDME - PS FUEL ONLY - HIGH REC - OPTION 2

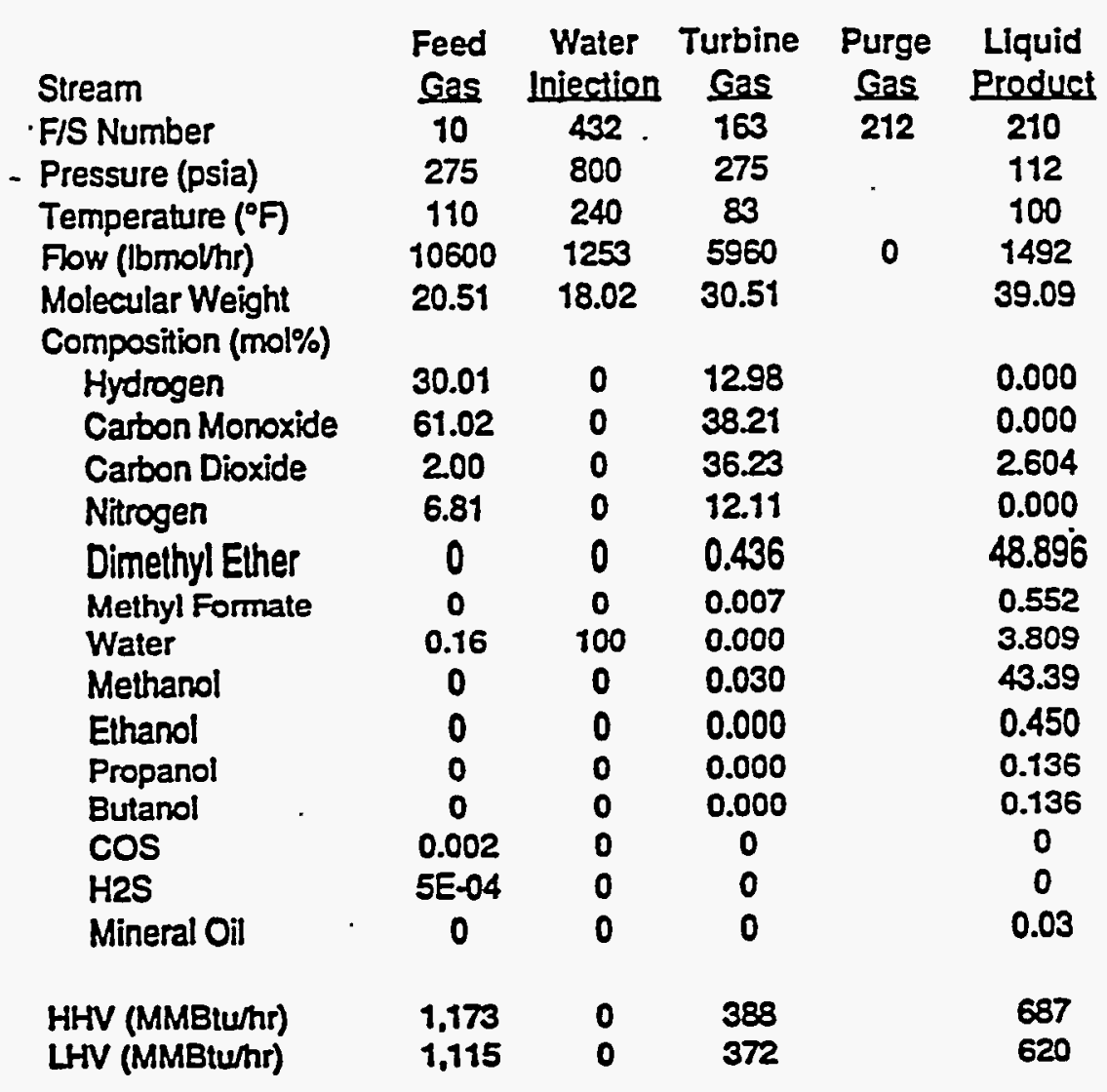

\section{ISSUED FOR ESTIMATE}


TABLE 2.5: CASE 5

\begin{tabular}{|c|c|c|c|c|c|}
\hline Stream & $\begin{array}{l}\text { Feed } \\
\text { Gas }\end{array}$ & $\begin{array}{l}\text { Water } \\
\text { Iniection }\end{array}$ & $\begin{array}{l}\text { Turbine } \\
\text { Gas }\end{array}$ & $\begin{array}{c}\text { Purge } \\
\text { Gas }\end{array}$ & $\begin{array}{l}\text { Product } \\
\text { Eraction }\end{array}$ \\
\hline F/S Number & 10 & $432^{\circ}$ & 163 & 212 & 163 \\
\hline Pressure (psia) & 275 & 800 & 275 & 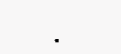 & 275 \\
\hline Temperature $\left(^{\circ} \mathrm{F}\right)$ & 110 & 240 & 120 & & 120 \\
\hline Fow (lbmol/hr) & 12398 & 498.4 & 7252 & 0 & 1125 \\
\hline $\begin{array}{l}\text { Molecular Weight } \\
\text { Composition (mol\%) }\end{array}$ & 20.51 & 18.02 & 29.16 & & 46.07 \\
\hline Hydrogen & 30.01 & 0 & 11.60 & & 0.000 \\
\hline Carbon Monoxide & 61.02 & 0 & 50.56 & & 0.000 \\
\hline Carbon Dioxide & 2.00 & 0 & 26.02 & & 0.000 \\
\hline Nitrogen & 6.81 & 0 & 11.64 & & 0.000 \\
\hline Dimethyl Ether & 0 & 0 & 0.00 & & 100.0 \\
\hline Methyl Formate & 0 & 0 & 0.01 & & 0.000 \\
\hline Water & 0.16 & 100 & 0.03 & & 0.000 \\
\hline Methanol & 0 & 0 & 0.13 & & 0.00 \\
\hline Ethanol & 0 & 0 & 0.00 & & 0.000 \\
\hline Propanol & 0 & 0 & 0.00 & & 0.000 \\
\hline Butanol & 0 & 0 & 0.00 & & 0.000 \\
\hline $\cos$ & 0.002 & 0 & 0 & & 0 \\
\hline H2S & 5E-04 & 0 & 0 & & 0 \\
\hline Minerai oil & 0 & 0 & 0 & & 0.00 \\
\hline HHV (MMBtu/hr) & 1,372 & 0 & 551 & & 709 \\
\hline LHV (MMBtu/hr) & 1,305 & 0 & 535 & & 645 \\
\hline
\end{tabular}


TABLE 2.6: CASE 6

GENERIC LP.PLANT - MATERIAL BALANCE LPDME - DME AS VAPOR WICO2, MEOH RECYCLE

Stream

F/S Number

Pressure (psia)

Temperature $\left({ }^{\circ} \mathrm{F}\right)$

Flow (lbmolhr)

Molecular Weight

Composition (mol\%)

Hydrogen

Carbon Monoxide

Carbon Dioxide

Nitrogen

- Dimethyl Ether

Methyl Formate

Water

Methanol

Ethanol

Propanol

Butanol

cos

H2S

Mineral Oi

HHV (MMBtwhr)

LHV (MMBtu/hr)
Feed Water Turbine Purge Vapor

Gas Iniection Gas Gas Produc

$\begin{array}{lllll}10 & 432 & 139 & 212 & 160\end{array}$

$\begin{array}{llll}275 & 800 & 275 & 275\end{array}$

$110 \quad 240 \quad 120$

$12398 \quad 489.7 \quad 6377$

$20.51 \quad 18.02 \quad 27.52$

$\begin{array}{lll}30.01 & 0 & 13.09\end{array}$

55.84

17.16

13.00

0.91

0.00

0.00

0.16100

0.00

0.000

0.000

0.000

0

0

0

100

$\begin{array}{lll}1,372 & 0 & 571\end{array}$

$1,305 \quad 0 \quad 552$
115

1996

43.91

0.338

5.635

39.503

0.771

53.5

0.014

0.092

0.14

0.000

0.000

0.000

0

0.00

688

628

\section{ISSUED FOR ESTIMATE}


TABLE 2.7: CASE 7

GENERIC LP PLANT - MATERIAL BALANCE LPDME - DME AS LIQUID, MEOH RECYCLE

\begin{tabular}{|c|c|c|c|c|c|}
\hline Stream & $\begin{array}{l}\text { Feed } \\
\text { Gas }\end{array}$ & $\begin{array}{c}\text { Water } \\
\text { Injection }\end{array}$ & $\begin{array}{c}\text { Turbine } \\
\text { Gas }\end{array}$ & $\begin{array}{l}\text { Purge } \\
\text { Gas }\end{array}$ & $\begin{array}{l}\text { Liquid } \\
\text { Product }\end{array}$ \\
\hline F/S Number & 10 & 432 & 163 & $\overline{212}$ & 180 \\
\hline Pressure (psia) & 275 & 800 & 275 & & 133 \\
\hline Temperature ( ${ }^{\circ} \mathrm{F}$ ) & 110 & 240 & 62 & & 100 \\
\hline Flow (lbmoVhr) & 12398 & 489.7 & 7300 & 0 & 1072 \\
\hline $\begin{array}{l}\text { Molecular Weight } \\
\text { Composition (mol\%) }\end{array}$ & 20.51 & 18.02 & 29.29 & & 45.96 \\
\hline Hydrogen & 30.01 & 0 & 11.52 & & 0.000 \\
\hline Carbon Monoxide & 61.02 & 0 & 50.32 & & 0.000 \\
\hline Carbon Dioxide & 2.00 & 0 & 25.53 & & 1.795 \\
\hline Nitrogen & 6.81 & 0 & 11.57 & & 0.000 \\
\hline Dimethyl Ether & 0 & 0 & 1.06 & & 97.79 \\
\hline Methyl Formate & 0 & 0 & 0.00 & & 0.017 \\
\hline Water & 0.16 & 100 & 0.00 & & 0.120 \\
\hline Methanol & 0 & 0 & 0.00 & & 0.27 \\
\hline Ethanol & 0 & 0 & 0.00 & & 0.000 \\
\hline Propanol & 0 & 0 & 0.00 & & 0.000 \\
\hline Butanol & 0 & 0 & 0.00 & & 0.000 \\
\hline $\cos$ & 0.002 & 0 & 0 & & 0 \\
\hline H2S & 5E.04 & 0 & 0 & & 0 \\
\hline Mineral Oil & 0 & 0 & 0 & & 0.00 \\
\hline HHV (MMBtu/hr) & 1,372 & 0 & 597 & & 661 \\
\hline LHV (MMBtu/hr) & 1,305 & 0 & 578 & & 602 \\
\hline
\end{tabular}

ISSUED FOR ESTIMATE 
TABLE 3: GENERIC LP PLANT DESIGN EQUIPMENT LIST

ITEM NUMBER F.S. DESCRIPTION

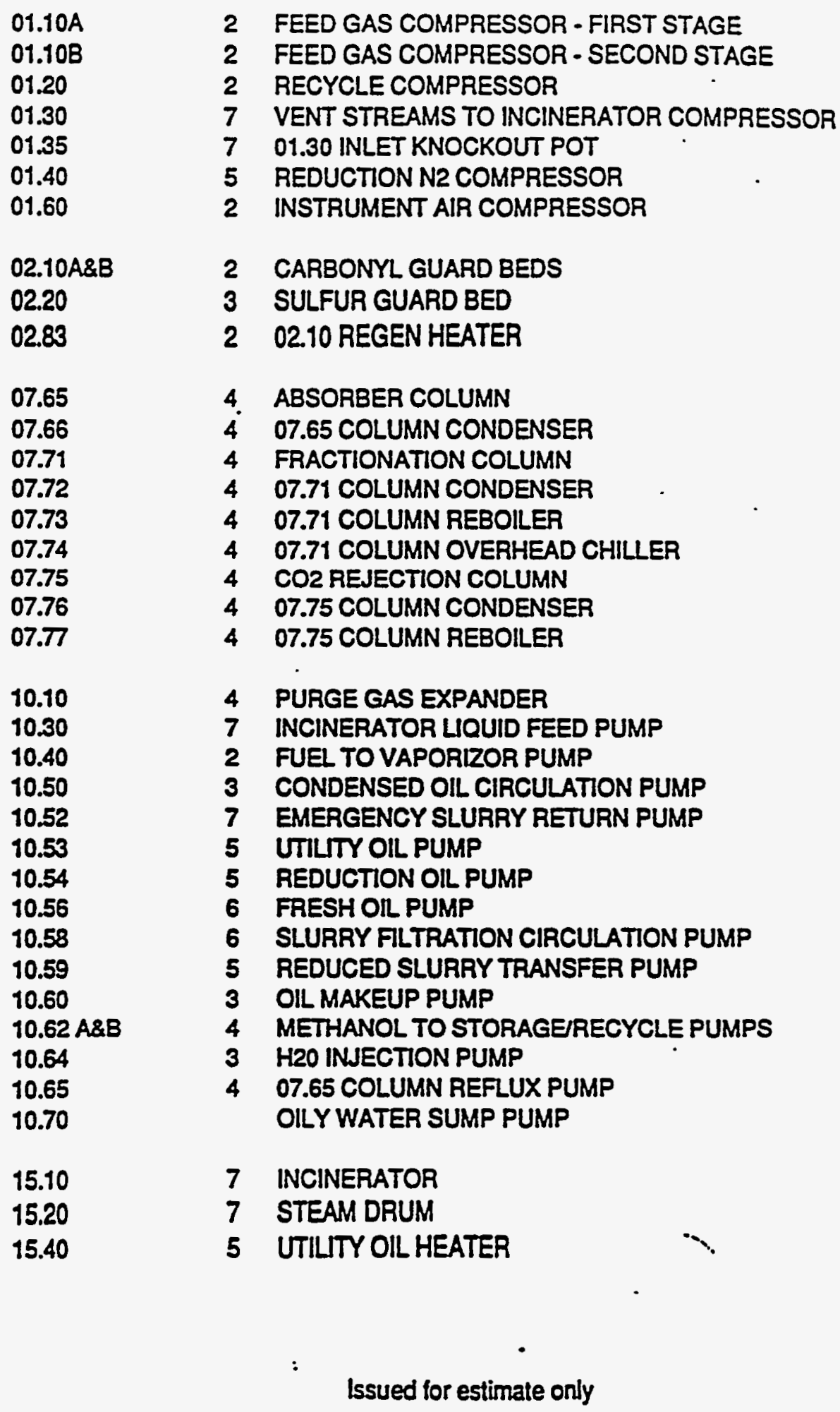


TABLE 3: GENERIC LP.PLANT DESIGN EQUIPMENT LIST

ITEM NUMBER F.S. DESCRIPTION

21.01

21.02

21.03

21.11

21.20

21.31

21.32

21.33

21.40

21.41

21.53

21.60

21.61

21.71

21.72

21.73

21.80

22.02

22.10

22.11

22.12

22.13

22.40

22.50

22.51

22.52

22.53

22.54

22.90

27.10

28.10

28.30

28.31

28.35

28.40

28.45

28.46

28.50

28.53
201.10 COMPRESSOR INTERCOOLER

2 01.10 COMPRESSOR RECYCLE CHILLER

2 01.20 COMPRESSOR RECYCLE CHILLER

3 REACTOR FEED/PRODUCT DEPHLEGMATOR

3 REACTOR INTERNAL HEAT EXCHANGER

4 METHANOL PRODUCT CONDENSER

4 RECOVERY SECTION CROSS EXCHANGER

4 RECOVERY SECTION ECONOMIZER

5 REDUCTION FEEDIPRODUCT ECONOMIZER

5 REDUCTION GAS COMPRESSOR COOLERS

5 UTILITY OIL AIRCOOLER

2 INSTRUMENT AIR COMPRESSOR COOLERS

.7 01.30 RECYCLE COOLER

4 LIQUID PRODUCT COOLER

4 LIOUID RECYCLE COOLER

4 LIOUID RECYCLE CROSS EXCHANGER

2 LIQUID FUEL VAPORIZOR

2. FEED GAS COMPRESSOR SECOND STAGE KNOCKOUT DRUM

4 H.P. METHANOL SEPARATOR

4 H.P.LIQUIDS SEPARATOR

4 M.P. FLASH POTIABSORBER

4 L.P.FLASH POT

5 REDUCTION CONDENSATE ACCUMULATOR

6 RECLAIMED OIL FILTER

4 LIQUID PRODUCT/RECYCLE FILTER

2 TURBINE FUEL FILTER

2 D210 GUARD BED REGEN TO TURBINE FILTER

2 02.10 GUARD BED REGEN HEATER OUTLET FILTER OILYNATER SEPARATOR

3 LPMEOH REACTOR

6 OIL STORAGE TANK

5 SLURRY MIX TANK \& REDUCTION VESSEL

5 SLURAY MIX TANK AGITATOR

5 CATALYST BIN, HOPPER \& FEEDER

2 LIQUID FUEL STORAGE

6 SLURRY CENTRIFUGE

6 SLURRY FILTRATION SURGE POT

7 FLARE KNOCKOUT POT

5 UTILITY OIL EXPANSION TANK.

: Issued for estimate only

Page 2 


\section{TABLE 3: GENERIC LP PLANT DESIGN}

\section{EQUIPMENT LIST}

\begin{tabular}{lcl} 
ITEM NUMBER & F.S. & DESCRIPTION \\
\hline 28.60 & 7 & SLURRY TANK \\
28.61 & 7 & SLURRY TANK AGITATOR \\
30.00 & 2 & SULFUR REMOVAL UNIT \\
& \multicolumn{1}{c}{ PROPANE COMPRESSOR } \\
40.10 & & PROPANE STORAGE \\
40.20 & PROPANE MP FLASH POT \\
40.21 & PROPANE CONDENSER
\end{tabular}


CAse 1

CASE 5

CASE 0

CASE 7

01.10A EEER GAS COMPRESSQR. EIAST STAGE

TYPE

INLET P (PSIA)

OUTLET P (PSIA)

ADIABATIC EFFICIENCY (\%)

GAS M.W. (LBRB.MOLE)

COMPRESSION POWER (HP)

MOTOA POWER (HP)

LOW (MMOLEAA)

SAMEAS

O201.05
17681

SAME AS


9302.11
17684

AECIPAOCATING
13.2
23
40
40.3
70
15.5709
CS
AECIPROCATING
1045
1100
17684
25.0
75
527
554.737
CS

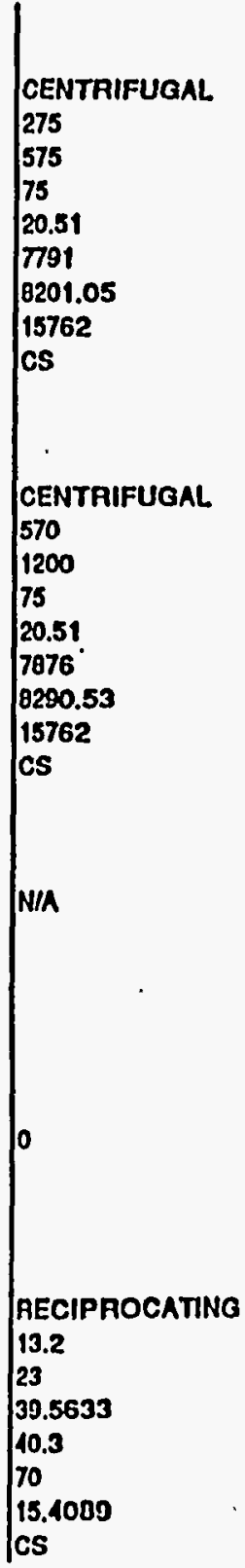

CENTAIFUGAL
275
575
75
20.51
5240
5515.79
10600
CS


CENTAIFUGAL
570
1200
75
20.51
5297
5575.79
10600
CS

\begin{tabular}{|l} 
\\
CENTAIFUGAL \\
275 \\
575 \\
75 \\
20.51 \\
6128 \\
6450.53 \\
12398 \\
$C S$
\end{tabular}

CENTAIFUGAL,

275

575

75

20.51

6128

6450.53

12398

CS

CENTAIFUGAL

275

75

20.51

6128

6450.53

12398

CS

01.108 EEED GAS COMPAESSOA. SECOND STAGE

TYPE

INLET P (PSIA)

OUTLET P (PSIA)

ADIABATIC EFFICIENCY (\%)

OAS M.W. (LBRB-MOLE)

COMPRESSION POWER (HP)

S FLOW (WMOLEHA)

MATEAIAL

CENTRIFUGAL.

CENTRIFUGAL

CENTAIFUGAL.

CENTRIFUGAL

1200

20.61

6837

17684

cs

01.20 BECYGLE COMPAESSOB

TYPE

INLET P (PSIA)

OUTET P (PSIA)

TOTAL OUTLET FLOW (UMOLEAH)

OUTLET M.W. (LELLB.MOLE)

ADIABATIC EFFICIENCY (\%)

COMPAESSION POWEA (HP)

MOTOR POWEA (HP)

MATEAIAL.

01.30 MCINEAATORFEED COMPAESSOA

TYPE

INLET P (PSIA)

OUTLET P (PSIA)

TOTAL OUTLET FLOW (MMOLEAA)

OUTLET M.W. (LBR.B.MOLE)

POLVTAOPIC EFFICIENCY (\%)

TOTAL POWEN (HP)

MATERIAL

ISSUED FOR ESTIMATE

$570 \quad 570$

$1200+1200$

75

RECIPROCATING

13.2

2317918

1.7318

70.3

20.1481

CS

AECIPROCATING

1025

10600

27.37

432.632

CS

o

20.51

(20.5

6521.05

12398

CS

NIA

570

1200

75

20.51

6195

6521.05

$12398^{\circ}$

CS.

N/A

RECIPROCATING 13.2

23

101.405

10.3

70
39.4045

39.4045

CS

CS

13.2
23
101.105
10.3
70
30.4945
$\mathrm{CS}$

AECIPROCATING 
CASEJ

CASE 4

CASE 5

CASE 8

CAsE7:・

01.95 WCINEAATOR COMP SUCTIONKNOCKOUTPOT

TYPE

VESSELID (FT)

T-T HEIGHT (FN)

DESIGN T (F)

DESIGN P (PSIO)

VAPOA KV

VESSEL MATERIAL

01.40 BEDUCTIONNR COMPAESSOR

TYPE

INLET P (PSIA)

OUTLET P (PSIA)

ADIABATIC EFFICIENCY (\$)

OAS MW. (LBRB-MOLE)

POWER (HP)

FLOW (MMOLEMA)

MATERIAL

01.60 INSTRUMENT SIA COMPBESSOB

TYPE

INLET P (PSIA)

OUTLET P (PSIA)

OUTLET FLOW (UROLEMA)

OUTLET FLOW (SCFH)

M.W. (LBLE-MOLE)

ADIABATIC EFFICIENCY (\%)

TOTAL POWER (HP)

MATEAIAL

02.10 A GABBONYL GULARD BEDS

TYPE

DIAMETER (FT)

HEIOHT T.T (FT)

BED VOLUME (FTA3)

SPACE VELOCITY (HA^-1)

DESIGNTIF)

DESIGN P (PSIG)

DESION FE(CO)S LEVEL (PPB)

DESION NI(CO) 4 LEVEL (PPB)

MATERIAL

ASSUMED ONSTAEAM FACTOR (\%)

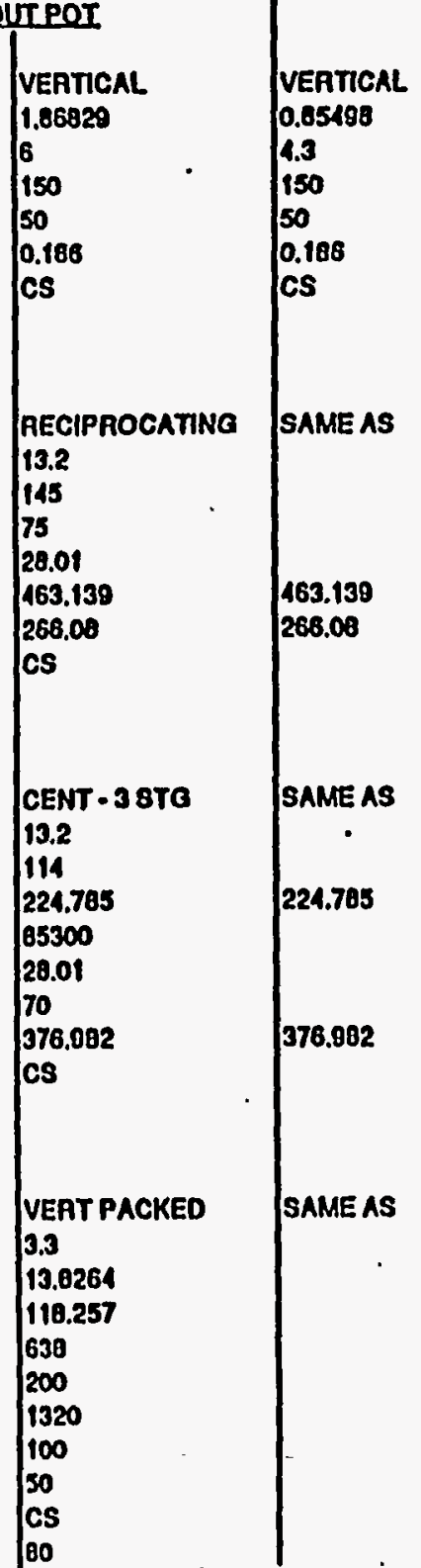

\begin{tabular}{|l} 
\\
VERTICAL \\
0.8503 \\
1.3 \\
150 \\
50 \\
0.188 \\
CS \\
\\
RECIPROCATING \\
13,2 \\
145 \\
75 \\
28.01 \\
458.083 \\
263.175 \\
$C S$ \\
\\
\\
SAMEAS \\
\\
224.785 \\
\\
VERTPACKED \\
3.3 \\
12.3237 \\
105.101 \\
638 \\
200 \\
1320 \\
100 \\
50 \\
$C S$ \\
180 \\
\\
\end{tabular}

VEATICAL
0.97231
4.3
150
50.
0.186
CS

(5)

VERTICAL.

1.36131
5
150

150

50
0.186
$c S$

RECIPROCATING

13.2

145

75

28.01
598.973

344.119

CS

RECIPROCATING

13.2

145

75

28.01

1174.11

CS

VERTICAL

1.36131

5

150

50

0.186

CS

VERTICAL

1.36131

150

0.186

cs

RECIPROCATING 13.2

145

75

28.01

1174.11

674.545

CS

AECIPROCATING

13.2

75

28.01

1174.11
674.545

CS

SAMEAS

SAME AS

SAME AS

SAMEAS

224.785

224.785

224.785

376.982

224.785

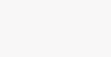

376.082

376.982

VERT PACKED VERT PACKED

3

10.0281

70.8848

638

200

1320

100

50

CS

376.98

VERT PACKED

VEAT PACKED

3

11.7291

3

11.7291

3

638

82.008

11.7291

02.9084

638

200
1320

200
1320

100

50

$\mathrm{CS}$
80

100

50

CS

638

200

1320

100

50

CS

ISSUED FOR ESTIMATE 
CASE 1

CASE 2

CASE 3

CASE :

CASE 0

CASE 7

02.20 SULFUACUARDBED

TYPE

NUMBER OF UNITS

DIAMETER (FT)

HEIOHT T.T (FT)

BED VOLUME (FTA3)

SPACE VELOCITY (HA^-1)

DESIONT (F)

DESION P (PSIG)

MATEAIAL.

DESION SULFUA LEVEL (PPM)

VERT PACKEO

SAME AS
SAME AS

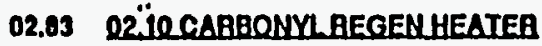

TYPE

HEATEA KW

REGENERATION TEMPEAATUAE (F)

oै TIME TO HEAT (HAS)

TIME ON HOLD (HRS)

SUP. VELOCITY IN 02.10 (FT/SEC)

AEGEN FLOW WITH SYNGAS (LBMOLEH 21.3773

07.03 ABSOABER COLUMA

TYPE

TRAYED SECTION

DIAMETER (IN)

OVEAALL HEIGHT (FT)

ASSUMED EFFICIENCY (\%)

ACTUAL TAAY COUNT

OVEANLL HEIGHT (FT)

DESIGNT T $F$

DESION P (PSIG)

MATEAIAL.

\begin{tabular}{|c|c|c|c|c|}
\hline $\begin{array}{l}\text { VERT PACKED } \\
t\end{array}$ & $\begin{array}{l}\text { VEAT PACKEO } \\
1\end{array}$ & $\begin{array}{l}\text { VEAT PACKED } \\
1\end{array}$ & $\begin{array}{l}\text { VEAT PACKED } \\
1\end{array}$ & $\begin{array}{l}\text { VEAT PACKED } \\
1\end{array}$ \\
\hline 6.25 & 6.75 & 5.5 & 5.5 & 5.5 \\
\hline 16.5175 & 19.0468 & 16.7772 & 16.772 & 16.772 \\
\hline 2.64281 & 2.82175 & 3.0504 & 3.0504 & 3.0504 \\
\hline 506.752 & 681.584 & 398.598 & 398.598 & 398.598 \\
\hline 228,488 & 228.488 & 456.976 & 456.976 & 456.976 \\
\hline 600 & 600 & 600 & 600 & 600 \\
\hline 1320 & 1320 & 1320 & 1320 & 1320 \\
\hline $\begin{array}{l}\text { SS CLAD ON CS } \\
0.3\end{array}$ & $\begin{array}{l}\text { SS CLAD ON CS } \\
0.3\end{array}$ & $\begin{array}{l}\text { SS CLAD ON CS } \\
0.3\end{array}$ & $\begin{array}{l}\text { SS CLAD ON CS } \\
0.3\end{array}$ & $\begin{array}{l}\text { SS CLAD ON CS } \\
0.3\end{array}$ \\
\hline 80 & 80 & Bo & 80 & 80 \\
\hline ELECTRIC & ELECTAIC & ELECTAIC & ELECTAIC & ELECTAIC \\
\hline 20.2701 & 13.6317 & 15.8439 & 15.8439 & 15.9439 . \\
\hline 250 & 250 & 250 & 250 & 250 \\
\hline 8 & 8 & 8 & 8 & $\boldsymbol{\theta}$ \\
\hline 10 & 10 & & 10 & 10 \\
\hline 0.25 & 0.25 & 0.25 & 0.25 & 0.25 \\
\hline 19.0539 & 12.8138 & 14.9873 & 14.9873 & 14.9873 \\
\hline TRAYED - I SECT & TAAYED - 1 SECT & N/A & N/A & N/A \\
\hline 80 & 86 & & & \\
\hline 24 & 32 & . & & \\
\hline 50 & 50 & & & \\
\hline 12 & 16 & & & \\
\hline 33 & 12 & & & \\
\hline-150 & .30 & & & \\
\hline 350 & 1320 & & & \\
\hline SS & ss & & & \\
\hline
\end{tabular}


CASE 5

CASE 6

CASE 7 :-

TYPE

DUTY (MMBTU/HR)

U ASSUMED (BTUHR.FT^2.F)

LMTD (F)

AREA (FTA2) + 20\% S.F.

SHELL DIAMETER (IN)

SHELLLENGTH (FT)

TUBE LENGTH IFT

NUMBER OF TUBES

TUBE OD (IN)

SHELL: DESIGNT(F)

DESION P (PSIG)

material

TUBES: DESIGNT(F)

DESION P (PSIG)

MATERIAL.

07.71 ERAGTIONATIONCOLUMAN

$\downarrow \quad$ TYPE

TOP SECTION

DIAMETER (N)

OVEAALL HEIGHT (FT)

ASSUMED EFFICIENCY (\%)

ACTUAL TAAY COUNT

BOTTOM SECTION

DIAMETER (IN)

OVERALL HEIGHT (FT)

ASSUMED EFFICIENCY (\%)

ACTUAL TAAY COUNT

OVERALL HEIGHT (FT)

DESIGN T (F)

DESIGN P (PSIG)

MATERIAL

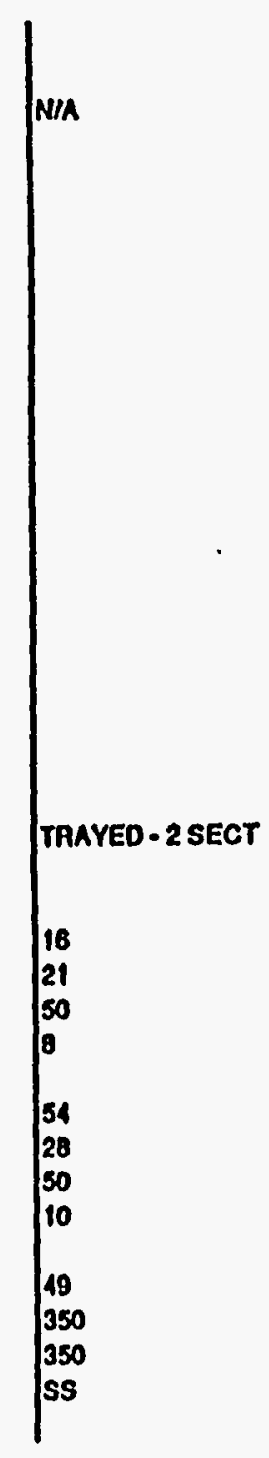

NIR

N/A

N/A

100

28.8216

3830.08

20.1173

18.1173

616

1,25

.50

SS

.50

1320

Ss

TRAYED-2SECT TRAYED-2SECT

TRAYED-2SECT TAAYED-2SECT TRAYED-2 SECT

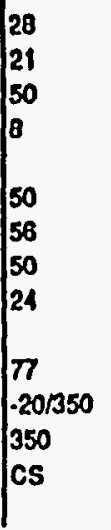

36
21
50
8

62
52
50
22.
73
350
350
$\mathrm{CS}$

26
25
50
10

34
28
50
10
53
350
350
$C S$

52
29
50
12
52
24
50
8
53
350
350
$\mathrm{CS}$

43

50

46

24

$.20 / 350$

350

cs 
TABLE A: EQUIPMENT SPECIFICATIONS

CASE 1

CASE 2

Case 3

CASE 1

CASE 5

CASE O

CASE 7 -

07.72 OZZLCOLUMN CONDENSER

TYPE

DUTY (MMBTU/HA)

U ASSUMED (BTUAHA.FTA2.F)

LMTD (F)

AREA (FTA2) + 20\% S.F.

SHELL DIAMETEA (IN)

SHELL. HEIGHT (FT)

TUBE HEIGHT (FT)

NUMBEA OF TUBES

TUBE OD (IN)

COOLING WATEA FLOW (GPM)

SHEUL: DESIGNTIF)

DESIGN P (PSIG)

MATERIAL

TUBES: DESIGNTIF)

$\vec{N}$ DESIGN P (PSIG)

07.T3 OZTLCOLUMANAEBOLLEB

TYPE

DUTY (MMBTUMA)

U ASSUMED (BTUAHA.FTA2.F)

LMTD (F)

AREA (FTA2) + 20\% S.F.

SHELL. DIAMETER (IN)

SHELL:LENOTH (FT)

TUBE LENGTH (FT)

NUMBEA OF TUBES

TUBE OD (IN)

STEAM FLOW (LBHR)

SHELL DESIGNT(F)

DESIGN P (PSIG)

MATERIAL

TUBES DESIGNTIF)

DESIGN P (PSIO)

MATERIAL

\begin{tabular}{|c|c|c|}
\hline $\begin{array}{l}\text { SHELL. \& TUBE } \\
1.03 \\
30 \\
55.0 \\
738.351 \\
20 \\
29.2841 \\
19.2811 \\
117 \\
1.25 \\
09.8563\end{array}$ & $\begin{array}{l}\text { SHELLL \& TUBE } \\
0.45 \\
50 \\
22.4 \\
182.113 \\
20 \\
17.5025 \\
12.6925 \\
117 \\
1.25 \\
0\end{array}$ & $\begin{array}{l}\text { SHELL \& TUBE } \\
1.65 \\
75 \\
38.9705 \\
677.438 \\
20 \\
22.6931 \\
17.6931 \\
117 \\
1.25 \\
0\end{array}$ \\
\hline $\begin{array}{l}250 \\
100 \\
C S\end{array}$ & $\begin{array}{l}-100 \\
350 \\
\text { Ss }\end{array}$ & \begin{tabular}{|l}
-100 \\
350 \\
SS
\end{tabular} \\
\hline $\begin{array}{l}250 \\
100 \\
C S\end{array}$ & $\begin{array}{l}-100 \\
350 \\
\text { ss }\end{array}$ & $\begin{array}{l}-100 \\
350 \\
\text { SS }\end{array}$ \\
\hline $\begin{array}{l}\text { KETTLE } \\
4.41 \\
65 \\
211.472 \\
339.456 \\
12 \\
10.7907 \\
0.7007 \\
116 \\
1.25 \\
5222\end{array}$ & $\begin{array}{l}\text { KETTLE } \\
14.70 \\
65 \\
72.1060 \\
3768.45 \\
90 \\
20.1062 \\
10.1062 \\
636 \\
1.25 \\
17402\end{array}$ & $\begin{array}{l}\text { KETTLE } \\
13.1 \\
65 \\
651.3952 \\
64755.65 \\
90 \\
20.0447 \\
18.0147 \\
636 \\
1.25 \\
15121\end{array}$ \\
\hline $\begin{array}{l}250 \\
100 \\
C S\end{array}$ & $\begin{array}{l}350 \\
350 \\
C S\end{array}$ & $\begin{array}{l}350 \\
350 \\
\text { CS }\end{array}$ \\
\hline $\begin{array}{l}450 \\
350 \\
\text { CS }\end{array}$ & \begin{tabular}{|l}
150 \\
350 \\
CS
\end{tabular} & $\begin{array}{l}450 \\
350 \\
C S\end{array}$ \\
\hline
\end{tabular}

\begin{tabular}{|c|c|}
\hline $\begin{array}{l}\text { SHELL \& TUBE } \\
10\end{array}$ & SHELL \& TUBE \\
\hline so & | 0.94 \\
\hline 28.6 & 68 \\
\hline 8391.61 & 221.176 \\
\hline & \\
\hline 32.5662 & 10.7766 \\
\hline 25.5662 & 5.77663 \\
\hline 1003 & 117 \\
\hline 1.25 & 1.25 \\
\hline 970.45 & 0 . \\
\hline 250 & 250 \\
\hline 50 & 350 \\
\hline CS & cs \\
\hline 250 & 250 \\
\hline 350 & 350 \\
\hline cs & cs \\
\hline KETTLE & KETTLE \\
\hline 23.27 & 4.7 \\
\hline 65 & 65 \\
\hline 59.3864 & 72.1068 \\
\hline 7233.98 & 1198,36 \\
\hline 108 & 62 \\
\hline 25.3673 & 14.9855 \\
\hline 23.3673 & 12.9855 \\
\hline 946 & 202 \\
\hline 1.25 & 1.25 \\
\hline 27394 & 5534 \\
\hline 350 & 350 \\
\hline 350 & 350 \\
\hline cs & cs \\
\hline 450 & |450 \\
\hline 350 & 350 \\
\hline cs & cs \\
\hline
\end{tabular}

SHELL \& TUBE

50

27.0988

2357.24

37

23.1507

16.1507

446

1.25

266.874

SHELL \& TUBE

5.19

75

35.3283

2350.52

39

21.195

14.195

506

1.25

350

so

.50

CS SS

250

350
CS

Ss

.20

350

KETTLE

11.82

KETTLE

65

6.83
35

70.4042

3099.47

80

16.8919

14.8919

636

1.25

13915

224.47

224.47
1043.22

62

13.3044

11.3044

282

1.25

$350 \quad 350$

$350 \quad 350$

cs

350

cs

350
CS 
07.7407 .75 COLUMN OVERHEAD CHILLER

\section{TYPE}

DUTY (MMBTU/AR)

U ASSUMED (BTUAR-FTA2-F)

LMTO (F)

AREA $\left(F^{\wedge}{ }^{\wedge}\right)+20 \%$ S.F.

SHELL DIAMETER (IN)

SHELLHEIGHT (FT)

TUBE HEIGHT (FT)

NUMBER OF TUBES

TUBE OD (IN)

COOLING WATEA FLOW (GPM)

SHELL. DESIGNT T(F) DESIGN P (PSIG) MATERIAL.

TUBES

\section{DESIGNT (F)}

DESIGN P (PSIG)

$\vec{\omega}$

07.75

DMEPUALEICATIONCOLUMAN

TYPE

TPAYED SECTION

DIAMETER (IN)

OVERALL HEIGHT (FT)

ASSUMED EFFICIENCY (\%)

ACTUAL TAAY COUNT

OVERALL HEIGHT (FT)

DESION T (F)

DESIGN P (PSIG)

MATEAIAL

\begin{tabular}{l|l} 
SHELL \& TUBE & N/A \\
3.72 \\
75 \\
23 \\
2587.83 \\
36 \\
18.9636 \\
18.0636 \\
117 \\
1.25 \\
\\
250 \\
350 \\
CS \\
250 \\
350 \\
CS \\
\\
\\
TAAYED \\
14 \\
52 \\
50 \\
21 \\
62 \\
$-20 / 350$ \\
350 \\
SS \\
\end{tabular}

N/A

SHELL \& TUBE

8.8

75

60

2346.67

36

17.1964

17.1964

417

1.25

853.996

250

50

250

350
CS

CS

N/A

TRAYED

50

52

50

350

cs 
07.70 OZ7. COLUMNCONDENSEA

TYPE

DUTY (MMBTUMA)

U ASSUMED (BTUAR.FT^2.F)

LMTD (F)

AAEA (FT^2) + 20\% S.F.

SHELL DIAMETER (IN)

SHELLLENGTH (FT)

TUBE LENGTH (FT)

NUMBEA OF TUBES

TUBE OD (IN)

COOLINO WATER FLOW (GPM)

SHELL: DESIGNT(F)

DESIGN P (PSIG)

MATERIAL

TUBES: DESIGNT(F) DESIGN P (PSIG) MATERIAL

I

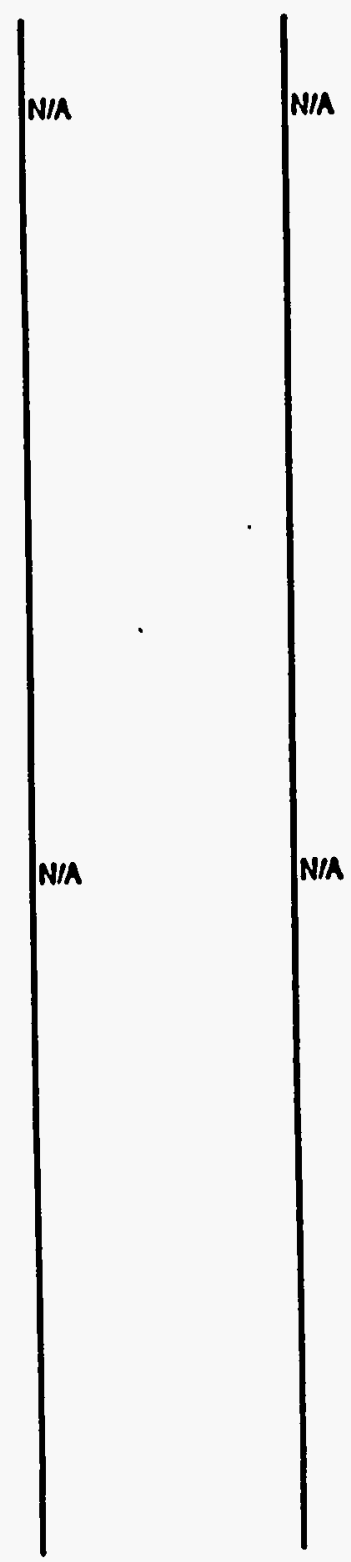

TYPE

OUTY (MMBTUMA)

U ASSUMED (BTUAR.FT^2.F)

LMTO (F)

AREA (FTA2) + $20 \%$ S.F.

SHELL DIAMETEA (IN)

SHELL LENGTH (FT)

TUBE LENOTH (FT)

TUBE OD (IN)

SHELL DESIGNT (F)

MATERIAL

TUBES DESIGN T (F)

DESIGN P (PSIG) MATERIAL
SHELL \& TUBE

3.20

75

N/A

STEAM FLOW (LBAR)

DESIGN P (PSIG)
N/A

SHELL \& TUBE

20.4504

1844.62

26.0326

21.0328

1.25

.50

so

ss

.50

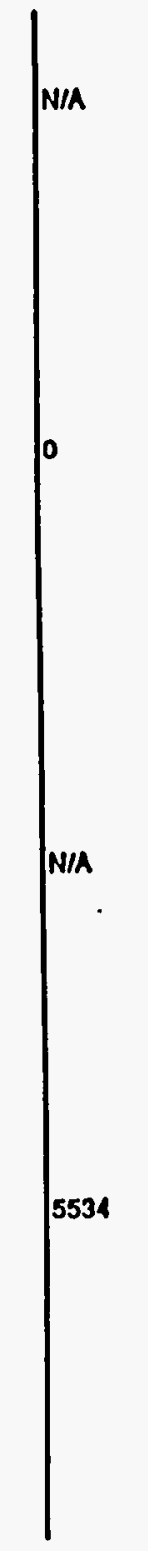

\begin{tabular}{l|l} 
KETTE & N/A \\
7.7 & \\
65 & \\
105.954 \\
1341.66 \\
51 \\
22.499 \\
20.499 \\
200 \\
1.25 \\
\\
\\
350 \\
350 \\
CS \\
\\
350 \\
350 \\
CS
\end{tabular}

N/A

13915
11.1

65.3960

3136.36

90

17.0692

15.0692

636

1.25

8042

70

15.2945

10.2945

1.25

383.328

c5

350

CS 


\begin{tabular}{|c|c|}
\hline 10.10 & $\begin{array}{l}\text { RURGE GAS EXEANDER } \\
\text { TYPE } \\
\text { INLETP (PSIA) } \\
\text { OUTLET P (PSIA) } \\
\text { ADIABATIC EFFICIENCY (Y) } \\
\text { GAS M.W. (LBRB-NOLE) } \\
\text { POWER (HP) } \\
\text { FLOW (WMOLENA) } \\
\text { MATEAIAL. }\end{array}$ \\
\hline 10.30 & $\begin{array}{l}\text { WNGINEAATORWUUUD FEED PUMP } \\
\text { TYPE } \\
\text { INLET P (PSIA) } \\
\text { HEAD (FT) } \\
\text { EFFICIENCY (\%) } \\
\text { FLOWAATE (GPM) } \\
\text { BAAKE HOASEPOWEA (BHP) } \\
\text { MATEAIAL }\end{array}$ \\
\hline 10.40 & EUFLTO YAROAIZER BUMP \\
\hline जै & $\begin{array}{l}\text { TYPE } \\
\text { FLOW (GPM) } \\
\text { HEAD (FT) } \\
\text { DENSITY (LB/FTA3) } \\
\text { VISCOSTY (CP) } \\
\text { POWER (BHP) } \\
\text { EFFICIENCY (\%) } \\
\text { DESION T (F) } \\
\text { SUCTION P (PSIA) } \\
\text { MATEAIAL }\end{array}$ \\
\hline 10.50 & $\begin{array}{l}\text { COND. OULCIRCULATION PUMP } \\
\text { TYPE } \\
\text { FLOW (GPM) } \\
\text { HEAD (FT) } \\
\text { DENSITY (LBIFTA3) } \\
\text { VISCOSITY (CP) } \\
\text { POWER (BHP) } \\
\text { EFFICIENCY (X) } \\
\text { DESION T (F) } \\
\text { SUCTION P (PSIA) } \\
\text { MATERIAL. }\end{array}$ \\
\hline
\end{tabular}

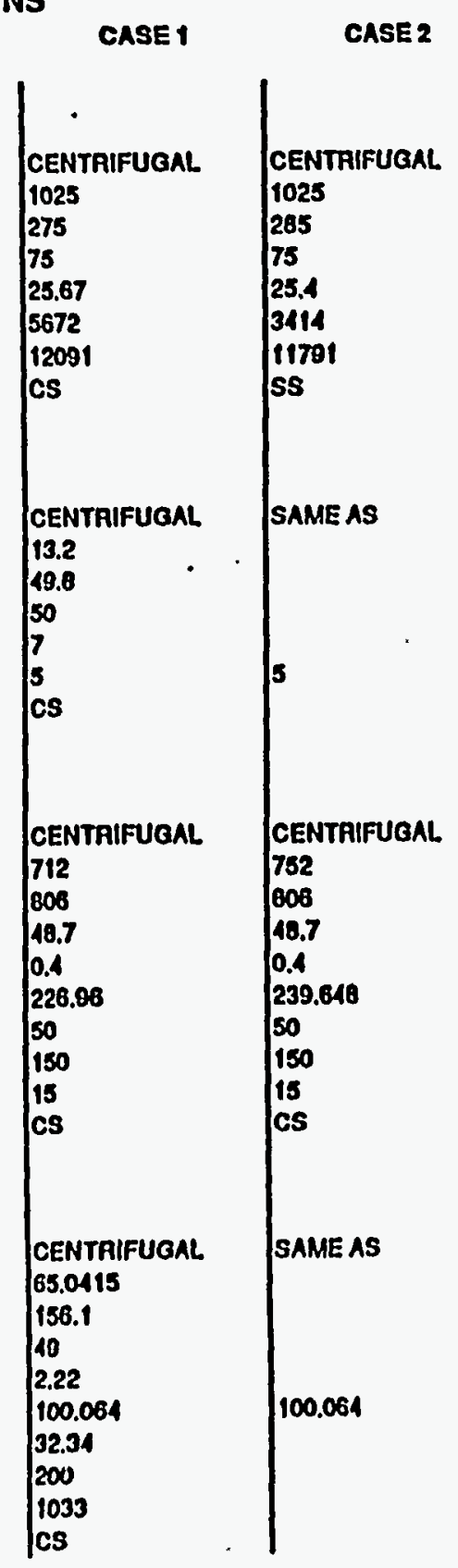

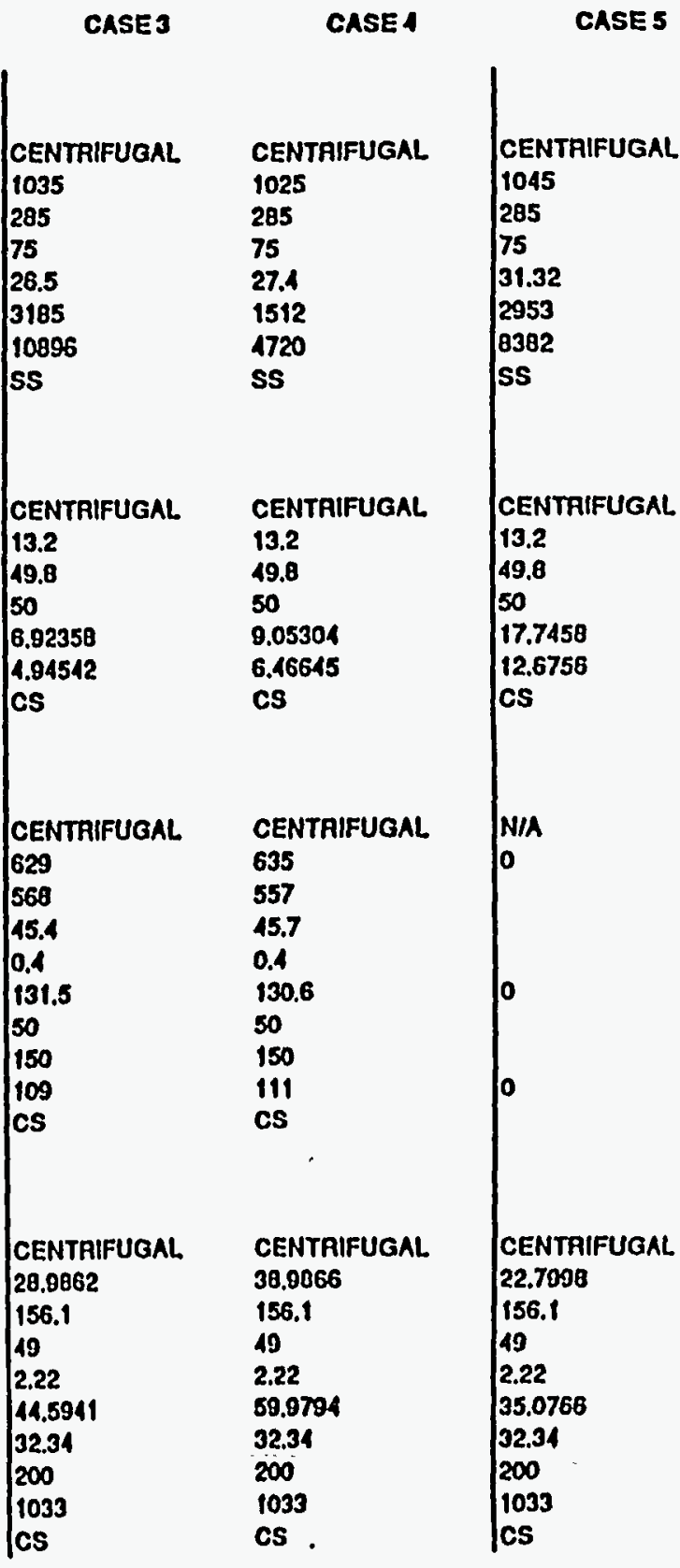

CASE 6

CASE 7

Centrifugal. Centaifugal

10351035

280

75

28.55

1953

6789

1035
280
75

280

75
28.55

1953

ss

sS

$\begin{array}{ll}\text { CENTRIFUGAL } & \text { CENTAIFUGAL } \\ 13.2 & 13.2 \\ 49.8 & 49.8 \\ 50 & 50 \\ 17.7458 & 17.7458 \\ 12.6756 & 12.6756 \\ \text { CS } & \text { CS }\end{array}$

CS

N/A CENTRIFUGAL

0

613

560

0.4

$\begin{array}{ll}0 & 111\end{array}$

$\begin{array}{ll}150 \\ 0 & 133\end{array}$

133
$0 S$

ISSUEO FOR ESTIMATE

$\begin{array}{ll}\text { CENTAIFUGAL } & \text { CENTAIFUGAL } \\ 22.7990 & 45.5006 \\ 156.1 & 156.1 \\ 19 & 49 \\ 2.22 & 2.22 \\ 35.0766 & 70.1533 \\ 32.34 & 32.34 \\ 200 & 200 \\ 1033 & 1033 \\ \text { CS } & \text { CS }\end{array}$


CASE 1

CABE 2

CASE J

CASE 4

CAse 5

CASE O

CASE 7

10.52 EMERGENCY SLURAY RETURN PUMP

TYPE

SLUARY TAANSFER TIME (HAS)

VOL OF SLUAAY TO BE TAANS (GAL)

INLET P (PSIA)

OUTLET P (PSIA)

HEAD (FT)

EFFICIENCY (\%)

FLOWAATE (GPM)

BRAKE HORSEPOWER (BHP)

MATERIAL.

10.53 imitreollpeump

TrYPE

INLET P (PSIA)

OUNLET P (PSIA)

HEAD (FT)

EFFICIENCY $(\%)$

FLOWAATE (GPM)

BAAKE HORSEPOWER (BHP)

$\sigma$ MATERIAL

DESIONT (F)

DESION P (PSIG)

10.54 BEDUCTIONOLLPUMP

TYPE

INLET P (PSIA)

OUTLET P (PSIA)

HEAD (FT)

EFFICIENCY (\%)

FLOWRATE (GPM)

BAAKE HOASEPOWEA (BHP)

MATERIAL.

10.56 ERESHOILPUMP

TYPE

INLET P (PSIA)

HEAD (FT)

FLOWRATE (GPM)

POWER (HP)

MATERIAL

\begin{tabular}{|c|c|c|}
\hline $\begin{array}{l}\text { CENTRIFUGAL } \\
8 \\
35938 \\
14 \\
10 \\
70.5 \\
35.5 \\
74.6625 \\
14.9263 \\
\text { CS }\end{array}$ & SAME AS & $\begin{array}{l}\text { SAME AS } \\
8 \\
35446.8 \\
11 \\
10 \\
78.5 \\
35.5 \\
73.8474 \\
14.7633 \\
C S\end{array}$ \\
\hline $\begin{array}{l}\text { CENTAIFUGAL } \\
58 \\
108 \\
53 \\
50 \\
600 \\
10 \\
C S \\
500 \\
150\end{array}$ & SAME AS & $\begin{array}{l}\text { CENTAIFUGAL. } \\
58 \\
108 \\
53 \\
50 \\
593.45 \\
47.476 \\
C S \\
500 \\
150\end{array}$ \\
\hline $\begin{array}{l}\text { CENTAIFUGAL } \\
19 \\
39 \\
58.2 \\
36.6 \\
83.6 \\
\text { O } \\
\text { CS }\end{array}$ & SAME AS & $\begin{array}{l}\text { CENTAIFUGAL } \\
19 \\
39 \\
58.2 \\
38.6 \\
82.6874 \\
7.91267 \\
C S\end{array}$ \\
\hline $\begin{array}{l}\text { AECIPAOCATING } \\
13.2 \\
07.4 \\
52.2 \\
4 \\
\text { CS }\end{array}$ & SAMEAS & SAME AS \\
\hline
\end{tabular}

SAME AS
8
46349
14
10
78.5
35.5
96.5603
19.304
CS

$\mid \begin{aligned} & \text { CENTRIFUGAL } \\ & \text { B } \\ & 60716 \\ & 11 \\ & 40 \\ & 70.5 \\ & 35.5 \\ & 126.492 \\ & 25.2878 \\ & \text { CS }\end{aligned}$

CENTRIFUGAL

CENTAIFUGAL 60716

14

14
10

78.5

35.5

126.492

25.2878

CS

60716

14

40
78.5

35.5

126.492

25.2870

CS

CEnTAifugal

58

108

53

50

775.075

62.078

cs

500

150

CENTRIFUGAL

CENTRIFUGAL

58

108

53

53

50
1521.07

121.686

CS

500

150

1521.07

121.686

CS

500

150

CENTAIFUGAL

58

108

53

50

1521.07

$121.686^{\circ}$

CS

500

Centrifugal

19

39

58.2

36.6

108.119

10.3463

CS

CENTRIFUGAL

CENTAIFUGAL

CENTAIFUGAL

1919

39

58

39

58.2

58.2

36.6

211.036

58.2

211.936

20.281

36.6
211.936

20.281

CS

20.281

RECIPROCATINO

13,2

87.4

67.6098

5.17316

cs

CS

RECIPROCATING
13.2
07.4
132.333
10.1405
CS

RECIPROCATING

13.2

67.4

132.333

CS

13.2

87.1

132.333

10.140

cs

ISSUEO FOR ESTIMATE

PAGE 9 


\begin{tabular}{|c|c|c|c|c|c|c|c|c|}
\hline & & CASE 1 & CASE 2 & CASEJ & CASEA & CASE 5 & CASEO 0 & CASE 7 \\
\hline \multirow[t]{2}{*}{10.58} & SLUABYFILTRATION CIRCULATONPUME & & & & & & & \\
\hline & $\begin{array}{l}\text { TYPE } \\
\text { INLETP (PSIA) } \\
\text { HEAD (FD } \\
\text { FLOWAATE (GPM) } \\
\text { BRAKE HORSEPOWER (BHP) } \\
\text { MATEAIAL }\end{array}$ & $\begin{array}{l}\text { CENTAIFUGAL } \\
13.2 \\
58.2 \\
5.2 \\
2 \\
\text { CS }\end{array}$ & SAMEAS & SAMEAS & $\begin{array}{l}\text { CENTAIFUGAL } \\
13.2 \\
58.2 \\
6.72511 \\
2.58658 \\
\text { CS }\end{array}$ & \begin{tabular}{|l} 
CENTAIFUGAL \\
13.2 \\
58.2 \\
13.1826 \\
5.07024 \\
CS
\end{tabular} & $\begin{array}{l}\text { CENTAIFUGAL } \\
13.2 \\
58.2 \\
13.1826 \\
5.07024 \\
\text { CS }\end{array}$ & $\begin{array}{l}\text { CENTRIFUGAL } \\
13.2 \\
58.2 \\
13.1826 \\
5.07024 \\
\text { CS }\end{array}$ \\
\hline \multirow[t]{2}{*}{10.59} & BEDUCED SLUABYY TRANSEER PUMP & & & & & & & \\
\hline & $\begin{array}{l}\text { TYPE } \\
\text { INLET P (PSIA) } \\
\text { OUTLET P (PSIA) } \\
\text { HEAD (FI) } \\
\text { EFFICIENCY (\%) } \\
\text { FLOWAATE (GPM) } \\
\text { GRAKE HORSEPOWER (BHP) } \\
\text { MATERIAL }\end{array}$ & $\begin{array}{l}\text { ARECIPAOCATINO } \\
14 \\
1120 \\
3200 \\
32 \\
8 \\
24 \\
\text { CS }\end{array}$ & SAMEAS & $\begin{array}{l}\text { AECIPAOCATING } \\
11 \\
1128 \\
3200 \\
32 \\
7.91267 \\
23.738 \\
\text { CS }\end{array}$ & $\begin{array}{l}\text { RECIPROCATING } \\
14 \\
1128 \\
3200 \\
32 \\
10.3463 \\
31.039 \\
\text { CS }\end{array}$ & $\begin{array}{l}\text { RECIPROCATING } \\
114 \\
1128 \\
3200 \\
32 \\
20.281 \\
60.8429 \\
\text { CS }\end{array}$ & $\begin{array}{l}\text { RECIPROCATTNG } \\
11 \\
1128 \\
3200 \\
32 \\
20.281 \\
60.8129 \\
\text { CS }\end{array}$ & $\begin{array}{l}\text { RECIPROGATING } \\
14 \\
1120 \\
3200 \\
32 \\
20.281 \\
60.8129 \\
\text { CS }\end{array}$ \\
\hline 10.00 & OLLAAKEUP PUMP & & & & & & & \\
\hline$\vec{z}$ & $\begin{array}{l}\text { TYPE } \\
\text { CALCD MAKEUP FLOW (GPM) } \\
\text { DESIGN FLOWAATE (GPM) } \\
\text { HEAD (FT) } \\
\text { DENSITY (LQRFA') } \\
\text { VISCOSITY (CP) } \\
\text { POWER (BHP) } \\
\text { EFFICIENCY (\%) } \\
\text { DESIGN T (F) } \\
\text { SUCTION P (PSIA) } \\
\text { MATERIAL }\end{array}$ & $\begin{array}{l}\text { AECIPAOCATINO } \\
0.45184 \\
5 \\
3093.3 \\
50.9 \\
15.71 \\
22.5 \\
31.5 \\
200 \\
17 \\
C S\end{array}$ & SAME AS & \begin{tabular}{|l} 
RECIPROCATING \\
0.2027 \\
2 \\
3093.3 \\
50.1 \\
15.71 \\
9 \\
31.5 \\
200 \\
17 \\
$\mathrm{CS}$
\end{tabular} & $\begin{array}{l}\text { RECIPROCATING } \\
0.272 .63 \\
3 \\
3093.3 \\
50.1 \\
15.71 \\
13.5 \\
31.5 \\
200 \\
17 \\
C S\end{array}$ & \begin{tabular}{|l} 
RECIPROCATING \\
0.15941 \\
2 \\
3093.3 \\
50.1 \\
15.71 \\
9 \\
31.5 \\
200 \\
17 \\
$\mathrm{CS}$
\end{tabular} & $\begin{array}{l}\text { RECIPROCATING } \\
0.15914 \\
2 \\
3093.3 \\
50.1 \\
15.71 \\
9 \\
31.5 \\
200 \\
17 \\
\text { CS }\end{array}$ & $\begin{array}{l}\text { RECIPROCATING } \\
0.318 B 8 \\
3 \\
3093.3 \\
50.1 \\
15.71 \\
13.5 \\
31.5 \\
200 \\
17 \\
\text { CS }\end{array}$ \\
\hline \multirow[t]{8}{*}{10.62} & METHANOL TO STOAAGEIRECYCLL & & & & & & & \\
\hline & TYPE & CENTAIFUGAL. & [N/R & CENTAIFUGAL & CENTAIFUGAL & CENTAIFUGAL & CENTAIFUGAL & CENTAIFUGAL \\
\hline & $\begin{array}{l}\text { DESION FLOWAATE (GPM) } \\
\text { HEAD (FT) }\end{array}$ & & & 100 & 2240 & $\begin{array}{l}5023 \\
10.0\end{array}$ & $\begin{array}{l}3103 \\
40.1\end{array}$ & $\begin{array}{l}2023 \\
10.2\end{array}$ \\
\hline & $\begin{array}{l}\text { DENSITY (LBAFTA3) } \\
\text { VISCOSTY (CP) }\end{array}$ & & & $\int_{0.5}^{43.3}$ & 0.5 & 0.5 & 0.5 & 0.5 \\
\hline & POWEA (BHP) & $\begin{array}{l}1.70190 \\
50\end{array}$ & jo & $\begin{array}{l}2.4 \\
50\end{array}$ & $\begin{array}{l}239 \\
\text { so }\end{array}$ & $\begin{array}{l}24 \\
50\end{array}$ & $\begin{array}{l}24 \\
50\end{array}$ & $\begin{array}{l}24 \\
50\end{array}$ \\
\hline & $\begin{array}{l}\text { EFFICIENCY (Y) } \\
\text { DESIGN T (F) }\end{array}$ & 200 & & 200 & 200 & 350 & 350 & 350 \\
\hline & $\begin{array}{l}\text { SUCTION P (PSIA) } \\
\text { MATERIAL }\end{array}$ & $\mid \begin{array}{l}15 \\
\text { CS }\end{array}$ & & $\begin{array}{l}265 \\
\mathrm{CS}\end{array}$ & $\begin{array}{l}285 \\
\text { CS }\end{array}$ & cs & $\begin{array}{l}275 \\
\text { CS }\end{array}$ & $\begin{array}{l}275 \\
\text { CS }\end{array}$ \\
\hline & & & & UED FOR ESTIMATE & & & & PAgE 10 \\
\hline
\end{tabular}


CAse 3

CAse 4

Case 5

CAse 6

CASE $\mathbf{7}^{\text {: }}$

10.04 WHSTERINJECTIONPUMP

TYPE

DESIGN FLOWAATE (GPM)

HEAO (FT)

DENSITY (LB/FT'^3)

VISCOSITY (CP)

POWEA (BHP)

EFFICIENCY (\%)

DESIGNT(F)

SUCTION P (PSIA)

MATEAIAL

10.65 OZ.65 AEELUX PUMP

TYPE

DESIGN FLOWAATE (GPM)

HEAD (FT)

DENSITY (LERTA3)

VISCOSITY (CP)

POWER (BHP)

EFFICIENCY
DESIONT
(F)

DESION T (F)

MATERIAL

10.75 OllYwateasump pUMP

TYPE

INLETP (PSIA)

MEAD (FT)

EFFICIENCY ( $\left.\boldsymbol{Y}_{6}\right)$

FLOWAATE (GPM)

BAAKE HORSEPOWER (BHP) MATERIAL.

15.10 IMCINERATOR

TYPE

HEAT LOAD (MMBTU/HR)

EXCESS AIA (Y)

OPEAATINO TEMPERATUAE (F)

WASTE GAS FLOW (LBMOLAA)

CHA FUEL GAS FLOW (LBNOLNA)

COMB. AIA BLOWER POWER (HP)

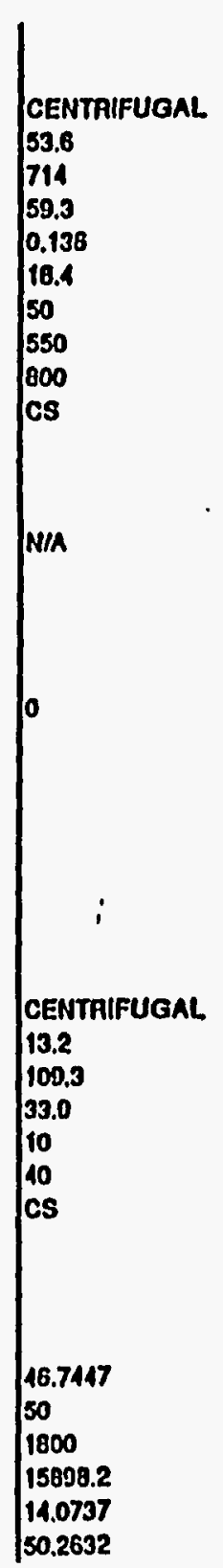

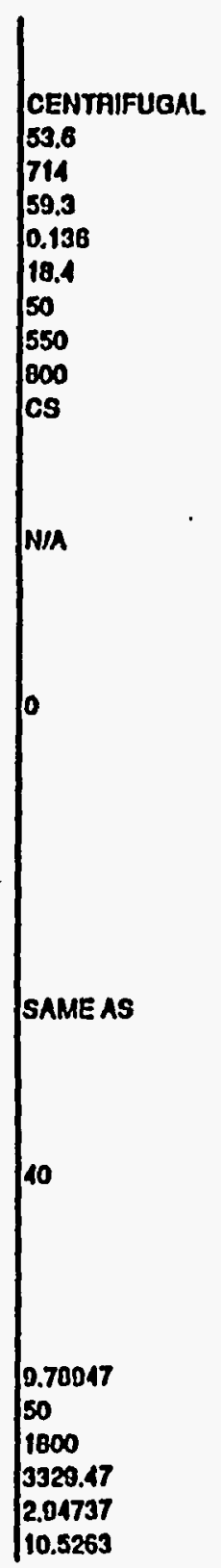

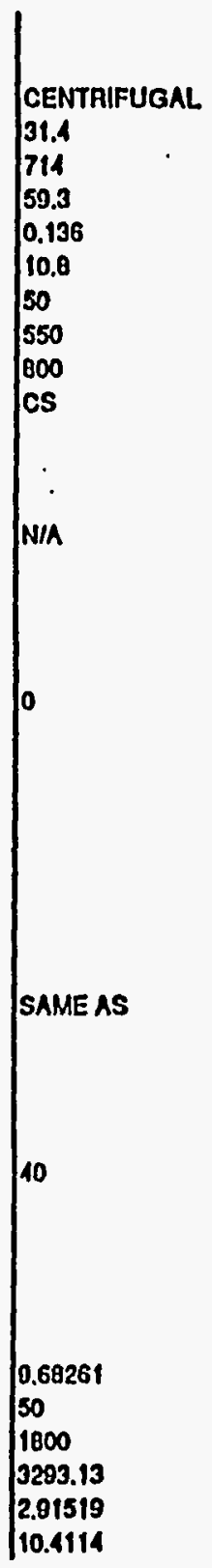

CENTRIFUGAL
48.1
725
58.5
0.136
16.6
50
550
600
CS

CENTRIFUGAL
18.9
714
59.3
0.136
6.5
50
550
800
$C 5$

CENTRIFUGAL

CENTAIFUGAL

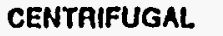

N/A

18.6

714

0.136

6.39683

50

550

CS

N/A

18.6

714

59.3

0.136

6.39603

50

550

CS

318

120
55.8

0.8

17.2274

50

.20

800
CS

SAME AS

SAME AS

SAMEAS

SAME AS

40

40

40

12.6606

50

1800

1305.08

3.8118

13.6136

ISSUED FOA ESTIMUTE 
15.20 STEAM
TYPE

RESPONSE TIME (MIN)

NORMAL \& FULL.

BFW FEED RATE (LBSHA)

SAT. WATER DENSITY (LBSIGAL)

TOTAL VOLUME (GAL)

DIAMETEA (FT)

LENGTH(FT)

DESIGN PAESSURE (PSIG)

DESIGN TEMPERATURE (F)

MATEAIAL.

15.10 UIIUTYOULHEATER

TYPE

HEATER KW

DESIGN T (F)

DESION P (PSIO)

mateaIAL

21.01 OL10.COMPBESSOR INTERCOOLER

ปั TYPE

DUTY (MMBTUMA)

U ASSUMED (BTUAR.FTA2.F)

LMOT (F)

AREA (FTA2) + $20 \%$ S.F.

SHELL DIAMETEA (IN)

SHELLLENGTH (FT)

TUBE LENGTH (FT)

NUMBER OF TUBES

TUBE OD (IN)

COOLINO WATER FLOW (GPM)

$\begin{array}{ll}\text { SHELL DESIGNTIF) } & \\ & \text { DESIGNP(PSIO) } \\ & \text { MATERIAL }\end{array}$

TUBES DESIGNT(F) DESIGN P (PSIG) MATEAIAL
CAsE 1

CASE 2

CASE 3

CAse 4

CASE 5

CASE O

CASE 7

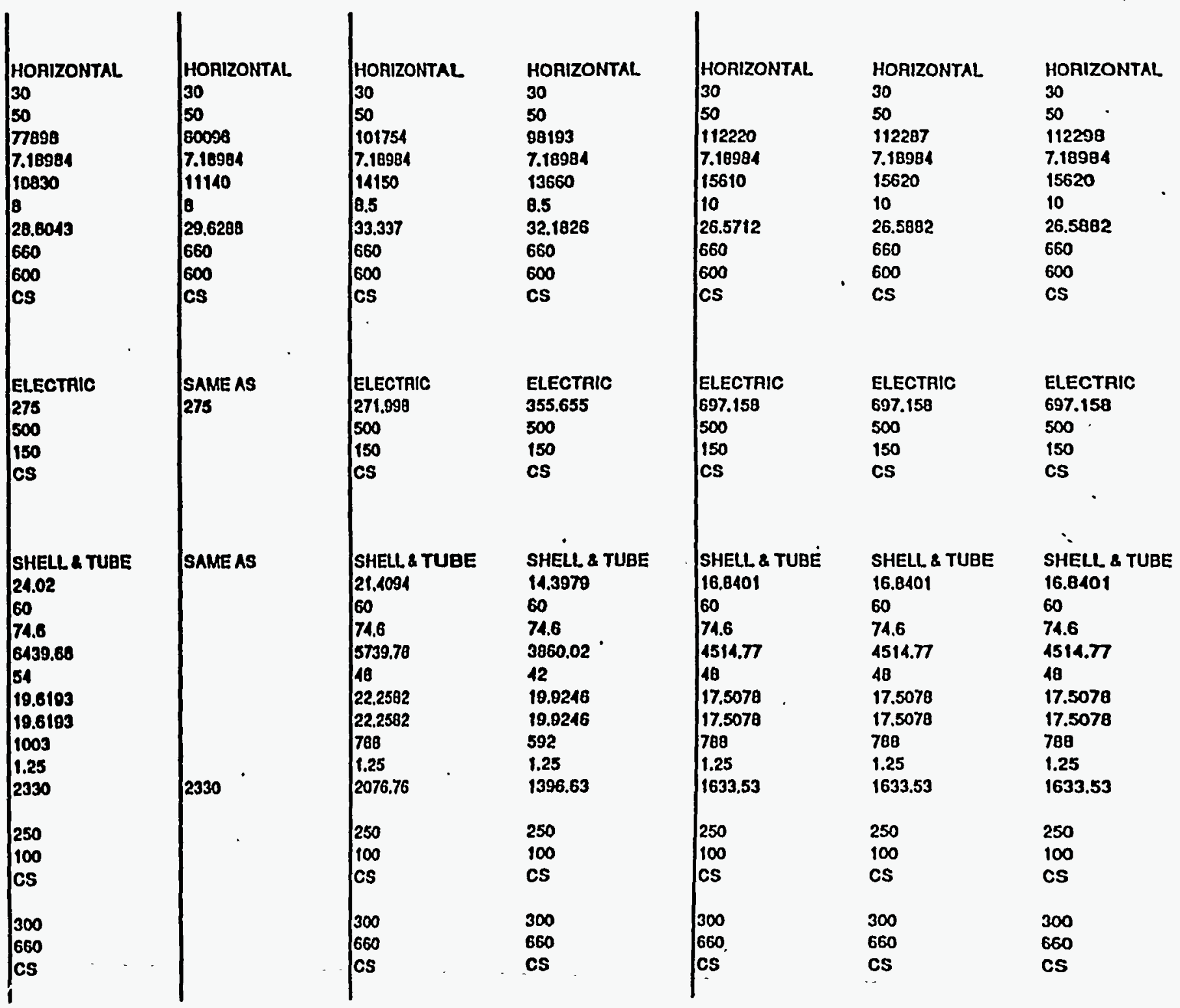

ISSUED FOR ESTIMATE 
TABLE 4: EQUIPMENT SPECIFICATIONS

CAse 1

CAsE 2

CASE 3

CAsE 4

CASE 5

CASE 6

CASET

21.02 OLWOCOMPAESSORAECYCLLECHILEA

TYPE

DUTY (MMBTUAH)

UASSUMED (BTUAR.FT^2-F)

LMDT (F)

AREA (FT^2) $+20 \%$ S.F

SHELL DIAMETER (IN)

SHELLLLENGTH (FT)

TUBE LENGTH (FT)

NUMBER OF TUBES

TUBE OD (IN)

COOLING WATER FLOW (GPM)

SHELL DESIGNT (F)

DESIGN P (PSIG)

MATERIAL

TUBES DESIGNT (F)

DESIGN P (PSIG)

MATERIAL

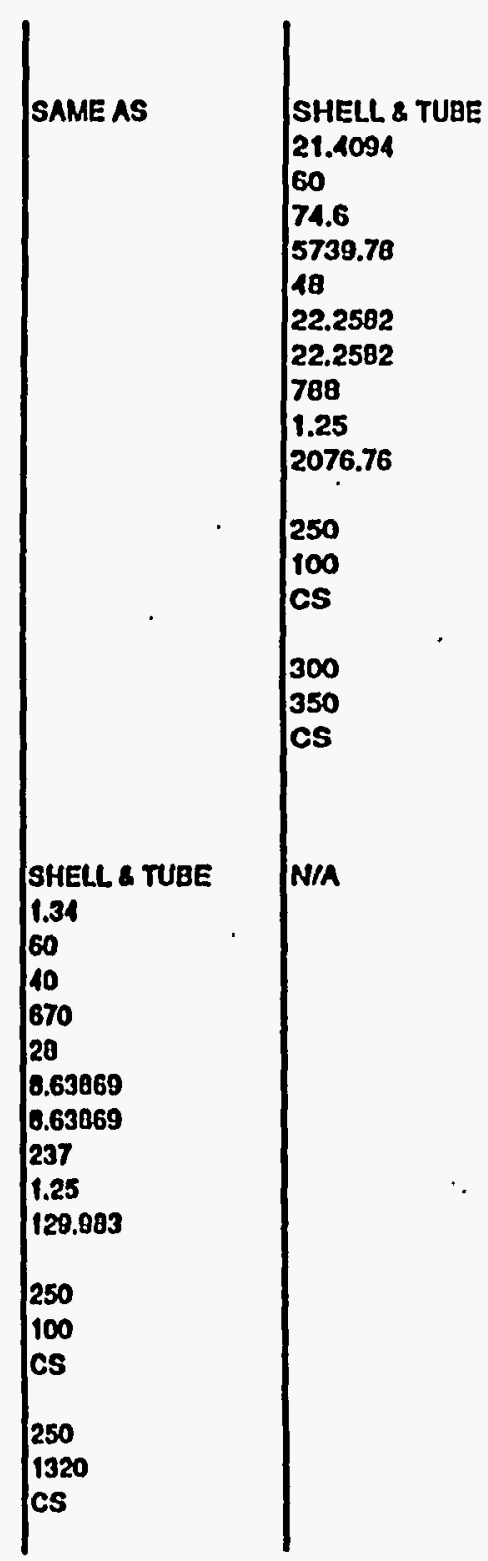

SHEUL \& TUBE

602

74.6

8430.68

54

19.6193

19.6183

1003

1.25

2330

250

100

cs

300

350

21.03 OL2OCOMPAESSOABECYCLE CHILLEA

$\stackrel{\text { TVPE }}{\circ \quad \text { DUTY (MMBTUHA) }}$

U ASSUMED (BTUMR-FT^2-F)

LMDT (F)

AREA (FTA2) + $20 \%$ S.F.

SHELL OIAMETER (IN)

SHELL.LENGTH (FT)

TUBE LENOTH(FT)

NUMBEA OF TUBES

TUBE OD (IN)

COOLING WATEA FLOW (GPM)

SHELL DESIGNTIF)

DESIGN P (PSIG)

MATERIAL

TUGES DESIGNTIF)

DESIGN P (PSIG)

MATERIAL

SHELL \& TUBE
1.6
60
40
600
28
10.3149
10.3149
237
1.25
155.204
250
100
$C S$
250
1320
25

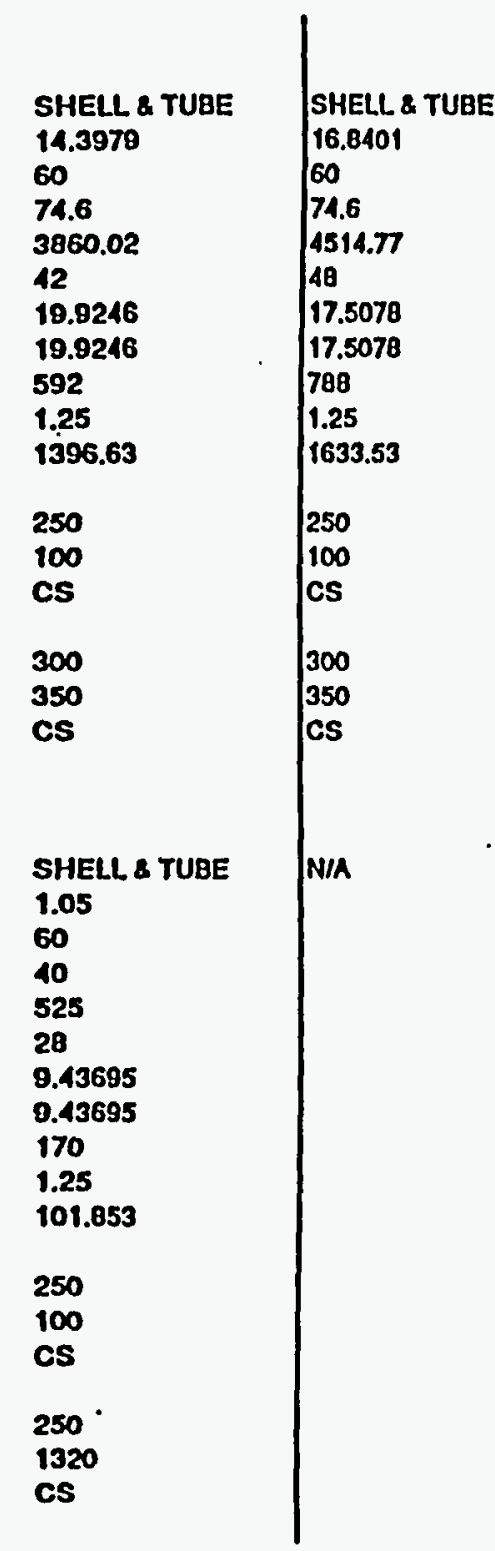

SHELL \& TUBE

16.8401

SHELL \& TUBE

$74.6 \quad 60$

$4514.77 \quad 4514.7$

48

17.5078

17.5078

788

1.25

1633.53

42

23.3042

23.3042

592

1.25

250

1633.53

250

$100-100$

cs cs

300

350

300

CS

N/A

N/A 
TABLE 4: EQUIPMENT SPECIFICATIONS

case 1

CASE 2

CASE 3

GASE 4

CASE 5

CASEO

CASE 7

21.11 BEACTOREEEDMRQODUCTDEPHLEGMATOB

TYPE

DUTY (MMBTUMA)

UASSUMED (BTUAR.FTA2.F)

LMTO $(F)$

AREA $\left(F T^{\wedge} 2\right)+20 \%$ S.F

SHELL DIAMETER (IN)

SHELL HEIGHT (FI)

TUBE HEIGHT (FT)

NUMBEA OF TUBES

TUBE OD (IN)

SHELL DESIGNT(F)

DESIGN P (PSIG)

MATERIAL.

TUBES DESIGNT (F)

DESIGN P (PSIG)

MATERIAL

21.20 BEACTOBINTERNALHEATEXCHANGEB

$\infty$ HEAT DUTY (MMBTU/HA)

STEAM PRODUCED (LBS/HA)

Uovorall (BTUMAR-FT^2-F) with factor

LMTD (F)

AREA (FTA2)

PIPES PRODUCED STEAMP (PSIG)

EXTEANAL DESIGNP (PSIG)

INTERINAL DESION P (PSIO)

DESIGNT (F)

MATEAIA

- PIPES

PIPE LENGTH (FT)

NOMINAL PIPE OD (IN)

\% of SLUAaY Volume

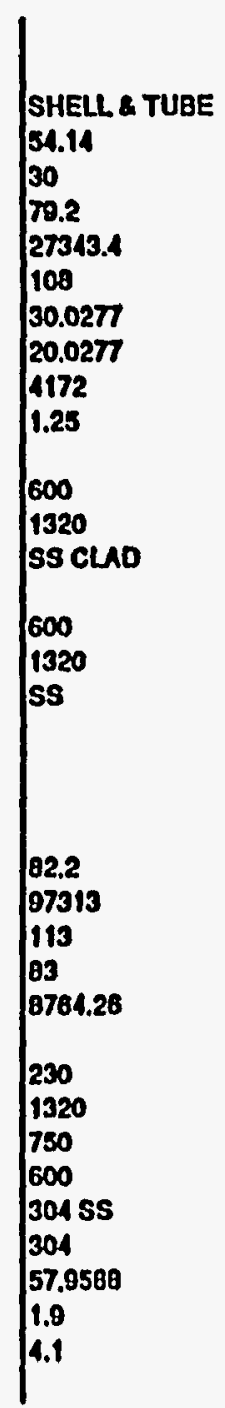

\begin{tabular}{|l} 
SHELL \& TUBE \\
22.65 \\
30 \\
81.4 \\
11130.2 \\
72 \\
28.7194 \\
18.7491 \\
1811 \\
1.25 \\
600 \\
1320 \\
$S S \mathrm{CLAD}$ \\
600 \\
1320 \\
SS \\
\\
\\
104.5 \\
123606 \\
104 \\
82.7 \\
12150 \\
230 \\
1320 \\
750 \\
600 \\
$304 \mathrm{SS}$ \\
361 \\
67.6625 \\
1.9 \\
6.6 \\
\end{tabular}

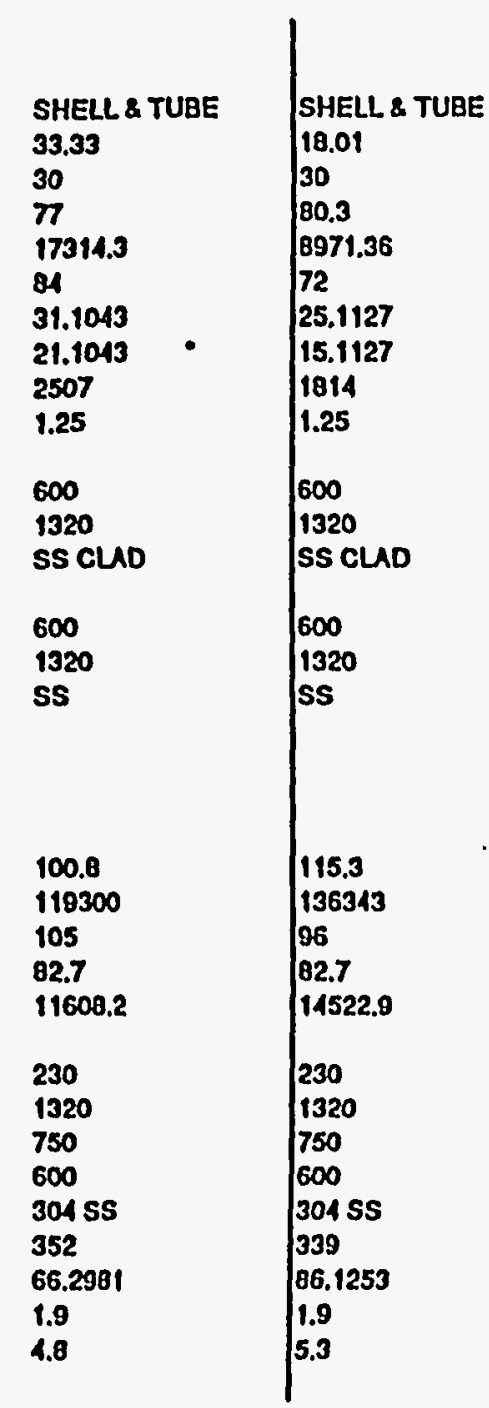

18.01

30

80.4

8960.2

72

25.0939

15.0939

1814

1.25

600

1320

SS CLAD

600

1320

SS

115.3
136424
96
82.7
14522.0

230
1320
750
600
30455
339
86.1253
1.9
5.3

115.3
136424

82.7
14522.0

230

600

$304 \mathrm{SS}$

85.1253

5.3
SHELL \& TUBE

30

80.4

8955.22

25.0855

15.0955

1814

1,25

600

1320

SS CLAD

600

1320

ss

115.3
136438
96
82.7
14522.9

230
1320
750
600
30455
339
86.1253
1.9
5.3

115.3

045

6.1253

5.3 
CABE 1

CASE 2

CASE 3

CASE 4

CASES

CAsE 6

CASE 7

21.31 METHANOLERODUCTCONDENSER

TYPE

DUTY (MMBTU/HA)

U ASSUMED (BTUMA.FTA2.F)

LMTD (F)

AREA (FTA2) + $20 \%$ S.F.

SHELL DIAMETER (IN)

SHELLLENGTH (FT)

TUBE LENGTH (FT)

NUMBER OF TUBES

TUBE OD (IN)

COOLINO WATER FLOW (GPM)

SHELL DESIGNT TF)

DESIGN P (PSIG)

MATERIAL.

\begin{tabular}{|l} 
\\
SHELL \& TUBE \\
81.09 \\
60 \\
72.9 \\
22246.0 \\
78 \\
31.7522 \\
31.7522 \\
2141 \\
1.25 \\
7865 \\
250 \\
100 \\
$C S$ \\
400 \\
1320 \\
304 SS \\
\\
SHELL \& TUBE \\
10.02 \\
60 \\
31.45 \\
6372.02 \\
51 \\
19.4132 \\
19.4132 \\
1003 \\
1.25 \\
.100 \\
1320 \\
$5 S$ \\
.100 \\
1320 \\
$5 S$ \\
\\
\end{tabular}

\begin{tabular}{|l} 
SHELL \& TUBE \\
29.99 \\
60 \\
70.1 \\
8556.35 \\
60 \\
21.1360 \\
21.1368 \\
1237 \\
1.25 \\
2908 \\
\\
250 \\
100 \\
CS \\
100 \\
1320 \\
304 SS \\
\\
SHELL \& TUBE \\
9.66 \\
60 \\
35.6 \\
5539.33 \\
51 \\
16.8763 \\
16.8763 \\
1003 \\
1.25 \\
-100 \\
1320 \\
SS \\
.100 \\
1320 \\
SS \\
\\
\end{tabular}

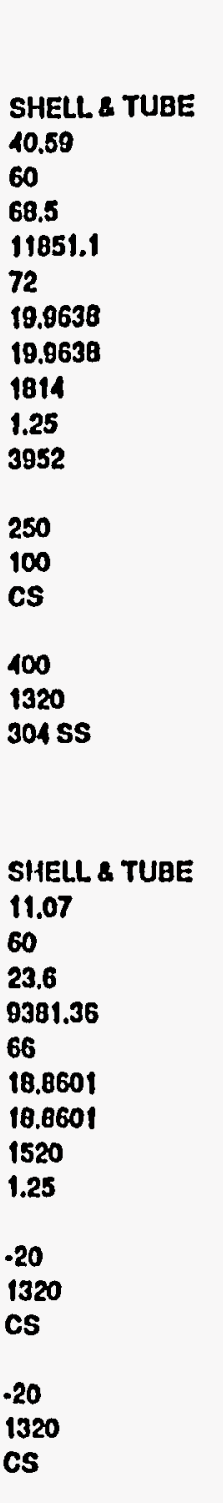

\begin{tabular}{|l} 
SHELL \\
11.12 \\
60 \\
128 \\
1737.5 \\
35 \\
12.7324 \\
12.7324 \\
417 \\
1.25 \\
1079 \\
\\
250 \\
100 \\
$C S$ \\
400 \\
1320 \\
304 SS \\
\\
NIA
\end{tabular}

SHELL \& TUBE

20.75

60

6355.28

54

54
19.3622

19.3622

1003

1.25

2012

250

100

CS

400

1320

304 SS

SHELL \& TUBE

7.76

60

19

0160.42

60

20.1785

20.1785

1237

1.25

$-20$

350

sS

.20

1320

SHELL \& TUBE

20.74

60
65.6

65.6

6323.17

19.2644

19.2644

1003

1.25

2011

250

100

CS

400

1320

304 SS

DESIGN P (PSIG)

MATERIAL

SS

SHELL \& TUBE

7.8

60

19

8210.53

60

20.2826

20.2826

1237

1.25

-20
350

.20

1320

CS 
TABLE 4: EQUIPMENT SPECIFICATIONS

CASE 1

CASE 2

CASE3

CASEA

CASE 5

CASE 0

CASE T

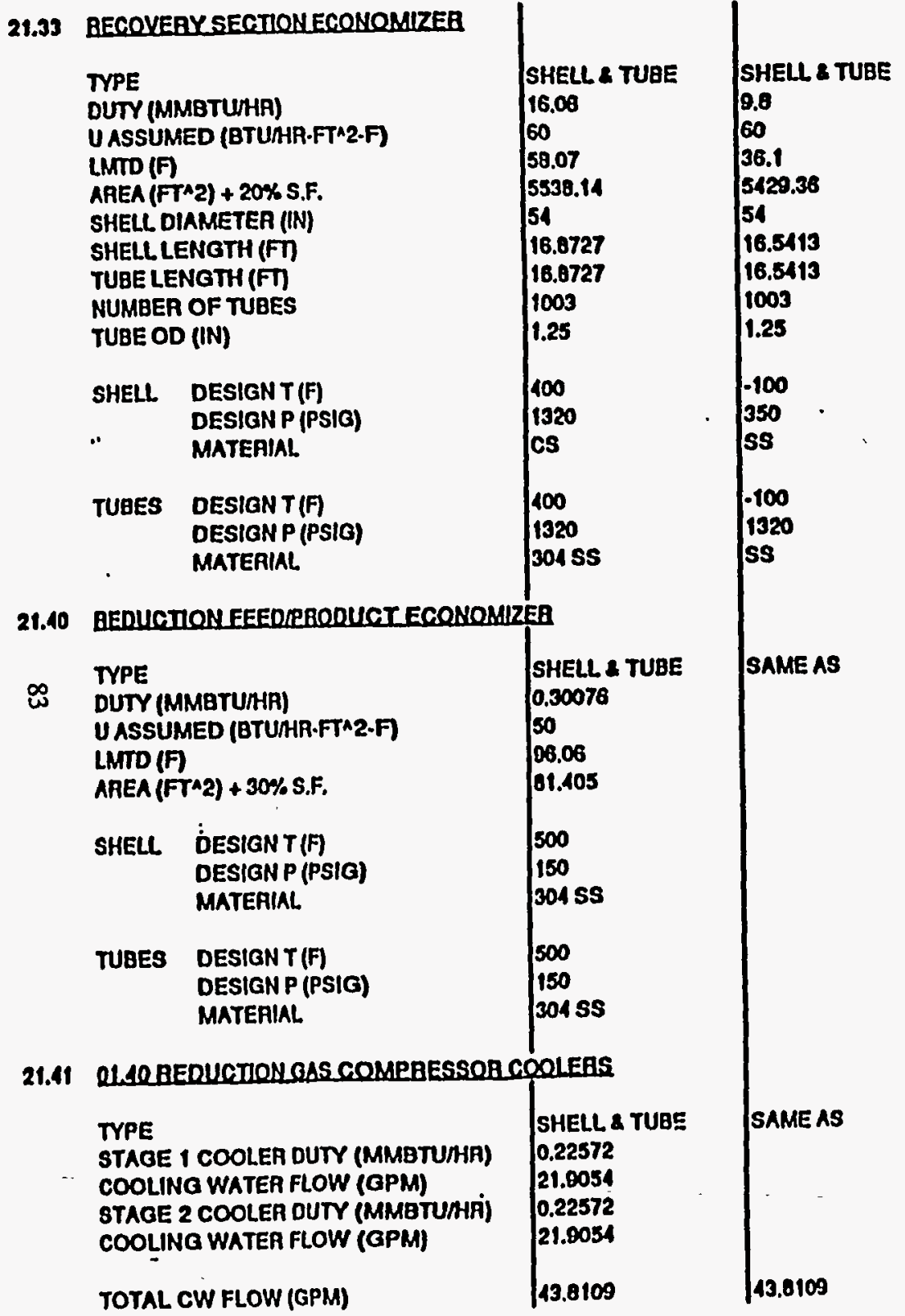

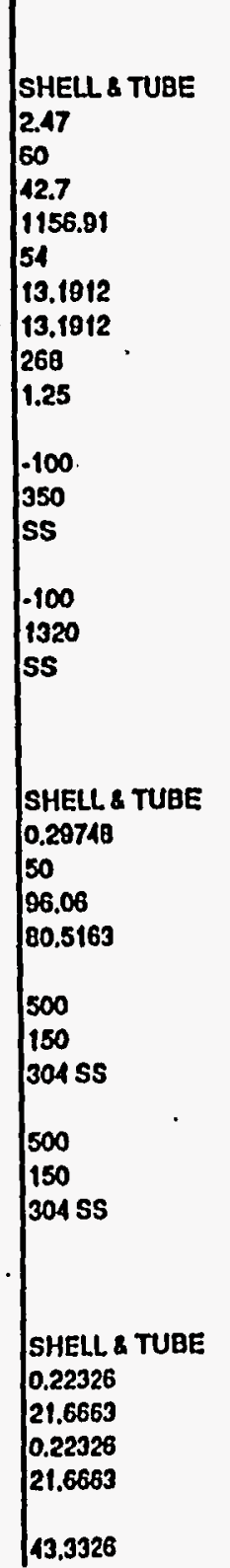

\begin{tabular}{|c|c|}
\hline $\begin{array}{l}\text { SHELL \& TUBE } \\
6.14\end{array}$ & SHELL \& TUBE \\
\hline $\begin{array}{l}6.14 \\
60\end{array}$ & 6.8 \\
\hline $\begin{array}{l}21.9 \\
5607.31\end{array}$ & $\begin{array}{l}60 \\
70.9\end{array}$ \\
\hline $\begin{array}{l}5607.31 \\
54\end{array}$ & $\begin{array}{l}1918.19 \\
33\end{array}$ \\
\hline 17.0834 & 16.419 \\
\hline 17.0034 & 16.119 \\
\hline 1003 & 357 \\
\hline 1.25 & 1.25 \\
\hline $\begin{array}{l}-100 \\
350 \\
5 S\end{array}$ & $\begin{array}{l}20 \\
350 \\
C 5\end{array}$ \\
\hline $\begin{array}{l}-100 \\
1320 \\
S S\end{array}$ & $\begin{array}{l}20 \\
1320 \\
C S\end{array}$ \\
\hline $\begin{array}{l}\text { SHELL \& TUBE } \\
0.38897 \\
50 \\
96.06 \\
105.28\end{array}$ & $\begin{array}{l}\text { SHELL \& TUBE } \\
0.76246 \\
50 \\
96.06 \\
206.371\end{array}$ \\
\hline $\begin{array}{l}500 \\
150 \\
304 \text { SS }\end{array}$ & $\begin{array}{l}500 \\
150 \\
30455\end{array}$ \\
\hline $\begin{array}{l}500 \\
150 \\
30155\end{array}$ & $\begin{array}{l}500 \\
150 \\
304 \text { SS }\end{array}$ \\
\hline $\begin{array}{l}\text { SHELL. \& TUEE } \\
0.29103 \\
28.3301 \\
0.29103 \\
28,3301\end{array}$ & $\begin{array}{l}\text { SHELL \& TUBE } \\
0.57221 \\
55.5329 \\
0.57224 \\
55.5320\end{array}$ \\
\hline 56.6602 & 111.066 \\
\hline
\end{tabular}

SHELL \& TUBE

6.88

60

21

54

17.4674

17.4674

1003

1.25

$-100$

350
SS

SS

.100

1320
SS

SHELL \& TUBE

.8

23.84

5780.59

17.6357

17.6357

1003

1.25

.100

-100
350

SS

$-100$

1320

ss

SHELL \& TUBE

0.76246

50

96.06

206.371

0.76246

50

206.371

500
150

304 SS

500

150

500

150
304

500

500
150

304 SS

304 SS

ISSUED FOR ESTIMATE

$\begin{array}{ll}\text { SHELL \& TUBE } & \text { SHELL \& TUBE } \\ 0.57221 & 0.57224 \\ 55.5329 & 55.5329 \\ 0.57221 & 0.57221 \\ 65.5329 & 55.5329 \\ 111.066 & 111.066\end{array}$

PAGE 16 
TABLE 4: EQUIPMENT SPECIFICATIONS

CASE 1

CASE 2

CASE 3

CAsE 4

CASE 5

CASE 8

CASE 7

21.53 UTIUITYOULAIR COOLEB

TYPE

DUTY (MMBTU/HA)

AAEA (FT^2) + 20\% S.F.

FAN MOTOR (BHP)

TUBES DESIGNT(F)

DESIGN P (PSIG)

MATERIAL

\begin{tabular}{|l} 
SAME AS \\
5.26514 \\
\\
SAMEAS \\
\\
\\
01.1122 \\
SHELL TUBE \\
0.03965 \\
60 \\
27.28 \\
22.0891 \\
12 \\
2.3392 \\
2.3392 \\
38 \\
1.25 \\
3.86004 \\
250 \\
100 \\
CS \\
300 \\
500 \\
CS \\
\\
\end{tabular}

\begin{tabular}{|l} 
AIR COOLER \\
0.19454 \\
1521.21 \\
5.22744 \\
500 \\
150 \\
CS \\
\\
SAME AS \\
\\
\\
91.4122 \\
\\
SHELL \& TUBE \\
0.03922 \\
60 \\
27.26 \\
28.7715 \\
8 \\
7.32661 \\
7.32661 \\
12 \\
1.25 \\
3.81791 \\
250 \\
100 \\
CS \\
300 \\
50 \\
$6 S$ \\
\end{tabular}

\section{AIA COOLER \\ 0.64665}

1989.08

6.83522

21.60

INSTRUMENTAIA COMPAESSOR COOLEAS

STAGE I COOLEA DUTY (MMBTUNAA)

COOLING WATER FLOW (GPM)

STAGE 2 COOLEA DUTY (MMBTUMA)

COOLINO WATER FLOW (GPM)

AFTERCOOLER DUTY (MMBTUMA)

COOLING WATER FLOW (GPM)

$\$$ TOTAL CW FLOW (GPM)

21.61 OL3OAECYCLECOOLEB

TYPE

DUTY (MMETU/AR)

U ASSUMED (BTUAR.FT^2.F

LMTD (F)

AREA (FT^2) + $20 \%$ S.F.

SHELL DIAMETER (IN)

SHELLLENGTH (FT)

TUBE LENGTH (FT)

NUMBEA OF TUBES

TUBE OD (IN)

COOLING WATER FLOW (GPM)

SHELL DESIGNT (F)

DESIGN P (PSIG)

MATEAIAL

TUBES DESIGNT(F)

DESIGN P (PSIG)

- mateaial

SHELL R TUBE
0.34253
33.2400
0.29971
29.0057
0.29971
20.0057
91.4122

SHELL 2 TUBE
0.18932
60
27.26
138.9
12
11.1697
11.1607
38
1.25
18.4317
250
100
$C S$
300
50
$C S$

500
150
CS

SAME AS




91.4122

SHELL R TUBE
0.05128
60
27.26
37.6206
B
9.58002
9.58002
12
1.25
4.99216
250
100
CS
300
50
CS

\begin{tabular}{|l} 
AIR COOLER \\
1.26756 \\
3899.02 \\
13.3985 \\
500 \\
150 \\
CS \\
\\
SAME AS \\
\\
\\
91.4122 \\
\\
$5 H E L L \&$ TUBE \\
0.10051 \\
60 \\
27.26 \\
73.7444 \\
12 \\
5.03016 \\
5.93016 \\
38 \\
1.25 \\
9.78568 \\
250 \\
100 \\
CS \\
\\
\\
\\
\\
\end{tabular}

AIR COOLEA

1.26756

3899.02

13.3985

500

150

CS

SAMEAS

SAMEAS

91.1122

SHELL \& TUBE

0.10051

60

27.26

73.7444

8

18.7708

18.7780

12

1.25
9.78568

250

100

cs

300

50
CS

1.4122

$\because$

SHELL \& TUBE 0.10051 60

27.26

73.7444

18.7788

18.7780

12

1.25

9.78568

250

100

CS

300

50
C5 
CASE 3

CASE 4

CAsE 5

CASE O

CASEY

21.71 LOUURPRODUGTCOOLER

TYPE ‥

DUTY (MMBTUNA)

UASSUMED (BTUHA.FTA2-F)

LMTD (F)

AREA (FT^2) + 20\% S.F.

SHELL DIAMETER (IN)

SHELLLENGTH (FT)

TUBE LENOTH (FT)

NUMBER OF TUBES

TUBE OD (IN)

COOLING WATER FLOW (GPM)

SHELL DESIGNTIF)

DESIGN P (PSIG)

MATERIAL

TUBES DESIGNTIF)

DESIGN P (PSIG)

MATERIAL

21.72 LQUURAECYGLLECOOLEB

品 DUPE (MMBTUMA)

U ASSUMED (BTUAA.FTA2.F)

U ASSUMED

AREA (FT ${ }^{\text {A2 }}$ ) + 20\% S.F.

SHELL DIAMETER (IN)

SHELL LENGTH (FN)

TUBE LENGTH (FT)

NUMBER OF TUBES

TUBE OD (IN)

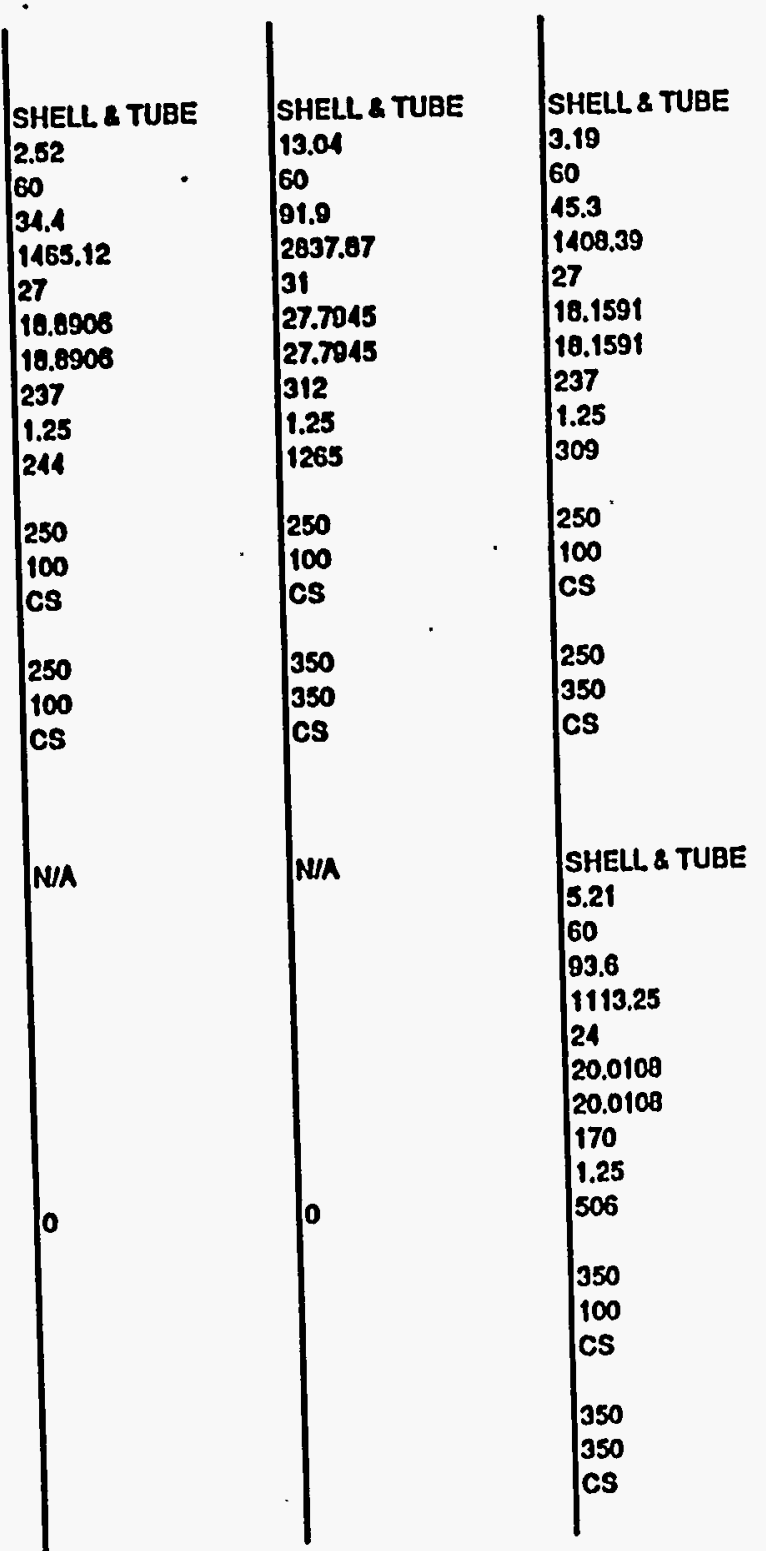

SHELL \& TUBE $\mid$ NIA N/A

N/A

3.39

60

16.5

27

18.7996

18.7998

237

1.25

328.373

0

250

100

cS

250

550

cS

COOLIN O WATER FLOW (GPM)

SHELL DESIGNTIF)

DESIGN P (PSIG)

MATERIAL

TUBES DESIONTT(F)

DESIGN P (PSIO)

MATEAIAL

\begin{tabular}{l|l} 
SHELL \& TUBE & NIA \\
13.23 & \\
60 & \\
46.2 & \\
5727.27 \\
54 \\
17.4489 \\
17.4489 \\
1003 \\
1.25 \\
0 \\
350 \\
350 \\
CS \\
350 \\
350 \\
CS
\end{tabular}

N/A

N/A

0

0

ISSUED FOR ESTIMATE 
21.73 LOUIR RECYCLE CBOSS EXCHANGEA

TVPE

DUTY (MMBTU/HA)

U ASSUMED (BTUAA.FTA2.F

LMTO (F)

AREA (FTA2) + $20 \%$ S.F.

SHELL DIAMETER (IN)

SHELL LENGTH (FT)

TUBE LENGTH (FT)

NUMBER OF TUBES

TUBE OD (IN)

SHELL DESIGNT (F)

DESIGN P (PSIG)

MATEAIAL

TUBES DESIGNT(F) DESIGN P (PSIG)

$\infty$ MATEAIAL

\subsection{LOUIRE EUEL YAPOAIZOR}

\section{TYPE}

OUTY (MMBTUHR)

UASSUMED (BTUNA.FT^2.F)

LMTD (F)

AREA (FT^2) + 20\% S.F.

SHELL DIAMETER (IN)

SHELLLENGTH (FT)

TUBE LENGTH (FT)

NUMBER OF TUBES

TUBE OD (IN)

STEAM FLOW (WHA)

STEAM PRESSURE (PSIG)

SHELL DESIGNT(F)

DESIGN P (PSIG) MATEAIAL

TUBES DESIGNT(F)

DESIGN P (PSIG)

MATERIAL

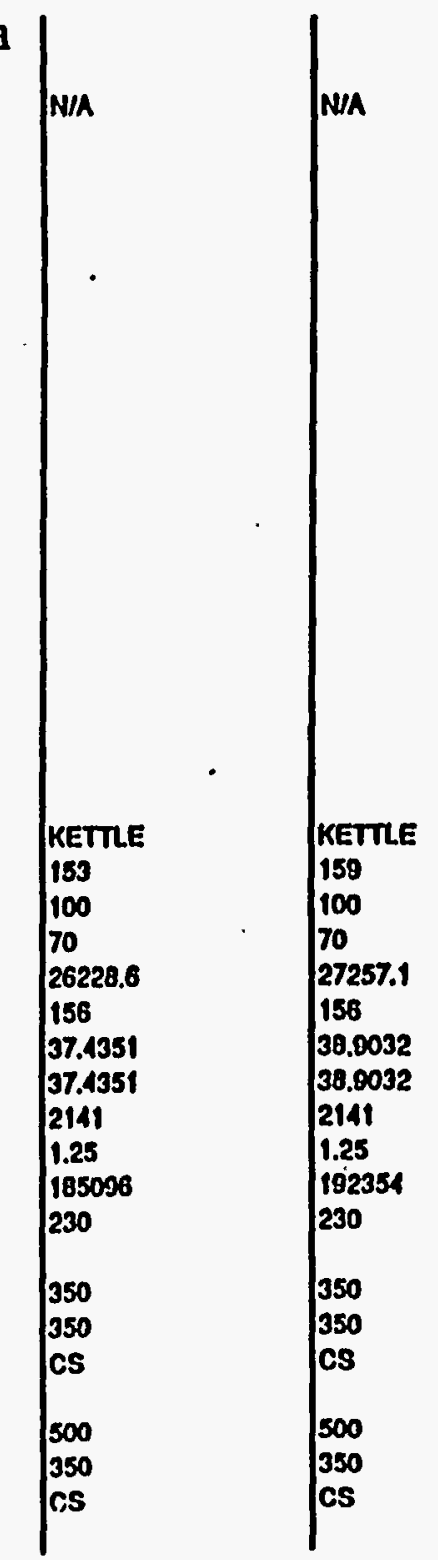

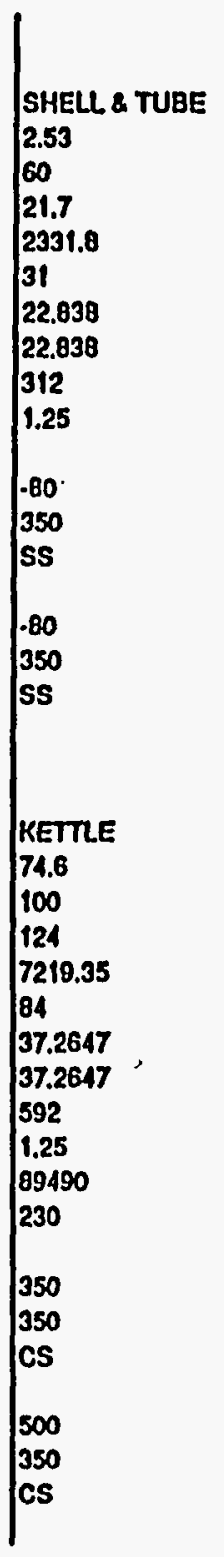

N/A

N/A

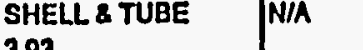

3.83

24.1 3261.41

37

22.3456

22.3456

116

1.25

20

350

1320
c5

CS

\begin{tabular}{l|l} 
KETTLE & N/A \\
79 & \\
100 \\
121 \\
7834.71 \\
81 \\
10.1411 \\
10.1411 \\
592 \\
1.25 \\
93517 \\
230 \\
350 \\
350 \\
CS \\
500 \\
350 \\
CS
\end{tabular}

N/A

KETILE
34.9
100
230
1820.87
66
15.5859
15.5859
357
1.25
11342
230
.350
350
$C S$
500
350
CS


TABLE 4: EQUIPMENT SPECIFICATIONS

CAse 1

CASE 2

CASE 3

CASE 4

CASE 5

CASE 6

CASE 7

22.02 EEED OAS COMP 2ND STAGE KNOCKOUU

TYPE

VESSELLI.D. (FT)

T-T HEIGHT (FN)

DESIONT $(F)$

DESION P (PSIG)

VAPOR KY

\begin{tabular}{|c|c|}
\hline SAME AS & $\begin{array}{l}\text { VERTICAL } \\
7.25 \\
12.1 \\
300 \\
600 \\
0.19 \\
C S\end{array}$ \\
\hline $\begin{array}{l}\text { VEATICAL } \\
0.7 \\
13.3 \\
100 \\
1320 \\
0.2 \\
\text { SS CLAD ON CS }\end{array}$ & $\begin{array}{l}\text { YERTICAL } \\
6.1 \\
10.4 \\
100 \\
1320 \\
0.2 \\
C S\end{array}$ \\
\hline $\begin{array}{l}\text { VERTICAL } \\
5 \\
0.5 \\
-100 \\
1320 \\
0.21 \\
59\end{array}$ & $\begin{array}{l}\text { VEATICAL } \\
5.7 \\
10 \\
-20 \\
1320 \\
0.21 \\
C S\end{array}$ \\
\hline $\begin{array}{l}\text { VEATICAL } \\
2.5 \\
8.2 \\
200 \\
350 \\
0.03 \\
C S\end{array}$ & NIA \\
\hline
\end{tabular}

VERTICAL
VE
6
10.9
300
600
0.19
CS


VEATICAL
7.5
11.5
100
1320
0.2
SS CLAD ON


VERTCAL
6.1
10.6
-20
1320
0.2
CS

100
VEATICAL
3.5
0.06
CS

150

22.11 H.P.LOULS SEPARATOR

$\infty$ TYPE

VESSELID (FI)
T.THEIGHT (FT)

DESIGN T (F)

DESIGN P (PSIG)

VAPOA KV

MATERIAL

22.12 MPFLASHEOTIABSOABEB

TYPE

VESSEL ID (FT)

T-T HEIGHT (FT)

DESIGN T (F)

DESION P (PSIG)

VAPOR KV

MATERIAL

VEATICAL
8
12.6667
300
600
0.10
$C S$

VERTCAL
10
13.5
100.0
1320
0.19
SS CLAD ONCS

NIA

VEATCAL
2.5
0.6
200.0
350.0
0.0
CS

VERTICAL
6.5
11.1
300
600
0.2
CS

VEATICAL
5.3
9.7
400
1320
0.2
SS CLAD ONC

N/A
VERTICAL
6.8
11.7
-20
350
0.2
CS

VERTICAL
6.5
11.4
300
600
0.2
CS

VERTICAL

6.5

11.4

300

600
0.2

0.2
CS

S

VERTICAL VEATICAL

5.3

- 9.6

400

1320

0.2

5.3

9.6

400
1320

0.2

SS CLAD ON CS

VERTICAL VERTICAL

$\begin{array}{ll}4.5 & 4.5 \\ 9 & 9 \\ 20 & 20 \\ 1320 & 1320 \\ 0.2 & 0.2 \\ C S & C S\end{array}$

CS

cs

$\begin{array}{ll}\text { VERTICAL } & \text { VERTICAL } \\ 5.5 & 5.5 \\ 10.5 & 10.5 \\ .100 & -100 \\ 350 & 350 \\ 0.2 & 0.2 \\ \text { SS } & \text { SS }\end{array}$


22.15 LPELASHPOT

TYPE

VESSEL ID (FT)

T-T HEIGHT (FT)

DESIGNT TF)

DESIGN P (PSIG)

VAPOA KV

MATEAIAL

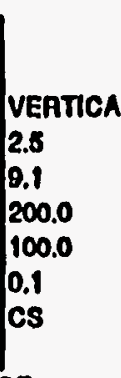

22.40 HERUGTIONCONDENSATEACCUMULATOR

TYPE

VESSEL. ID (FI)

T-T HEIGHT (FT)

DESIGNT(F)

DESIGN P (PSIG)

YAPOA KV
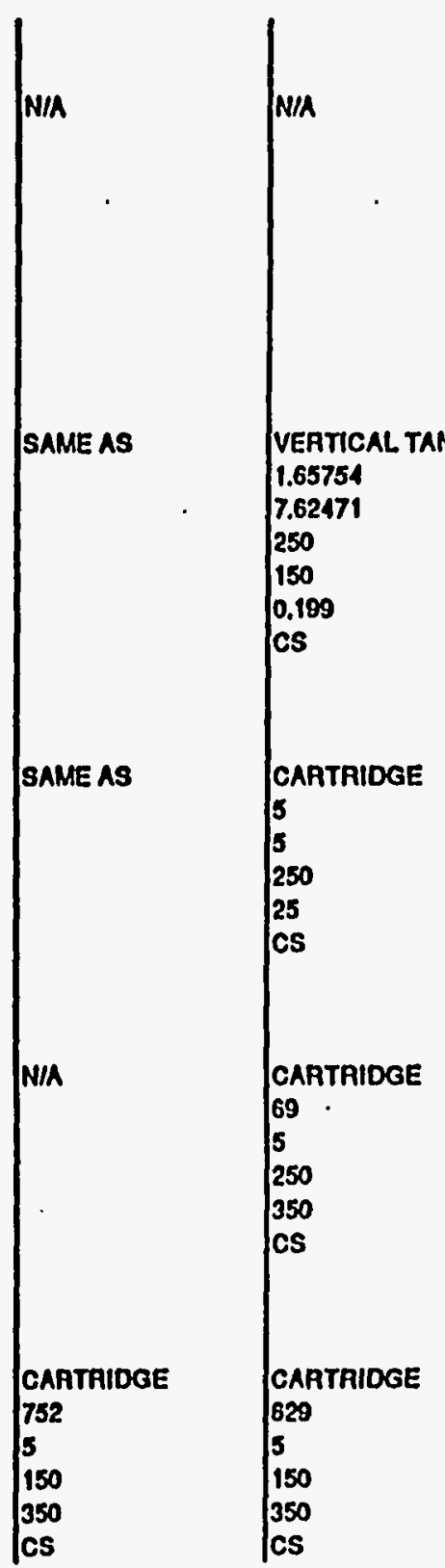

N/A

NIA

$N / A$

MATEAIAL

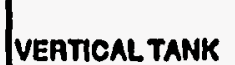

22.50 BECLAIMEDOILFILTER

FLOWAATE (GPM)

PARTICLE SIZE RATING (MICRON)

DESIGN T (F)

DESION P (PSIG)

MATERIAL

22.51 LOUUD PAODUCT/AECYCLE EILTER

TYPE

FLOWAATE (GPM)

PAATICLE SIZE RATINO (MICAON)

DESIGN T (F)

DESIGN P (PSIG)

MATEAIAL.

22.52 IURBINE EUELEILTER

TYPE

FLOWRATE (GPM)

PARTICLE SIZE RATING (MICAON)

DESIGN T (F)

DESIGN P (PSIG)

MATEAIAL.

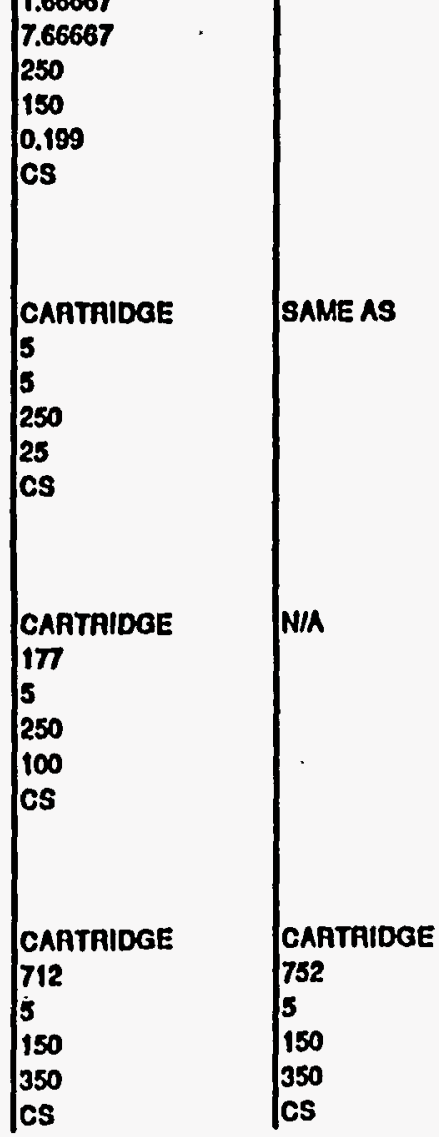

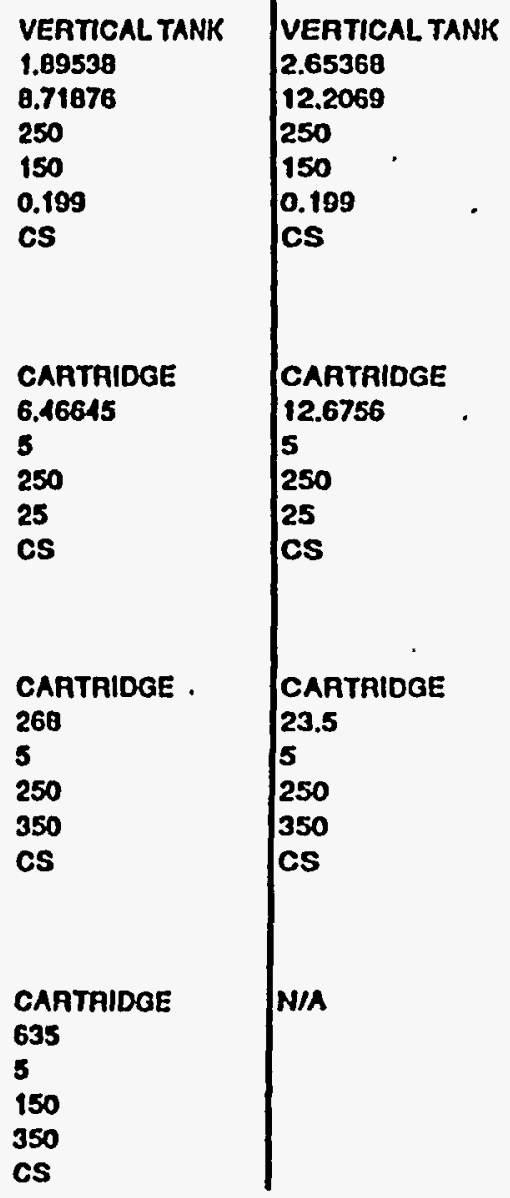

VEATICAL TANK 2.65368

12.2069

250

150

0.199

CS

CAATRIDGE

12.6756

5

250

CS

CARTAIDGE

24.1

250

350

CS

N/A
VEATICAL TANK 2.65368

2.2069

250

150

0.199

CS

\section{CARTRIDGE} 12.6756

5

250

25

cS

CAATRIDGE

24.2

250

350

CS

CARTRIDGE

613

5

150

350

CS 
TABLE 4: EQUIPMENT SPECIFICATIONS

CASE 1

CASE 2

CASE3

CASE 4

CASE 5

CASE 6

CASE 7

22.53 Q2. LOGUARD BED AEGENTO TUABINE FILTER

\section{TYPE}

FLOWRATE (LBMOLHA)

PARTCLE SIZE AATINO (MICGON)

FILTER DIAMETER (IN)

FILTEA HEIOHT (IN)

DESIGN T (F)

DESIGN P (PSIO)

MATERIAL.

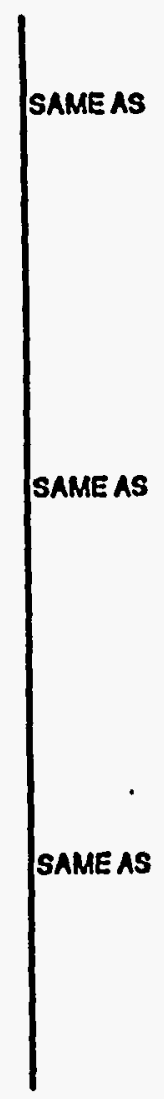

\begin{tabular}{|l} 
CAATAIDGE \\
19.0539 \\
5 \\
6 \\
18 \\
500 \\
600 \\
301 SS \\
\\
CAATRIDGE \\
10.0539 \\
5 \\
6 \\
18 \\
500 \\
1320 \\
304 SS \\
\\
SAMEAS \\
\end{tabular}

CARTAIDGE
12.8138
5
5
15
500
600
304 SS

CARTAIDGE
12.8138
5
6
18
500
1320
304 SS

\begin{tabular}{|l} 
CARTAIDGE \\
14.9873 \\
5 \\
6 \\
18 \\
500 \\
600 \\
304 SS \\
\\
CARTAIDGE \\
14.9873 \\
5 \\
6 \\
18 \\
500 \\
1320 \\
304 SS \\
\\
SAMEAS
\end{tabular}

CARTAIDGE 14.9873

5

6

18
500

600

304 SS

CARTRIDGE

11.9873

5

6

18

500

1320

301 SS

SAMEAS cartaioge

11.9873

5

500

600

304 SS

CARTAIDGE

14.9873

5

6

18

500

1320

304 SS

SAME AS

DESIGN \% FULL

TOTAL VOLUME (GAL)

WIDTH AND DEPTH (FT)

LENGTH (F

CONCAETE

\begin{tabular}{|l|l}
80 \\
10000 \\
10 \\
16.709 \\
CONCAETE
\end{tabular}


TABLE 4: EQUIPMENT SPECIFICATIONS

CAsE $i$

CASE 2

CAsE 3

CASE 4

CASE 5

Case 6

CASE $?$

27.10 LPMEOH AEACTOR

TYPE

FEED AATE (LB-MOLHA)

DESIGN S.V. (SLHA.KG)

NORMAL OPERATING T (F)

NORMAL OPERATING P (PSIA)

DESION SUP. GAS VEL (FT/S)

DESIGN GAS HOLDUP $(\%)$

DEgION CATALYSTCONC. MTR OXIDE

CATALYST INVENTORY (kD)

DIAMETER (FT)

T.T HEIGHT (FT)

SLURAY HEIGHT (FT)

SLURAYLD

GASSED SLUARY VOLUME (GAL)

MATEAIAL

\& DESIONTTF

DESION P (PSIG)

20.10 DllstoBdGE TANK

DESCAIPTION

CAPACITY (GAL)

VESSEL. ID (FT)

T.T HEIGHT (FT)

DESIONT (F)

DESION P (PSIO)

MATEAIAL

\begin{tabular}{|c|c|}
\hline SLUAAY & SLUAAY \\
\hline $\begin{array}{l}36782 \\
6250 \\
482 \\
1060 \\
0.75 \\
17 \\
10 \\
59850\end{array}$ & $\begin{array}{l}36793 \\
6250 \\
102 \\
1060 \\
0.75 \\
12 \\
10 \\
59852\end{array}$ \\
\hline $\begin{array}{l}13.6 \\
78.1 \\
61.5 \\
4.74265 \\
67508 \\
\text { SS CLAD ON CS } \\
600 \\
1320\end{array}$ & $\begin{array}{l}13.8 \\
76.1 \\
64.8 \\
4.74265 \\
67510 \\
\text { SS CLAD ON CS } \\
600 \\
1320\end{array}$ \\
\hline $\begin{array}{l}\text { VERTCAL TANK } \\
5000 \\
6.5 \\
20.1416 \\
200 \\
10 \\
C S\end{array}$ & SAMEAS \\
\hline
\end{tabular}

\begin{tabular}{|l} 
SLUARY \\
16590 \\
2850 \\
482 \\
1060 \\
0.47 \\
13 \\
10 \\
59107 \\
11.7 \\
90.7 \\
80.8 \\
6.80598 \\
60822 \\
SS CLAD ON CS \\
600 \\
1320 \\
\\
VEATCALTANK \\
4915.42 \\
6.5 \\
19.9217 \\
200 \\
10 \\
$C S$ \\
\end{tabular}

\begin{tabular}{|c|c|}
\hline SLURAY & SLUARY \\
\hline 22453 & 13155 \\
\hline 2950 & 1320 \\
\hline 482 & 482 \\
\hline 1060 & 1060 \\
\hline 0.47 & 0.29 \\
\hline 41 & 13 \\
\hline 40 & 10 \\
\hline$\pi 404$ & 101347 \\
\hline 13.6 & 13.2 \\
\hline 90.6 & 120.8 \\
\hline 79 & 1110 \\
\hline 5.60882 & 8.33333 \\
\hline 81414 & 106132 \\
\hline SS CLAD ON CS & SS CLAD ON CS \\
\hline 600 & 600 \\
\hline 1320 & 1320 \\
\hline VERTICAL TANK & VEATICAL TANK \\
\hline 6166.45 & 12675.6 \\
\hline 7 & 6.5 \\
\hline 22.4606 & 51.0614 \\
\hline 200 & 200 \\
\hline 10 & 10 \\
\hline $\operatorname{cs}$ & CS \\
\hline
\end{tabular}

SLURRY

SLURRY

13144

1320

182

1060

0.29

10

101347

13.2

120.8

110

8.33333

106132

SS CLAD ONCS

600

1320

22453

1320

482

1060

0.29

43

101347

13.2

120.8

110

B.33333

106132

SS CLAD ON CS

600

1320

VERTICAL TANK

12675.6

6.5

51.0614

200

10

10
CS

VERTICAL TANK

12675.6

7

44.0274

200

10

CS 
20.30 SUUARYMAX TANK \& BEDUCTON VESSEL

DESCAIPTION

VESSEL, ID (FT)

T-T HEIGHT (FT)

TOTAL VESSEL VOL (FT^J)

LB OXIDE PER AED'N

KQ OXIDE PEA AED'N

STARTING WT\% OXIDE

ENDINC WT\% OXIDE

GAL OIL PER AEDN

UNGASSED SLUARY VOL (FTA3)

ASSUMED \% GAS HOLDUP

GASSED SLLUAY VOL (FTA3)

SLUARY HEIGHT (FT)

SLUARY 10

FREEBOARD HEIGHT (FT)

FAEEBOARD UD

JACKET HEIGHT (FT)

JACKET H.T. AREA (FTA2)

REDUCTION GAS FLOW (SCFH)

SUP, OAS VEL. (FTSS)

SPACE VELOCITY (SLAA-KO OXIDE)

DESIGNT (F)

DESIGN P (PSIG)

MATERIAL.

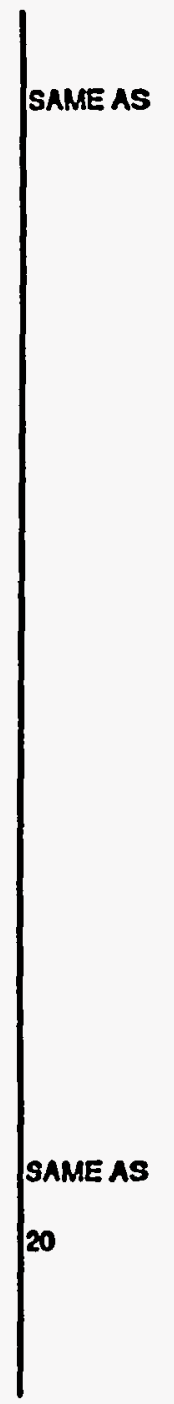

20.91

SLUABY MIX TANK \& BEQUCTLON YESSEI AGITATOA

TYPE

AGITATOA MOTOR HP

DESIGNT (F)

DESION P (PSIG)

MATERIAL

\begin{tabular}{|l|l} 
MOTOR \& IMP & SAME AS \\
20 \\
500 \\
150 \\
$3045 S$ & 20
\end{tabular}

\begin{tabular}{|l} 
SAME AS \\
\\
0.75714 \\
11.1596 \\
672.112 \\
1603.78 \\
2090.12 \\
35.2911 \\
10 \\
1201.99 \\
222.595 \\
10 \\
370.991 \\
6.15956 \\
0.70338 \\
5 \\
0.57096 \\
5.15956 \\
111.946 \\
209715 \\
0.20615 \\
2811.51 \\
500 \\
150 \\
$3015 S$ \\
\\
$M 0 T O A$ \\
50.7021 \\
500 \\
150 \\
304 SS \\
\\
\\
\end{tabular}

SAMEAS

SAMEAS

8.75714

11.1596

672.142

4603.78

2090.12

35.2941

40

1204.99

222.595

40

370.991

6.15956

0.70338

5

0.57096

5.15956

141.046

141.046

209715

0.20615
2841.54

500

150

304 SS

8.75714

11.1596

672.112

4603.78

2090.12

35.2941

40

1204.99

222.595

40

370.991

6.15956

0.70338

5

0.57096

5.15056 .

141.046

209715

0.20615

2841.54

500

$\cdot 150$

304 SS

\begin{tabular}{|ll} 
MOTOR \& IMP & MOTOR \& IMP \\
19.7817 & 25.8658 \\
500 & 600 \\
150 & 150 \\
301 SS & $301 \mathrm{sS}$
\end{tabular}

MOTOR \& MP

MOTOR \& IMP

50.7024

500

150

30455

50.7024

500

150

304 SS 
20.35 CATALYST BIN.HOPPER \& EEEDER DESCAIPTION

BIN CROSS SECTIONAL AAEA (FTA2) BIN HEIGHT (FT)

BIN VOLUME (FTA3)

BIN CAP (KQ OXIDE POWDEA)

TYPICAL LOAD (KG OXIDE POWDEA)

FILL TIME/OATCH (MIN)

FEEDER MOTOR (BHP)

MATEAIAL

20.40 LOUUDFUEL STOBAGE

TYPE

NUMBER

HOLD TIME (DAYS PER TANK)

DESION \% FULL

VESSEL ID (FT)

HEIOHT (FT)

DESIGN PAESSUAE (PSIG)

is DESION TEMP (F)

MATERIAL

28,45

SLURAYGENTRIEUGE

CONE DIAMETER (FT)

CONE LENGTH (FT)

MOTOR POWER (BHP)

MATERIAL.

28.46

SLUABYCEMTAIEUGE SURGE POI

HOLDUP TIME (MIN)

LLOUID FLOWRATE (GPM)

DESION\% FULL

VESSEL VOLUME (GAL)

VESSEL DIAMETER (FT)

T.T HEIOHT (FT)

DESIGNT (F)

DESIGN P (PSIG)

MATEAIAL

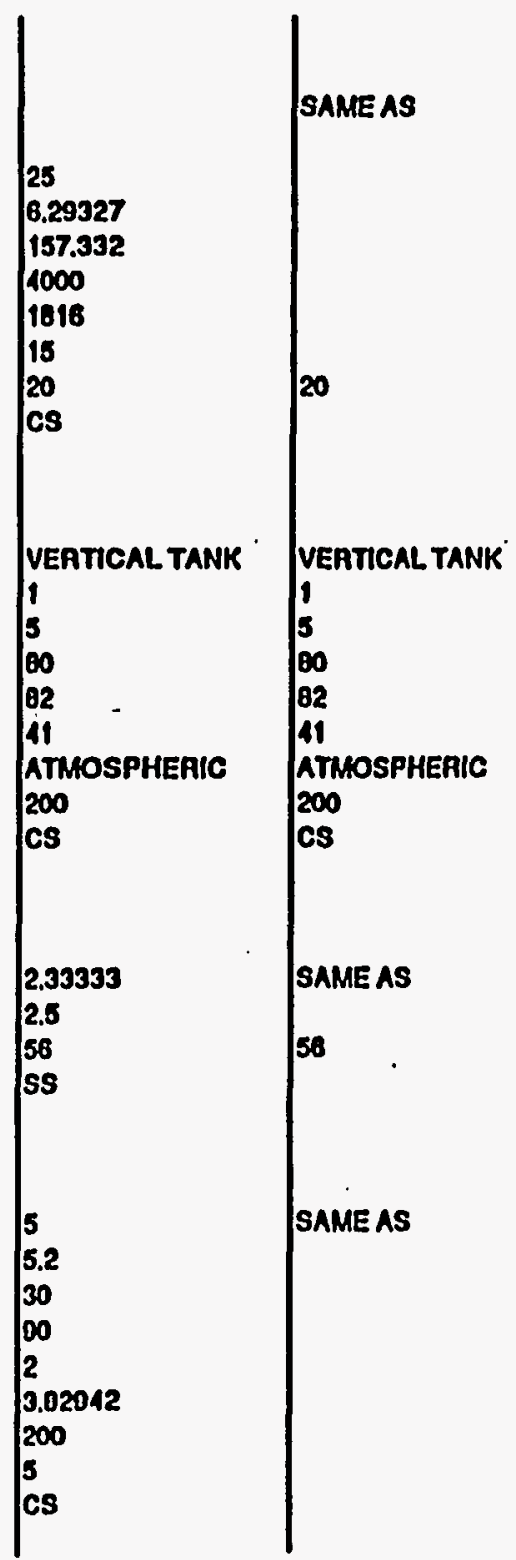

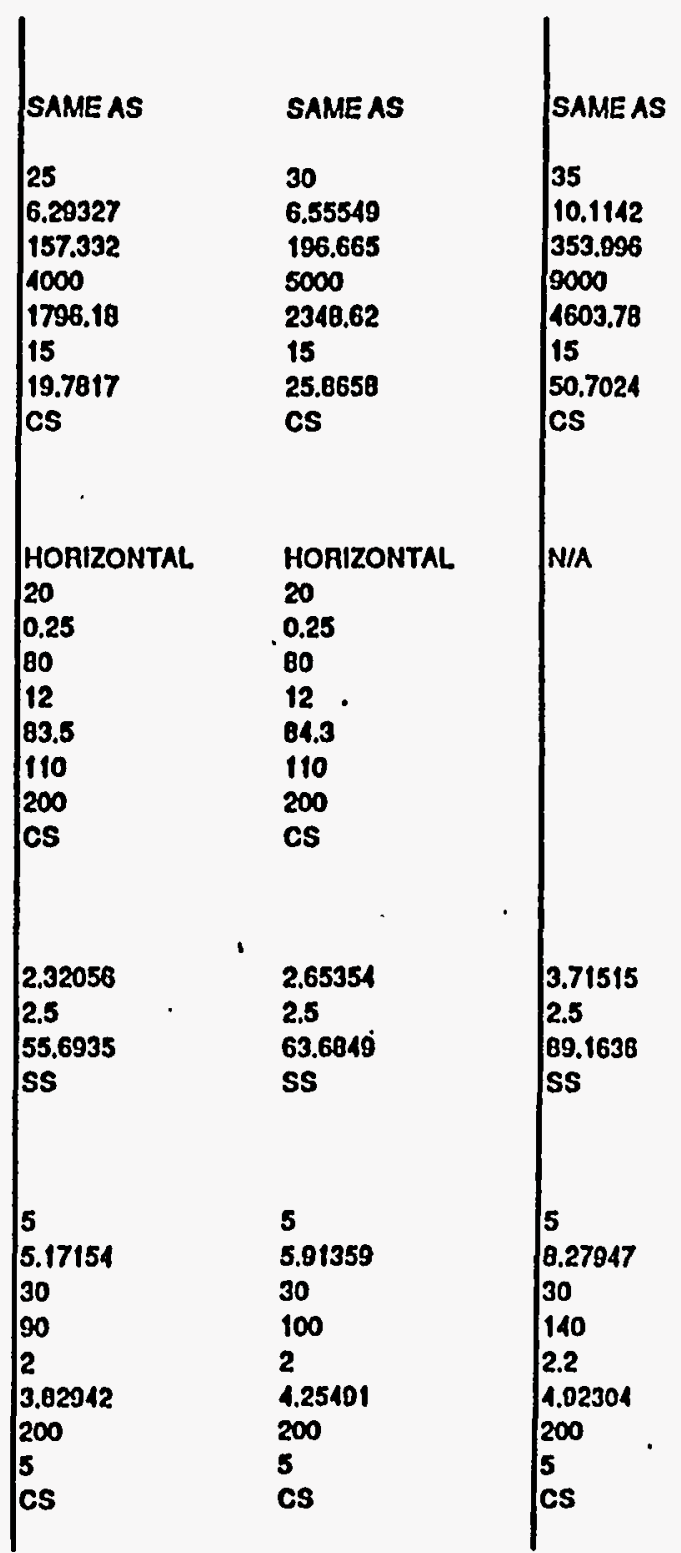

SAMEAS

35

10.1142

353.996

8000

1603.78

15

50.7024

CS

N/A

\section{5 \\ 89.1636}

3.71515

SS

5
8.27947
30
140
2.2
1.92304
200
5
CS

SAME AS

35

10.1142

353.996

9000

4603.78

15

50.7024

CS

HORIZONTAL

20

0.25

12

82

150

200

CS

3.71515

2.5

09.1636

ss

5

8.27947

30

140

2.2

4.02304

200

CS 
CAsE 1

CASE 2

CASE 3

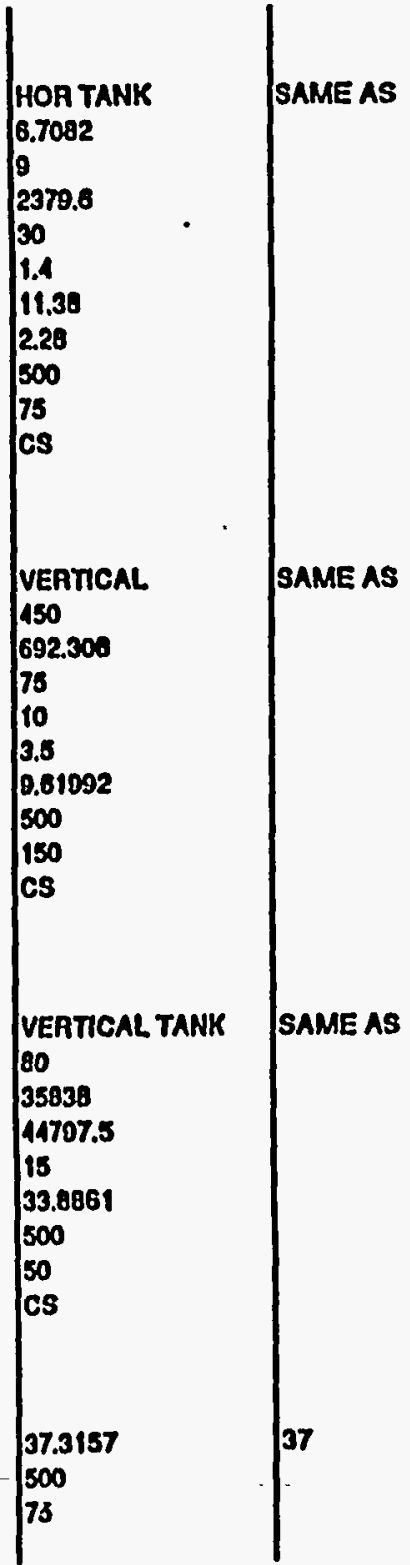

CASE4

CASE 5

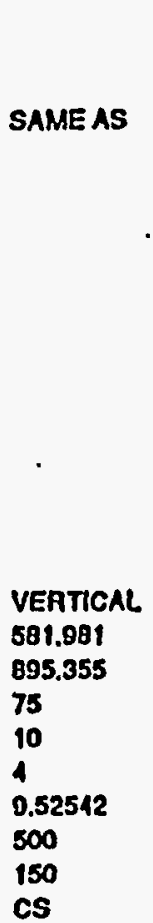

20,60 SLUABYTANKK

VESSEL I.D. (FT)

T-T LENGTH (FT)

VESSEL VOLUME (GAL)

DESION LIOUID HOLOUP TIME (MIN)

DESIGN LIQUID HEIGHT (FT)

VAPOA VELOCITY (FTISEC)

LLQUID DROPOUT VELOCITY (FT/SEC)

DESIGNT (F)

DESIGN P (PSIO)

MATERIAL.

28.53 yTLITYOILEXPANSIONIANAK

TYPE

WOAKING VOLUME (GAL)

NOMINAL VOLUME (OAL)

* Level hot

* LeVEl COLO

VESSEL DIAMETER (FT)

D T.T HEIGHT (FT)

DESIGNT T (P)

DESION P (PSIO)

MATEAIAL

TYPE

DESIGN \% FULL

TOTAL SLUAAY VOLUME (GAL)

VESSEL VOLUME (OAL)

VESSEL 1.D. (FT)

T-T LENGTH (FT)

DESIGNT TF

DESION P (PSIG)

MATERIAL

28.61 SLUARY TANKAgITATOR

MOTOR HP

DESIGNT(F)

DESION P (PSIG)

\begin{tabular}{|l} 
SAMEAS \\
\\
\\
\\
VERTICAL \\
145.068 \\
684.75 \\
75 \\
10 \\
3.5 \\
0.51491 \\
500 \\
150 \\
CS \\
\\
VEATICALTANK \\
60 \\
35464 \\
14330 \\
15 \\
33.5325 \\
500 \\
50 \\
$C S$ \\
\\
35.9263 \\
55 \\
75 \\
\end{tabular}

VERTICALTANK

80

46372

57065

15

43.8464

500

50

cs

48.284

500

75

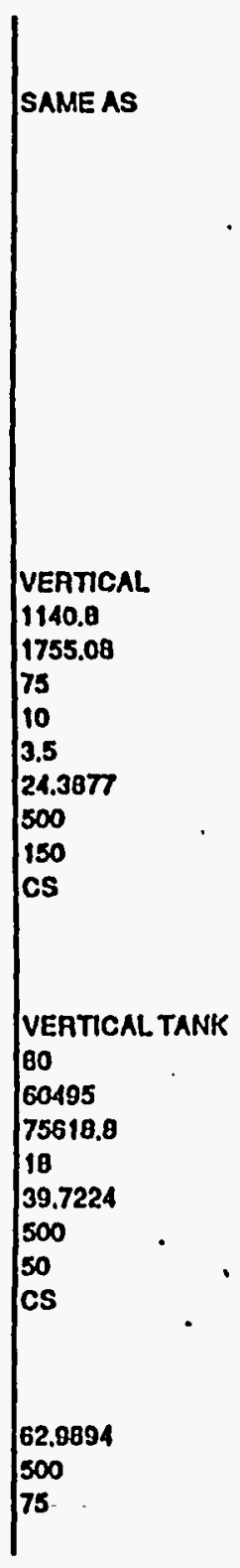

VERTICAL
1140.8
1755.08
75
10
3.5
24.3977
500
150
CS

VERTCAL TANK
80
60495
75618.8
18
39.7224
500
50
CS

62.8894
500
75

VEATICAL

1140.8

1755.08

75 18.6718

500 .

150

CS

VEATICAL TANK

80

60495

75618.8

18

39.7224

500

50

CS

\subsection{4}

500 
TABLE 4: EQUIPMENT SPECIFICATIONS

CASE 1

CAse 2

Case 3

CASE 4

CASE 5

caseo

CASE?

\subsection{SULEURAEMOVALUMII}

\begin{tabular}{|c|c|}
\hline $\begin{array}{l}E-50 \\
E-51 \\
E-52 \\
E-53\end{array}$ & $\begin{array}{l}\text { FT2 } \\
\text { FT2 } \\
\text { FT2 } \\
\text { FT2 }\end{array}$ \\
\hline F.50 & $\begin{array}{l}\text { DIA (F) } \\
\text { T-T (FT) }\end{array}$ \\
\hline F-51 . & $\begin{array}{l}\text { DIA (FT) } \\
\text { T-T (FT) }\end{array}$ \\
\hline F-53 & $\begin{array}{l}\text { DIA (F) } \\
\text { T-T (FT) }\end{array}$ \\
\hline & $\operatorname{DiA}(F T)$ \\
\hline
\end{tabular}

P.50 GPM

BHP

10.00 RgopaMEgEebigeaATIONSKID

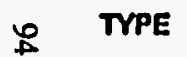

AEFAIGERATION LOAD (TONS)

BOILING TEMPEAATUAE (F)

CONDENSING TEMPEAATURE (F)

10.10 COMPAESSOR

\section{COMPAESSOA
GAS M.W. (LBRB.MOLE) MATEAIAL}

MOTOR POWEA (HP)

IST STAGE

INLET P (PSIA)

OUTLETP (PSIA)

ADIABATIC EFFICIENCY (y) COMPAESSION POWER (HP) 2ND STAGE FLOW (IMOLENAA)

INLET P (PSIA)

OUTLET P (PSIA)

ADIABATIC EFFICIENCY $\left(\varphi_{0}\right)$

COMPRESSION POWER (HP)

FLOW (UMOLEAH)

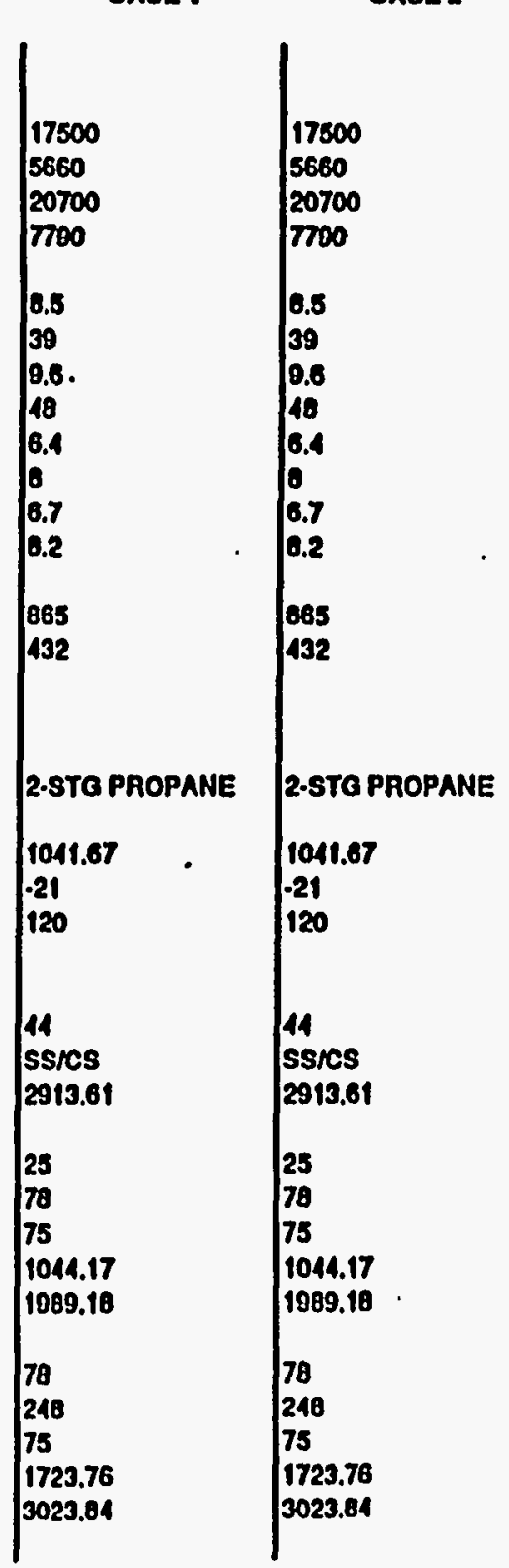

\begin{tabular}{|c|c|}
\hline $\begin{array}{l}15598 \\
5044.84 \\
18450.2 \\
6943.34\end{array}$ & $\begin{array}{l}10489.7 \\
3392.67 \\
12407.0 \\
4669.42\end{array}$ \\
\hline \begin{tabular}{|l}
7.57617 \\
39 \\
8.55662 \\
48 \\
5.70141 \\
7.5 \\
5.97101 \\
7.7
\end{tabular} & $\begin{array}{l}5.095 \\
39 \\
5.75435 \\
48 \\
3.83624 \\
6.2 \\
4.01606 \\
6.5\end{array}$ \\
\hline $\begin{array}{l}770.887 \\
385.048\end{array}$ & $\begin{array}{l}518.491 \\
258.916\end{array}$ \\
\hline 2-STG PROPANE & 2-STO PROPANE \\
\hline $\begin{array}{l}1065.85 \\
-21 \\
120\end{array}$ & $\begin{array}{l}1661.68 \\
-21 \\
120\end{array}$ \\
\hline $\begin{array}{l}14 \\
\text { SS/CS } \\
2981.54\end{array}$ & $\begin{array}{l}14 \\
\text { SS/Cs } \\
1656.16\end{array}$ \\
\hline $\begin{array}{l}25 \\
78 \\
75 \\
1068.51 \\
2035.56\end{array}$ & $\begin{array}{l}25 \\
78 \\
75 \\
1668.68 \\
3178.86\end{array}$ \\
\hline $\begin{array}{l}78 \\
248 \\
75 \\
1763.95 \\
3094.34\end{array}$ & $\begin{array}{l}78 \\
248 \\
75 \\
2751.69 \\
4832.32\end{array}$ \\
\hline
\end{tabular}

12269

3968.15

14512.5

5461.16

5.95923

39

6.73042

48

4.48695

7.5

4.69727

7.7

606.439

302.869

606.439

2.STG PROPANE 2.STG PROPANE

730.298

$-21$

-21
120

120

44

44

2042.69

SS/CS

2042.69

25

75

25

78

732.053

732.053
$\mathbf{1 3 9 4 . 5 9}$

78
248

75

1200.5

2110.07

2119.07

(10.07

1162.83

-21
120

44

3252.78

12269

3968.15

14512.5

5461.46

5.95923

39
6.73042

48

4.48695

6.2

4.69727

6.5

606.439

302.869

-STG PROPANE

25

78

75

1165.72

2220.74

78

248

75

1924.42

1924.42
3375.84 
TABLE 4: EQUIPMENT SPECIFICATIONS

Case 1

CA8E 2

case 3

CAsE 4

CASE 5

CAsE 6

CASET

40.20 STORAGE TANK

TYPE

VESSELID (FT)

T-T HEIGHT (FT)

DESIGNT TF)

DESIGN P (PSIG)

VAPOR KV

VESSEL MATEAIAL

40.21 FLASHPOT

TYPE

VESSEL ID (FT)

T.T HEIQHT (FT)

DESIGN T (F)

.. DESIGN P (PSIG)

VAPOA KV

VESSEL MATERIAL.

40.30 CONDENSER

\begin{tabular}{|c|c|c|}
\hline \multirow{3}{*}{\multicolumn{2}{|c|}{$\begin{array}{l}\text { DUTY (MMBTUMA) } \\
\text { U ASSUMED (BTUMR.FT^2.F) }\end{array}$}} & $\ln =8$ \\
\hline & & 10.8513 \\
\hline & & \\
\hline \multirow{5}{*}{\multicolumn{2}{|c|}{$\begin{array}{l}\text { LMDT (F) } \\
\text { AAEA (FTA2) + } 20 \% \text { S.F. } \\
\text { SHELL. DAAMETER (IN) } \\
\text { SHELLLENGTH (FT) } \\
\text { TUBE LENGTH (FT) } \\
\text { NUMBER OF TUBES } \\
\text { TUBE OD (IN) } \\
\text { COOLING WATER FLOW (GPM) }\end{array}$}} & $\begin{array}{l}31.0146 \\
9801.70\end{array}$ \\
\hline & & \\
\hline & & 10.7053 \\
\hline & & 1520 \\
\hline & & $\begin{array}{l}1.25 \\
1006.03\end{array}$ \\
\hline SHELL. & $\begin{array}{l}\text { DESIGNT (F) } \\
\text { DESIGN P (PSIG) } \\
\text { MATEAIAL }\end{array}$ & $\begin{array}{l}300 \\
265 \\
c S\end{array}$ \\
\hline & $\begin{array}{l}\text { DESIGNT (F) } \\
\text { DESIGN P (PSIG) } \\
\text { MATEAIAL. }\end{array}$ & $\begin{array}{l}300 \\
100 \\
C 3\end{array}$ \\
\hline
\end{tabular}

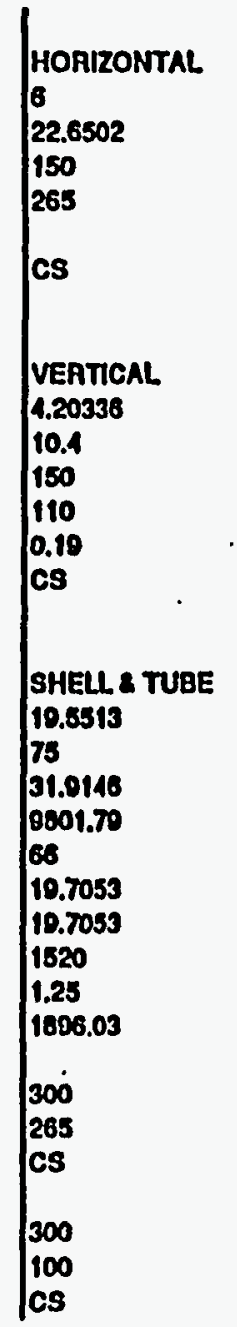

\begin{tabular}{|l} 
HOAIZONTAL \\
6 \\
23.1782 \\
150 \\
265 \\
CS \\
\\
VEATCAL \\
4.25208 \\
10.6 \\
150 \\
110 \\
0.19 \\
$C S$ \\
\\
SHELL. 8 TUBE \\
20.0071 \\
75 \\
31.9146 \\
10030.3 \\
68 \\
20.1647 \\
20.1647 \\
1520 \\
1.25 \\
1940.21 \\
300 \\
265 \\
CS \\
300 \\
100 \\
CS \\
\end{tabular}

\begin{tabular}{|c|c|}
\hline HORIZONTAL & HOAIZONTAL \\
\hline 7 & 5.5 \\
\hline 26.5935 & 18.8982 \\
\hline 150 & 150 \\
\hline 265 & 265 \\
\hline cs & cs \\
\hline VERTICAL & VERTICAL \\
\hline 5.31368 & |3.51951 \\
\hline 12 & 10.4 \\
\hline 150 & 150 \\
\hline 110 & 110 \\
\hline 0.19 & 0.19 \\
\hline cs & cs \\
\hline $\begin{array}{l}\text { SHELL \& TUBE } \\
31.2414\end{array}$ & $\begin{array}{l}\text { SHELL \& TUBE } \\
13.7071\end{array}$ \\
\hline 75 & 75 \\
\hline 31.9146 & 31.0146 \\
\hline $\begin{array}{l}15664 \\
78\end{array}$ & $\mid \begin{array}{l}6871.69 \\
54\end{array}$ \\
\hline 22.3567 & 20.9361 \\
\hline 22,3567 & 20.9361 \\
\hline 2141 & 1003 \\
\hline 1.25 & 1.25 \\
\hline 3030 & 1329.20 \\
\hline 300 & 300 \\
\hline 265 & 265 \\
\hline CS & cs \\
\hline 300 & 300 \\
\hline 100 & 100 \\
\hline cs & cs \\
\hline
\end{tabular}

HOAIZONTAL

HORI
5.5
18.8982

18.8982

150

265

cs

HOAIZONTAL

7

150

265

cs

VERTICAL VERTICAL

3.51951

10.6

150

110

0.19

CS

150

110

0.19

cs

SHELL \& TUBE 13.7071

75

31.0146

6871.89

54

20.0361

20.9361

1003

1.25

1329.28

SHELL \& TUBE 21.8273

75

31.0146

10942.8

66

21.9992

21.9992

1520

1.25

300

2116.75

265

300

cs

cs

300

300

100

100 


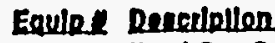

01.10 A Food Gas Compressor - first slage

01.10B Food Gas Compressor - second slage

Foed Gas Comprossor - kube oll pump

Food Gas Compressot - seal oll boosler pump

Food Gas Comprossor -coalescor gear pump

01.20 Recycto Compresso

Aocydo Compressor - hube oll pump

01.30 Vent Streams 10 Incineralor Compressor

O1.40 Peduction N2 Compressor

Peduction N2 Compressor - Lube oll pump

01.60 instrumont At Compressor

Instrument Ak Comprossor - hube oll pump

02.63 02.10 Carbonyt Rogen Healor

10.10 Purgo Gas Expandor

- Expandor - hubo oll pump

Expander - seal oll booster pump

Expander - coaloscer gear pump

10.30 01.30 Incinerator Liquid Foed Pump

10.10 Fuel b Vaporizor Pump

10.50 Condensed Oll Cliculation Pump

10.52 Emergancy Shurry Raturn Pump

\& 10.63 Utily On Pumps

10.51 Roduction Oll Pump

10.56 Frosh ON Pump

10.58 Slurry Firation Cliculation Pump

10.59 Rectuced Stumy Transfor Pump

10.60 OI Makoup Pump

10.62 MEOH to Storage/focyclo Pump

10.64 H2O Injaction Pump

10.65 07.65 Column Rollux Pump

10.70 Oliy Water Sump Pump

15.10 Inchnerator Forcod Drah Fan

16.40 Utinly Oll Healor

21.53 Utury Oll Ar Coolor

28.31 Shumy Mx Tank Agltator

28.35 Catalysl Bln Foodor

28.45 Slurny Centrlugo

20.61 Slumy Tank Agllator

30.00 Suthr Removal Unit

10.00

Sulfur Romor

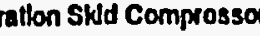

Bulding HVAC

EQUIPMENT TOTAL (IIP)

EOUIPMENT TOTAL (KW)

Ado 4 \% lor Transformar Losses, Ughts, . atc

TOTAL - KILOWATTS

\begin{tabular}{|c|c|c|c|c|c|c|}
\hline CAse 1 & CASE 2 & CASE 3 & CASE 4 & CASE 5 & CASE 6 & CASE 7 \\
\hline 0,201 & 9,201 & 0,201 & 5,516 & 6,451 & 6,151 & 6.451 \\
\hline 9,302 & 9,302 & 8,291 & 5,676 & 6,521 & 6,521 & 6,521 \\
\hline 143 & 143 & 127 & 86 & 100 & 100 & 100 \\
\hline 143 & 143 & 127 & 86 & 100 & 100 & 100 \\
\hline 6 & 6 & 5 & 3 & 4 & 4 & 4 \\
\hline 681 & 555 & 0 & 433 & 0 & 0 & 0 \\
\hline 32 & 27 & $\mathbf{0}$ & 21 & 0 & 0 & 0 \\
\hline 74 & 16 & 15 & 20 & 39 & 39 & 39 \\
\hline 268 & 266 & 263 & 344 & 675 & 675 & 675 \\
\hline 13 & 13 & 13 & 17 & 33 & 33 & 33 \\
\hline 377 & 377 & 377 & 37 & 377 & 377 & 377 \\
\hline 18 & 18 & 18 & 18 & 18 & 18 & 18 \\
\hline 1 & 1 & 1 & 1 & 1 & 1 & 1 \\
\hline $.5,672$ & $-3,414$ & $-3,105$ & $-1,512$ & $-2,953$ & $\cdot 1,953$ & $-1,953$ \\
\hline 44 & 26 & 25 & 12 & 23 & 15 & 15 \\
\hline 41 & 26 & 25 & 12 & 23 & 15 & 15 \\
\hline 2 & 1 & 1 & o & 1 & 1 & 1 \\
\hline 5 & 5 & 5 & 6 & 13 & 13 & 13 \\
\hline 57 & 60 & 33 & 33 & 0 & 0 & 28 \\
\hline 100 & 100 & 45 & 60 & 35 & 35 & 70 \\
\hline 0 & 0 & 0 & 0 & 0 & 0 & $\cdot 0$ \\
\hline 1B & 18 & 47 & 62 & 122 & 122 & 122 \\
\hline 0 & 0 & 0 & 0 & 0 & 0 & 0 \\
\hline 0 & 0 & 0 & 0 & 0 & 0 & 0 \\
\hline 2 & 2 . & 2 & 3 & 5 & 5 & 5 \\
\hline 0 & 0 & 0 & 0 & 0 & 0 & 0 \\
\hline 23 & 23 & 9 & 14 & $\mathbf{9}$ & 9 & 11 \\
\hline 2 & 0 & 2 & 239 & 24 & 24 & 24 \\
\hline 18 & 18 & 11 & 17 & 7 & 6 & 6 \\
\hline 0 & 0 & 0 & 17 & 0 & 0 & 0 \\
\hline 0 & 0 & 0 & 0 & 0 & 0 & 0 \\
\hline 80 & 11 & 10 & 14 & 27 & 27 & 27 \\
\hline 360 & 369 & 365 & 477 & 035 & 935 & 935 \\
\hline 5 & 5 & $\mathbf{5}$ & 7 & 13 & 13 & 13 \\
\hline 20 & 20 & 20 & 26 & 51 & 51 & 51 \\
\hline 0 & 0 & 0 & 0 & 0 & 0 & 0 \\
\hline 56 & 56 & 56 & 64 & 89 & 89 & 89 \\
\hline 37 & 37 & 37 & 48 & 63 & 63 & 63 \\
\hline 132 & 432 & 385 & 259 & 303 & 303 & 303 \\
\hline 2,014 & 2,914 & 2,882 & 4,656 & 2,043 & 2,043 & 3,253 \\
\hline 30 & 30 & 30 & 30 & 30 & 30 & 30 \\
\hline 16,822 & 20,836 & 18,347 & 17,039 & 15,170 & 16,164 & 17,141 \\
\hline 14,036 & 15,537 & 13,682 & 12,706 & 11,318 & 12,053 & 13,006 \\
\hline 561 & 621 & 547 & 800 & 453 & 482 & 520 \\
\hline 14,597 & 16,159 & 14,229 & 13,214 & 11,772 & 12,535 & 13,526 \\
\hline
\end{tabular}

ISSUED FOR ESTIMATE 


\section{TABLE 5: UTILITY SUMMARY}

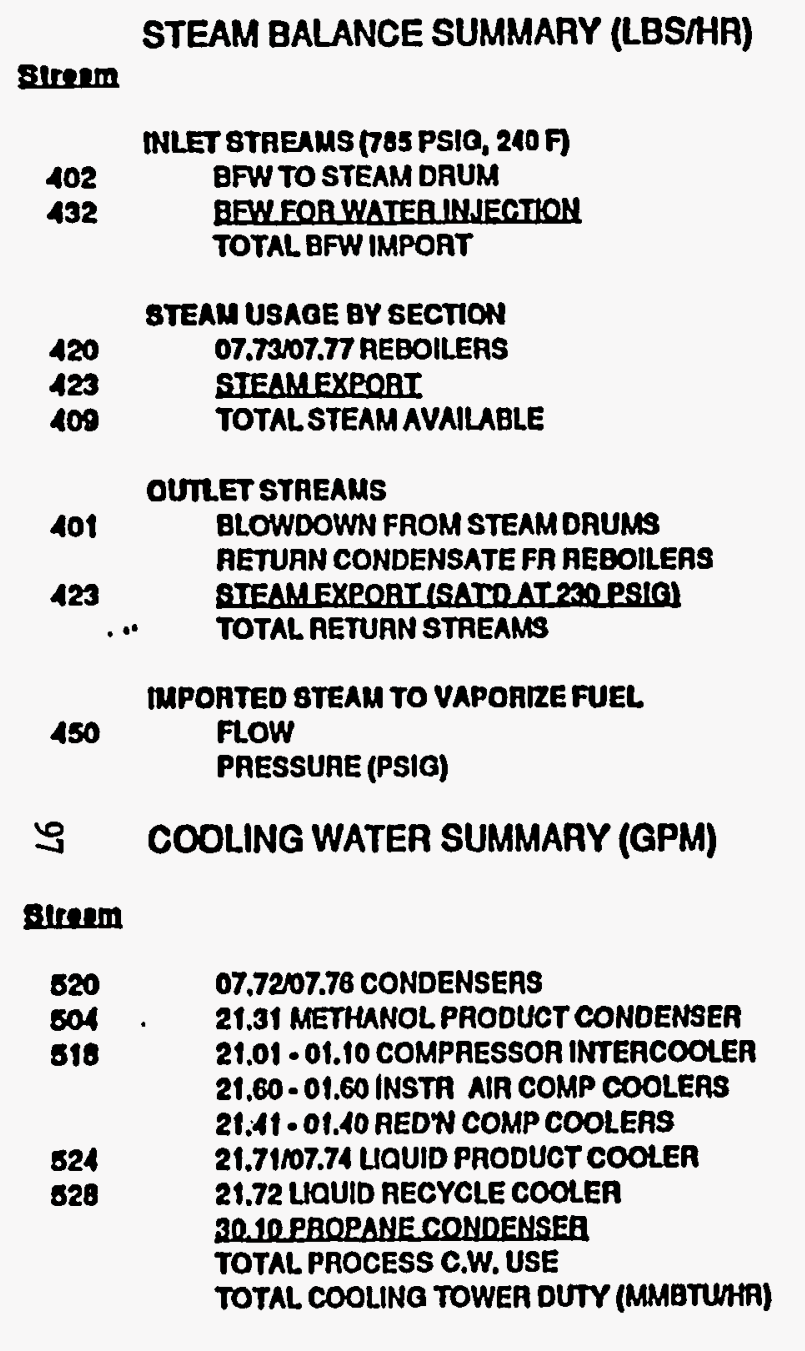

\begin{tabular}{|c|c|c|c|c|c|c|}
\hline CASE 1 & CASE 2 & CASE 3 & CASE 4 & CASE 5 & " case 6 & CASE 7 \\
\hline Op Avg & Op Avg & Op Avg & Op Avg & Op Avg & Op Avg & Op Avg \\
\hline $\begin{array}{c}77,490 \\
25,496 \\
103,394\end{array}$ & $\begin{array}{c}80,096 \\
25,496 \\
105,592\end{array}$ & $\begin{array}{c}101,751 \\
14,936 \\
116,690\end{array}$ & $\begin{array}{c}98,193 \\
22,571 \\
120,764\end{array}$ & $\begin{array}{c}112,220 \\
8,990 \\
121,210\end{array}$ & $\begin{array}{c}112,287 \\
8,847 \\
121,134\end{array}$ & $\begin{array}{c}112,298 \\
8,847 \\
121,145\end{array}$ \\
\hline $\begin{array}{c}8,222 \\
72,132 \\
77,354\end{array}$ & $\begin{array}{l}17,402 \\
62,133 \\
70,535\end{array}$ & $\begin{array}{c}15,421 \\
85,620 \\
101,041\end{array}$ & $\begin{array}{l}27,394 \\
70,111 \\
97,505\end{array}$ & $\begin{array}{c}5,534 \\
105,900 \\
111,434\end{array}$ & $\begin{array}{c}13,915 \\
97,586 \\
111,501\end{array}$ & $\begin{array}{c}16,084 \\
95,428 \\
111,512\end{array}$ \\
\hline $\begin{array}{c}845 \\
5,222 \\
72,132 \\
77,099\end{array}$ & $\begin{array}{c}561 \\
17,102 \\
62,133 \\
80,096\end{array}$ & $\begin{array}{c}712 \\
15,421 \\
85,620 \\
101,753\end{array}$ & $\begin{array}{cc} & 687 \\
\cdot & 27,394 \\
\cdot \quad 70,111 \\
98,192\end{array}$ & $\begin{array}{c}785 \\
5,534 \\
105,900 \\
112,219\end{array}$ & $\begin{array}{c}786 \\
13,915 \\
97,586 \\
112,287\end{array}$ & $\begin{array}{c}786 \\
16,081 \\
95,128 \\
112,298\end{array}$ \\
\hline $\begin{array}{c}46,274 \\
230\end{array}$ & $\begin{array}{c}48,089 \\
230\end{array}$ & $\begin{array}{c}22,373 \\
230\end{array}$ & $\begin{array}{c}23,370 \\
230\end{array}$ & $\begin{array}{l}0 \\
0\end{array}$ & $\begin{array}{l}0 \\
0\end{array}$ & $\begin{array}{c}10,336 \\
230\end{array}$ \\
\hline $\begin{array}{c}100 \\
6,370 \\
2,330 \\
01 \\
14 \\
241 \\
0 \\
1,096 \\
11,075 \\
111\end{array}$ & $\begin{array}{c}0 \\
7,865 \\
2,330 \\
91 \\
11 \\
1,265 \\
0 \\
1,896 \\
13,491 \\
135\end{array}$ & $\begin{array}{c}0 \\
2,908 \\
2,077 \\
91 \\
13 \\
309 \\
506 \\
1,940 \\
7,875 \\
70\end{array}$ & $\begin{array}{c}970 \\
3,952 \\
1,397 \\
81 \\
57 \\
328 \\
0 \\
3,030 \\
0,826 \\
98\end{array}$ & $\begin{array}{c}0 \\
1,079 \\
1,631 \\
91 \\
111 \\
0 \\
0 \\
1,329 \\
1,241 \\
43\end{array}$ & $\begin{array}{c}267 \\
2,012 \\
1,634 \\
91 \\
111 \\
0 \\
0 \\
1,329 \\
5,441 \\
55\end{array}$ & $\begin{array}{c}383 \\
2,011 \\
1,634 \\
91 \\
111 \\
854 \\
0 \\
2,117 \\
7,201 \\
72\end{array}$ \\
\hline
\end{tabular}


PAODUCTION

Mase Ralo (TPD)

Enorgy Aato (MM BTU/hr, LHM)

CAPITAL COMPONENT ( $\$ 1,000$ In 1992)

Faed Compresslon \& Gas Protteatmont

Basle 8ynthosis Sectlon

Extra 8ynthoule Equipment

Slumry Reduclion

Spent Catalyat Recovory

Storago Loading and Vaporlzatlon

Beneral Uilitilles

Indirect Cos

Inillat Culalyal Chargo

TOTAL.

UNIT PAODUCT COST (\$NAN BTU, LHV)

$£ \quad$ Byngas

Eloctito Power

Coollng Water

Mako-up OII

Catalyat 8upply

Adsorbont

CatalyavOII Dlaposal

Adsorbent DHaposal

Operalling Labor

Plant Overhead

Mahitonance

Toxos and ineurance

Caplial Cost

TOTAL

Unll Cost (\$nib)

$\mid$

\begin{tabular}{|c|c|c|c|}
\hline $\begin{array}{l}628 \\
635\end{array}$ & $\begin{array}{l}876 \\
676\end{array}$ & $\begin{array}{l}668 \\
618\end{array}$ & $\begin{array}{l}665 \\
620\end{array}$ \\
\hline 18,439 & 16,269 & 14,849 & 11,633 \\
\hline 23,575 & 24,171 & 17,531 & 22,306 \\
\hline 0 & 1,410 & 2,576 & 6,149 \\
\hline 1,273 & 1,260 & 1,270 & 1.494 \\
\hline 197 & 195 & 197 & 230 \\
\hline 3,003 & 3,018 & 7,795 & 7,692 \\
\hline 1,018 & 1,015 & 1,089 & 1,057 \\
\hline 17,165 & 17,759 & 17,116 & 18,739 \\
\hline 1,449 & 1.451 & 1,130 & 1,463 \\
\hline 34,139 & 66,648 & 63,653 & 70,763 \\
\hline 6.13 & 5.01 & 5.07 & 5.06 \\
\hline-0.13 & -0.07 & -0.32 & -0.24 \\
\hline 1.03 & 1.10 & 1.06 & 0.97 \\
\hline 0.10 & 0.12 & 0.08 & 0.10 \\
\hline 0.04 & 0.04 & 0.02 & 0.03 \\
\hline 0.29 & 0.27 & 0.29 & 0.38 \\
\hline 0.01 & 0.01 & 0.00 & 0.00 \\
\hline 0.04 & 0.04 & 0.04 & 0.05 \\
\hline 0.00 & 0.00 & 0.00 & 0.00 \\
\hline 0.09 & 0.09 & 0.10 & 0.10 \\
\hline 0.18 & 0.18 & 0.19 & 0.19 \\
\hline 0.24 & 0.24 & 0.25 & 0.27 \\
\hline 0.24 & 0.24 & 0.25 & 0.27 \\
\hline 1.70 & 1.66 & 1.73 & 1.92 \\
\hline 8.01 & 8.93 & 8.76 & 9.10 \\
\hline 0.003 & 0.083 & 0.097 & 0.102 \\
\hline
\end{tabular}

622

645

590
628

579

$12,319 \cdot 12,119$

$19,891 \quad 20,716$

$0 \quad 1,654$

2,706

408

0

1,538

14,476

1,812

53,150

1,654
2,662

401

0

1,513

15,191

1,811

56,067

602

5.09

$-0.52$

0.81

0.04

0.04

0.72

0.00

0.09

0.00

0.09

0.19

0.20

0.20

1.39

8.34

0.104 